\title{
II „Über die bürgerliche Verbesserung“ - Der Berliner jüdische Salon um 1800 im Schnittpunkt der Diskurse
}

\author{
Wir haben diese Phantasie, dass dies ein großartiger Platz ist. \\ Mascha Sominsky, Initiative „Salon Berlin“, Tel Aviv, 2009¹
}

Dass Mascha Sominsky, die Initiatorin eines avantgardistischen Kunst- und Modetreffs in Tel Aviv ihren Ort „Salon Berlin“ nennt, ist vielleicht poetischer Zufall. Er ist allerdings ebenso bezeichnend für das „Phantastische“ der Geschichte wie für die Ausstrahlungskraft des Ideals Salon bis heute. Die Distanz von Tel Aviv nach Berlin ist der Distanz der Forschung zu einem vergangenen Phänomen vergleichbar, dessen Quellenlage so heterogen ist, dass bei der rekonstruierenden Annäherung an den „Salon Berlin“ die Fantasie automatisch zur Hilfe genommen werden musste - und das war oft „eine Phantasie, dass dies ein großartiger Platz war“. Dieses Kapitel beschreibt den diskursiven ,Mehr- und Streitwert' des Salons in vier Schritten. Nach einer Vorstellung der zur Analyse verwendeten Begriffe (Abschnitt1) konfrontiert Abschnitt 2 die gewissermaßen ,kondensierte Idealgeschichte، (Master Narrative) des Salons die das ihm zugeschriebene emanzipatorische Potential zusammenfasst - mit einer exemplarischen Diskussion der Forschungskontroversen zu drei ausgewählten Topoi der Salonforschung: der Konversion als Weg individueller Emanzipation, dem „deutsch-jüdischen Dialog“ und der Emanzipation qua „Halböffentlichkeit“. In Abschnitt 3 werden die zeitgenössischen Emanzipationsdiskurse nachgezeichnet, um mögliche thematische und personelle Überschneidungspunkte mit dem Salon und die aus dieser Überschneidung resultierenden Fragen aufzuzeigen. Abschließend problematisiert Abschnitt 4 die mehrschichtige Funktion des Mediums Brief als wesentliche Quelle zur Beantwortung dieser Fragen.

\section{Emanzipation und „Judenreform“ - Begriffe}

Als Begriffe für den Prozess der Annäherung der jüdischen und nichtjüdischen Bevölkerung im 18. und 19. Jahrhundert wurden in der Forschung zunächst

1 Maritta Adam-Tkalec / Inge Günther: 100 Jahre Frühling. Tel Aviv feiert am 11. April den Jahrestag seiner Gründung. Hier gilt: Jeder lebt nach seiner Fasson, in: Berliner Zeitung, 9. April 2009. 
Assimilation, dann Akkulturation verwendet.. ${ }^{2} \mathrm{Da}$ die Begriffe gelegentlich noch nebeneinander stehen, wird in dieser Arbeit mit folgender Unterscheidung gearbeitet: Assimilation kann als Versuch oder Forderung betrachtet werden, die jüdische Tradition und Identität aufzugeben und in völliger „Angleichung“ Teil der Mehrheitsgesellschaft zu werden. ${ }^{3}$ Der heute überwiegend verwandte Begriff Akkulturation wird verstanden als Annäherung an die Kultur der Mehrheitsgesellschaft unter Bewahrung religiöser Identität, wobei eine immer noch diskutierte Forschungsfrage ist, inwieweit die Aufklärer emanzipationswilligen Juden die Bewahrung ihrer Identität zugestehen wollten. Zurecht plädiert Deborah Hertz dafür, den Begriffsrahmen zu erweitern und die beiden besetzten und tendenziell abwertenden Begriffe durch ein Spektrum von Begriffen und Strategien der Annäherung oder eines eigenen Weges zu ersetzen. ${ }^{4}$ Im Zusammenhang dieser Arbeit werden die Quellen daraufhin befragt, ob, wie und in welchen Worten der Status der jüdischen Bevölkerung in Briefen der Salongesellschaft diskutiert wurde. Zugleich wird gefragt, welche Forderungen für ein Miteinander die Teilnehmer der Salongesellschaft konkret an ihre jüdischen Bekannten stellten, welche Voraussetzungen sie als vorhanden konstatierten oder als fehlend vermissten. Die Analyse der Briefe konzentriert sich dabei vor allem auf zeitgenössisch gebräuchliche - oder auch im Salon erfundene - Begriffe und damit verbundene Wertigkeiten.

Der Begriff Emanzipation scheint zunächst nicht in dieses Programm zu passen, da er in den Jahren um 1800, hierin ähnlich dem Begriff Salon, zwar

2 Vgl. zur Begriffsgeschichte: Elke-Vera Kotowski: Wege der Akkulturation, in: dies. / Julius H. Schoeps / Hiltrud Wallenborn (Hrsg.): Handbuch zur Geschichte der Juden in Europa, 2 Bde., Darmstadt 2001, Bd.1, S. 353-363, und Jakob Toury: Emanzipation und Assimilation, in: Schoeps 1992, S. 132-134. Der Begriff „Judenreform“ aus der Überschrift nach: Rahel Levin Varnhagen an Markus Levin, 13. 6. 1814, in: ERLV III, S. 415, hier bezogen auf innerjüdische Reformbestrebungen.

3 Der Begriff Assimilation, der im 19. Jahrhundert auch von jüdischer Seite verwendet wurde, hat heute „Reizwortcharakter“, nicht nur, aber vor allem durch die Verwendung in der NS-Zeit.Toury 1992, S. 134.

4 Deborah Hertz: Masquerades and Open Secrets, Or New Ways to Understand Jewish Assimilation, in: Anna-Dorothea Ludewig / Hannah Lotte Lund / Paola Ferruta: Versteckter Glaube oder Doppelte Identität? Das Bild des Marranentums im 19. und 20. Jahrhundert / Concealed Faith or Double Identities? The Image of Marranism in the $19^{\text {th }}$ and $20^{\text {th }}$ Centuries, Hildesheim 2011, S. 57-97. Hertz plädiert dafür, das Modell des Politikwissenschaftlers Kenji Yoshino in die Diskussion einzubeziehen und mit den Termini „authenticity“, „,overing“, „passing“ and „total transformation“ (Yoshino) bzw. „masquerade“ und „open secret“ (Hertz) für verschiedene Strategien der Annäherung unter Bewahrung der eigenen Identität zu arbeiten. Inwieweit der Ansatz von der deutsch-jüdischen Historiografie aufgenommen wird, bleibt abzuwarten. 
bekannt war, aber nicht dafür verwendet wurde, wofür er heute steht. ${ }^{5}$ Wenn in dieser Arbeit, bei der strukturellen Analyse, dennoch mit ihm gearbeitet wird, geschieht das im Sinne eines abstrakten Oberbegriffs, der sowohl transitive (aus der Rechtshoheit anderer entlassen und emanzipiert werden) wie intransitive Elemente (des sich Emanzipierens, „Mündig“-Werdens) enthält. Emanzipation im weitesten hier angewandten Sinne meint die aktive oder passive Befreiung von Abhängigkeiten aus rechtlichen und gesellschaftlichen Zwängen.

Dass die Emanzipation der Juden, ${ }^{6}$ und auch die der Frauen, ${ }^{7}$ in Preußen und Deutschland zunächst nicht unter diesem Begriff, sondern als „,bürgerliche Verbesserung“ diskutiert wurde, ist kein Zufall: Zwar wird das preußische Verständnis der Judenemanzipation im Sinne des „Gewährens“ von Rechten im Begriff Emanzipation gut widergespiegelt, doch der zeitgenössische Begriff „bürgerliche Verbesserung“ deutet zugleich auf das wesentliche Merkmal preuBisch-deutscher Politik, diese Gewährung von Rechten noch von einer sittlichmoralischen „Besserung“, einem gewissen Grad der Akkulturation bzw. eben Assimilation abhängig zu machen.

5 Ursprünglich ein terminus technicus im römischen Recht für die förmliche Entlassung des Hauskindes aus väterlicher Gewalt, erfuhr der Begriff in der Frühen Neuzeit eine Erweiterung und partielle Sinnverschiebung hin zur Selbstbefreiung, auch von ganzen Bevölkerungsgruppen. Sinnfällig für die Reaktion der ständischen Welt ist die Tatsache, dass der Begriff zunächst überwiegend in abschätziger Form verwendet wurde im Sinne des „sich ungebührliche Freiheit anmaßen“. Obzwar in naher Verwandtschaft zum zeitgenössischen Begriff Aufklärung stehend, wird die Differenz deutlich am Beispiel Immanuel Kants, der Emanzipation nur in juristischen Zusammenhängen verwandte, sonst den Begriff Aufklärung, da Menschen rechtlich emanzipiert sein könnten, ohne in dem von ihm gewünschten Sinne „mündig“ zu sein. Georg Forster gilt als der erste, der den Begriff Emanzipation im politischen Sinne positiv verwendet hat. Im Vormärz ist der Begriff zu einem Bewegungsund Zielbegriff politischer Strömungen geworden. Grundlegend zur Begriffsgeschichte immer noch: Karl Martin Grass / Reinhart Koselleck: „Emanzipation“, in: Brunner / Conze / Koselleck 1972-1997, Bd. 2, S. 153-197, bes. S. 162-166.

6 Ergänzend, vor allem zur Relevanz des Begriffs und Vorganges heute Ulrich Weiss: „Emanzipation“, in: Wolfgang Fritz Haug (Hrsg.): Historisch-Kritisches Wörterbuch des Marxismus, Bd. 3, Hamburg 1997, S. 271-289. Eine konzise und vergleichende Begriffsgeschichte im Zusammenhang der europäisch-jüdischen Geschichte bei Ulrich Wyrwa: Die Emanzipation der Juden in Europa, in: Kotowski / Schoeps / Wallenborn 2001, Bd. 1, S. 336-352, bes. S. 342-344.

7 Charles Fourier formulierte erstmals den Satz von der Emanzipation der Frau als Gradmesser der allgemeinen Emanzipation. Demnach ist die „Erweiterung der Privilegien der Frauen [...] die allgemeine Grundlage allen sozialen Fortschritts“. Charles Fourier: Theorie der vier Bewegungen und allgemeinen (1841), hrsg. von Theodor W. Adorno, Frankfurt/M. 1966, S. 190, zit. nach: Weiss 2001, S. 275. 
Was ist aber diese große Aufgabe unserer Zeit?

Es ist die Emanzipation [...].

Heinrich Heine, $1828^{8}$

Die rechtliche Gleichstellung der Juden unter dem Begriff Emanzipation zu diskutieren wurde nach dem Wiener Kongress Brauch, wenn auch die Forderung danach traditionsgemäß meist abschlägig beurteilt wurde. ${ }^{9}$ Wann der Begriff Emanzipation erstmals für die rechtliche oder gesellschaftliche Gleichstellung der Frau verwendet wurde, ist nicht genau zu datieren. ${ }^{10}$ Vergleichbar der allgemeinen Entwicklung kam die Bewegung vor dem Begriff und wurden beide von der ,Mehrheitsgesellschaft‘ lange mit einem scheelen Blick als „,sich Freiheiten der Männer herausnehmend" gedeutet. ${ }^{11}$ Interessant ist hier eine Fundstelle im Werk Karl August Varnhagens, der in einem Artikel Frauen in Mannskleidern festhielt, dass schon um 1800 „vornehme Damen in Männer-

8 „Mögen immerhin einige philosophische Renegaten der Freiheit die feinsten Kettenschlüsse schmieden, um uns zu beweisen, daß Millionen Menschen geschaffen sind als Lasttiere einiger tausend privilegierter Ritter; sie werden uns dennoch nicht davon überzeugen können, solange sie uns, wie Voltaire sagt, nicht nachweisen, daß jene mit Sätteln auf dem Rücken und diese mit Sporen an den Füßen zur Welt gekommen sind.“ Heinrich Heine: Reisebilder und Reisebriefe. Reisebilder, 3. Teil. Reise von München nach Genua, in: ders.: Werke und Briefe in zehn Bänden, hrsg. von Hans Kaufmann, Bd. 3, Berlin [u. a.] 1972, S. 259.

9 So sprach sich etwa das Bayerische Ministerium des Inneren gegen eine „eine augenblickliche gänzliche emancipation der Israeliten“ aus. Zit. nach: Wyrwa 2001, S. 34, ohne Quelle. Auch nach der 1871 erlangten Emanzipation im Sinne des Rechtsaktes der bürgerlichen Gleichstellung, wurde der Begriff weiter verwendet für den langfristigen Prozess der Integration in die bürgerliche Gesellschaft. Nicht politisch, aber begriffsgeschichtlich vergleichbar, blieb der Begriff Emanzipation bzw. Frauenemanzipation auch innerhalb der Frauenbewegung noch lange nach der Erlangung des Bürger- und Wahlrechts ein Schlagwort, das angestrebte gesellschaftliche Gleichbehandlung und den Kampf dafür signalisierte. 10 Vgl. dazu: Gisela Heinrich: „Frauenemanzipation“, in: Frigga Haug (Hrsg.): HistorischKritisches Wörterbuch des Feminismus, Bd. I, Hamburg 2003, S. 268-278. Das Ende des Begriffs ist deutlicher zu fassen, von feministisch-theoretischer Seite wurde der Begriff der Frauenemanzipation seit den 1970er-Jahren zunehmend aufgegeben, bzw. für diejenigen verwendet, die die Geschlechterfrage der allgemeinen Klassenfrage nachordneten. Seit den 1990er-Jahren wurden beide Begriffe durch den der Differenz ersetzt, nach wachsender Kritik vor allem farbiger Frauen am Allgemeingültigkeitsanspruch der (weißen) Frauenbewegung. 11 Zur Interpretation des Begriffs Emanzipation bis ins 18. Jh. vgl. die lexikalischen Nachweise bei Wyrwa 2001, S. 342 f. Bemerkenswert auch die lexikalische Definition von 1904, die die Emanzipation der Frau als Befreiung von „natürliche[n] oder soziale[n]“ Beschränkungen definiert, „daher man von emanzipierten Frauen dann zu sprechen pflegt, wenn sich dieselben in auffallender Weise geflissentlich über jene Schranken hinwegsetzen“. „Emanzipation“, in: Meyers Großes Konversationslexikon, Bd.5, Leipzig [u. a.] 1904, S. 745. 
tracht ausgingen, unbegleitet und recht eigentlich emancipirt, lange vorher, ehe dieses Wort gebraucht wurde“.12

Im Zusammenhang dieser Arbeit ist der kürzlich auch in die Geschlechterforschung eingezogene Terminus der „kulturellen Emanzipation“ von Interesse, welcher „signalisiert, daß die Teilhabe an der Kulturproduktion für Frauen einen emanzipatorischen Charakter haben konnte“,13 bzw. in dieser abstrakten Definition für alle, die nicht Mitglied der dominierenden Gesellschaft waren. Dabei bedeutet kulturelle Emanzipation nicht nur Teilhabe an etablierten Prozessen, sondern sie konnte auch in solchen Räumen stattfinden, „die sich entweder am Rande oder sogar außerhalb der organisierten Wissenschaft konstituierten“.14 Während dies noch wie eine Neuformulierung des klassischen Diktums von Virginia Woolf klingt, dass schreibende Frauen ein „eigenes Zimmer“ bräuchten - und sich eines schufen ${ }^{15}$-, ist besonders die Ambivalenz dieses Konzept für diese Arbeit fruchtbar: Einerseits haben gewisse Ausschlussmechanismen, etwa Zuschreibungen an Frauen im Geschlechterdiskurs als natürlich und empfindsam, ihnen einen eigenen Raum, den des Briefeschreibens, nachhaltig eröffnet. Andererseits kann gefragt werden, ob so ein separater Raum Salon auf dem „langen Weg zur Mündigkeit“16 nicht auch einen Umweg darstellte, inwieweit bereits erkämpfte Positionen etwa der weiblichen Gelehrten durch die einer ,moderierenden und Briefe schreibenden“ Salonière wieder geschwächt wurden. Hier, ebenso wie mit Blick auf die Situation der Juden in Preußen mit dem Konzept ausgewählter Schutzjuden, wird die Dialektik zwischen allgemeiner und individueller Emanzipation, für die Arbeit relevant. Schließlich kann das Scheitern (kultureller) Emanzipationsbe-

12 Er datierte „die Sucht der Frauen, sich der nun so bequemen, jeder Freiheit günstigen Kleidung zu bedienen“ in vorrevolutionäre Zeiten. Karl August Varnhagen: Frauen in Mannskleidern, in: ders.: Denkwürdigkeiten und vermischte Schriften, Bd.1, Mannheim 1837, S. 503-505, hier S. 504. 1837 scheint der Begriff damit eingebürgert.

13 Angelika Ebrecht / Irmela von der Lühe [u. a.] (Hrsg.): Einführung in den Band, in: dies.: Gelehrsamkeit und kulturelle Emanzipation (Querelles. Jahrbuch für Frauenforschung 1), Stuttgart [u. a.] 1996, S. 9-22, hier, S. 9. Der Band Querelles 1 brachte den Begriff erstmals in die Debatte.

14 Ebrecht / von der Lühe 1996, S. 17

15 In ihren grundlegenden Arbeiten zur weiblichen Autorschaft definiert Woolf drei Voraussetzungen, die Frauen zum Schreiben brauchten: Muße, Geld und ein eigenes Zimmer. Virginia Woolf: Ein eigenes Zimmer, in: dies: Ein eigenes Zimmer. Drei Guineen. Essays, Leipzig 1992, S. 5-112.

16 Der Begriff der „Mündigkeit“ wurde von Barbara Becker-Cantarino in die Frauenliteraturgeschichte eingeführt. Dies.: Der lange Weg zur Mündigkeit. Frauen und Literatur und Deutschland von 1500 bis 1800, München 1989. 
strebungen sowohl durch politisch-historische oder gesellschaftliche wie durch individuelle und zwischenmenschliche Faktoren verursacht werden. ${ }^{17}$

Mit den bahnbrechenden Arbeiten von Reinhard Rürup, Rainer Erb, Werner Bergmann und Julius H. Schoeps hat es sich eingebürgert, den Prozess der Emanzipation der Juden in Deutschland mit judenfeindlichen Gegenströmungen seit dem ausgehenden 18. Jahrhundert zusammen zu denken. ${ }^{18}$ Dabei wird meist zwischen zwei Formen der Judenfeindschaft unterschieden, wobei Antijudaismus als Begriff für eine theologisch begründete Ablehnung der Juden bzw. historische Vorform verwendet wird und Antisemitismus „rassisch“ begründete Judenfeindschaft bedeutet. $\mathrm{Zu}$ Recht wurde allerdings darauf hingewiesen, dass auch und gerade bei Pamphleten der Zeit um 1800 eine „trennscharfe Differenzierung“ nicht möglich ist, da nicht selten „die Grenze zu einem antisemitischen Argumentationsmuster" überschritten wird. ${ }^{19}$ In dieser Arbeit wird von Antisemitismus gesprochen, wenn sich Argumentationen auf biologische oder „rassische“ Definitionen „des Jüdischen“ berufen. Der Schwerpunkt der Analyse liegt auch hier auf den zeitgenössischen Begriffen und Wertigkeiten in den Jahren um 1800.

17 Ebrecht/von der Lühe 1996, S. 13.

18 Antisemitismus und Emanzipation wurden in der Forschung zur deutsch-jüdischen Geschichte als zwei Antworten auf die „Judenfrage“ der bürgerlichen Gesellschaft gedeutet. Während die meisten neueren Deutungen sich deutlich gegen die Kontinuität eines ewigen Antisemitismus stellen, wird die Abgrenzung eines modernen Antisemitismus vom hergebrachten Antijudaismus unterschiedlich vorgenommen: Während Rürup die Entstehung des Antisemitismus in die Zeit der erfolgreichen Verbürgerlichung der Juden und der Wirtschaftskrise der 1870er datiert und den Antisemitismus als Gegenbewegung gegen die moderne Gesellschaft deutet, sehen Erb und Bergmann den Prozess früher einsetzen, bereits mit der Debatte um eine mögliche Emanzipation der Juden. Sie stimmen aber mit Rürup darin überein, dass der Antisemitismus ab 1870 eine neue Qualität annahm, zu einer „Weltanschauung“ wurde. Reinhard Rürup: Emanzipation und Antisemitismus. Studien zur „Judenfrage“ der bürgerlichen Gesellschaft. (Kritische Studien zur Geschichtswissenschaft, Band 15), Göttingen 1987; Rainer Erb / Werner Bergmann: Die Nachtseite der Judenemanzipation. Der Widerstand gegen die Integration der Juden in Deutschland 1780-1860, Berlin 1989, S. 10 f. Schoeps sieht die Dialektik zwischen Emanzipation als These und Antisemitismus als Antithese historisch in der Synthese Zionismus aufgehen. Schoeps 2002, S. 11 .

19 Marco Puschner: Antisemitismus im Kontext der Politischen Romantik. Konstruktionen des „Deutschen“ und des „,üdischen“ bei Arnim, Brentano und Saul Ascher, Tübingen 2008, S. 23 und 22 . 


\section{Forschungsdebatten zum Salon als Ort der Emanzipation}

\subsection{Zu einer Idealgeschichte des Salons}

Wie in I.2 erwähnt, besteht ein grundsätzliches Paradox der Salonforschung darin, dass trotz der Mündlichkeit und Flüchtigkeit des Phänomens - und obzwar es sich selbst selten so bezeichnet hat - Salonforscher aller Disziplinen ihm mit Definitionsmerkmalen beizukommen suchen. In einer aus Klassikern der Salonliteratur gefilterten Minimaldefinition wäre der Salon zu verstehen als Kommunikations- oder Geselligkeitsform, die auf Initiative einer Frau sowie in den Räumen einer Frau stattfindet und bei der Männer und Frauen verschiedener beruflicher, gesellschaftlicher und konfessioneller Herkunft zusammenkommen - zum Zweck der Unterhaltung, vornehmlich über Literatur und Kunst. Die Mischung der Gesellschaft bzw. das Zusammenkommen von Vertreterinnen und Vertretern unterschiedlicher Stände und Schichten wird dabei als besonderes Merkmal der Salongeselligkeit betrachtet. ${ }^{20}$

In der Untersuchung des emanzipatorischen Potentials stellte die traditionelle Salonforschung dann im Sinne der großen kulturgeschichtlichen Darstellung gewissermaßen zunächst den Beitrag der Salonfrauen zur „bürgerlichen Verbesserung“ der Männer in den Vordergrund. ${ }^{21}$ Personifiziert in der ersten Salonière, der Marquise de Rambouillet, wurde gezeigt, wie eine Frau zum von

20 Zu den Definitionen s.v. a. Wilhelmy 1989 und Seibert 1993(a). Wenn in der Literatur häufig die „Vermittlungsfunktionen des Salons [...] zwischen den Ständen“ betont werden, ist zu bedenken, dass sich eben in der Zeit um 1800 die so genannte preußische Ständegesellschaft im Umbruch befand. (Roberto Simanowski: Der Salon als dreifache Vermittlungsinstanz, in: Ders. / Turk / Schmidt 1999, S. 8-39, hier S. 11). Die neue Schicht des Bürgertums bildete sich heraus - ein Prozess, an dem, wie die jüngere Forschung betont, Juden (als außerhalb jeglicher Ständeordnung Stehende) wesentlich beteiligt waren. [Vgl. II.2.4]. Der preußische Adel selbst ist mit vielfachen Einbindungen ins Militär- oder Beamtenwesen nicht als homogen zu betrachten, und zumindest in Berlin ließe sich eine weitere Schicht der Intellektuellen identifizieren, zu der Schriftsteller, Verleger, Hofmeister und andere gehörten. Aus dieser Umbruchszeit heraus ist es daher korrekt, von Personen verschiedener Stände und Schichten im Salon zu sprechen. Es wäre noch zu fragen, inwieweit die gemischte Geselligkeit im Salon und an anderen Orten zur Bildung einer neuen Formation beitrug, die sich über gemeinsame kulturelle Interessen definierte und die man als „Gebildete Stände“ bezeichnet hat.

21 Das bedeutete in erster Linie gesellschaftliches Taktgefühl, Verbesserung des Ausdrucks und Hilfe zur Selbsthilfe. In diesem Sinne urteilte noch 2003 die Encyclopedia of Enlightenment, die die Aufgabe der Gastgeberinnen umschrieb, mit „bringing out the best in their circle, while encouraging others to shine, rather than attracting attention to themselves“. Rosena Davison [u. a.]: „Salons“, in: Alan Charles Kors (Hrsg.): Encyclopedia of Enlightenment, 4 Bde, Bd. 4, Oxford 2003, S. 7-14, hier S.7. 
männlichen Ritualen geprägten Hofleben Mitte des 17. Jahrhunderts in ihrem Salon eine Alternative schuf. ${ }^{22}$ So entstand zugleich ein alternatives Forum des Raisonnements, die französischen Salons wurden als Wegbereiter der bürgerlichen Öffentlichkeit diskutiert. ${ }^{23}$ Als ,Leistung der Salonièren wurde im Folgenden generell oder anekdotisch vermerkt, welche berühmten Gäste die Frauen um sich zu versammeln verstanden, auf die ihnen mehr oder minder kultivierender oder fördernder Einfluss zu haben attestiert wurde: Sei es, dass im Vorzimmer der Madame de Lambert ${ }^{24}$ über die Aufnahme in die französische Akademie entschieden wurde, sei es, dass Hester Thrale Piozzi ${ }^{25}$ den bedeutenden englischen Aufklärer Samuel Johnson durch Tischmanieren gesellschaftsfähiger gemacht haben soll, sei es schließlich, dass Rahel Levin Varnhagen Heinrich Heine mit „Makaroni und Geistesspeise“ stärkte. ${ }^{26}$ Dieser spezifische Beitrag der Frauen zur Literatur- und Kulturgeschichte wurde nicht zuletzt propagiert durch die Erinnerungen (männlicher) Salongäste, die ihre ideale Salonière als Muse verherrlichten. ${ }^{27}$

22 Bei ihrem Rückzug vom Hof Heinrichs IV. zog die Hofdame Christine de Vivonne, Marquise de Rambouillet (1588-1665), einen Großteil der Hofgesellschaft mit sich, der sich in ihrem Haus mit Künstlern und Vertretern des gehobenen Bürgertums zur Unterhaltung zusammenfand. Den angestrebten neuen Umgangsformen entsprach das Ambiente ihres Hotels, das sie so umbauen ließ, dass es Raum für persönliche Unterhaltung bot.

23 Grundlegend Habermas 1991, s. u. Zum Salon als Strukturelement der Öffentlichkeit auch Dena Goodman: The Republic of Letters. A Cultural History of the French Enlightenment, Ithaca [u. a.] 1994, bes. S. 12-15.

24 Anne Therese de Marguenat de Courcelles (1647-1733), Marquise de Lambert, ragt insofern aus der Gruppe der Salonièren des 18. Jahrhunderts heraus, als sie sich innerhalb und außerhalb der Salons für eine verbesserte Frauenbildung einsetzte. 1727 erschienen ihre „Réflexions nouvelles sur les femmes“.

25 Hester Thrale Piozzi, geb. Salusbury (1741-1821), Salonière und Autorin, war eine der umstrittensten Figuren des englischen Salons Bluestocking Circle. In der Literaturwissenschaft wurde sie zunächst vor allem berücksichtigt wegen ihrer engen Freundschaft zu Samuel Johnson, dessen erste Biografie sie schrieb. Sie publizierte aber selbst in ganz unterschiedlichen Genres, beispielsweise Reiseberichte und ein Synonymlexikon.

26 So erinnerte sich Heine, „wie Sie beyde [das Ehepaar Varnhagen] mir so viel Gutes und Liebes erzeigt, und mich mürrischen, kranken Mann aufgeheitert, und gestärkt, und gehobelt, [...] mit Makaroni und Geistesspeise erquickt.“ An Karl August Varnhagen. 17. 6. 1823, zit. als titelgebende Widmung in: Gatter 2001, Vorblatt.

27 Exemplarisch zu zitieren ist die ideale Salonière nach Marmontel: „Das Gefühl von Schicklichkeit, Relevanz und Maß, das Wort, das zum Gegenstand, zum Moment und zur Person am besten passt, die Unterschiede zwischen Dingen, der feinste Schatten des Ausdrucks, und was zu allen und zu jedem einzelnen im besonderen gesagt werden kann [...] wie sie ihre Gesellschaft animiert, verschönt und unterhält.“ Jean-Francois Marmontel, Memoirs, 2 Bde., London 1806, Bd.2, S. 244, zit. nach: Evelyn Gordon Bodek, Salonières and Bluestockings. Educated Obsolescence and Geminating Feminism, in: Feminist Studies 3 
Und während ich strickt' an meinen Strümpfen /

Hab ich lernen auf Wieland schimpfen.

Aus einer Satire, $1803^{28}$

Die Frauenforschung konnte an diesem Punkt, dem persönlichen Umgang mit Dichtern und Denkern, anknüpfen und die Gegenfrage stellen, was dieser den Frauen gebracht habe. Mit der angenommenen Herausbildung einer öffentlichen und einer privaten Sphäre im Zuge der Industrialisierung galt der Salon mit seiner Definition als Geselligkeitsform auf der Schnittstelle als erweiterter Handlungsspielraum für seine Betreiberinnen: „Außergewöhnlich gebildet und ehrgeizig, eroberten sie sich einen Platz in jenem Zwischenbereich des Nichtmehr-Privaten und Noch-nicht-Öffentlichen, das der Salon repräsentierte“.29 Weniger abstrakt wurde der emanzipatorische Effekt für die beteiligten Frauen bürgerlicher Herkunft in dieser Betrachtung besonders deutlich, wenn man den Salon vor dem Hintergrund der gesellschaftlichen Verhältnisse des 18. Jahrhunderts darstellte: Frauen hatten keinen Zugang zur Universität oder Berufsausbildung, selten die Möglichkeiten zur höheren Bildung, eine Betätigung von Frauen in künstlerischen Bereichen galt zumindest als ungewöhnlich, intellektuelle Betätigung war nicht wirklich gewünscht: „In spite of the general prejudice against the learned lady [...] the salon was the only place within a woman was encouraged to sharpen her wits". ${ }^{30}$

Je nach Definition von Emanzipation wurde der Salon dabei jeweils deswegen zum Modell, weil er den Frauen erlaubte, ihren eigenen Interessen nachzu-

(Frühj. / Sommer 1976), S. 185-199, hier S.191, Übersetzung von mir. Zum Verhältnis des Idealbilds Muse zur Salonführung s. ausführlicher Hannah Lotte Lund: Gar nicht ,zu fein für den Pressbengel' - Salonièren als Autorinnen, in: Caroline Bland / Elisa Müller-Adams (Hrsg.): Frauen in der literarischen Öffentlichkeit 1780-1918, Bielefeld 2007.

28 August von Kotzebue: Expectorationen. Ein Kunstwerk und zugleich ein Vorspiel zum Alarcos, zit. nach: Rainer Schmitz: Die Ästhetische Prügeley. Streitschriften der antiromantischen Bewegung, Göttingen 1992, S. 210.

29 Ute Frevert: Frauen-Geschichte. Zwischen Bürgerlicher Verbesserung und Neuer Weiblichkeit. Frankfurt/M. 1986, S.57. Frevert misst das aufklärerische Geschlechtermodell, den Salon und die Weiblichkeitsimagination der Romantiker an den (vermeintlich) ,auch in bürgerlichen Kreisen noch geltenden Gepflogenheiten eines traditionellen Geschlechterverhältnisses“ und so sei es einigen Frauen gelungen, vom „Lebensdogma“ abzuweichen. Ebd., S.61-62. Diese Sicht auf den Salon als Ort zwischen den Sphären wurde oft mit Bezugnahmen auf Schleiermachers zeitgenössische Theorie einer freien Geselligkeit untermauert, die zu gestalten beruflich nicht eingebundene Frauen prädestiniert seien. Friedrich Schleiermacher: Versuch einer Theorie geselligen Betragens, in: ders.: Philosophische Schriften, hrsg. und eingeleitet von Jan Rachold, Berlin 1984, S. 41-64. Da der Text erstmals 1799 erschien, wurde er oft als „Theorie des Salons“ missverstanden. 30 Bodek 1976, S. 185. 
gehen, ohne die vorgegeben Geschlechtererwartungen an die Gattin und Hausfrau zu vernachlässigen, oder aber weil er als „Einbruch“ der Frauen in die männlich geprägte Öffentlichkeit und Ausbruch aus eben diesen Geschlechtererwartungen gesehen wurde. Die künstlerisch oder politisch tätigen Gäste konnten durch das Gespräch und mitgebrachte Texte der Frau verbesserte Bildungsmöglichkeiten bringen. Der Salon wurde auch als erweiterter Schreibort diskutiert: ein größeres soziales Netz erforderte weitgefächerte Korrespondenz und schulte die Salonière als Schreiberin. ${ }^{31}$ Auch ein Zugewinn an Selbstvertrauen durch eigene literarische Aktivitäten wurde in Betracht gezogen, in der Forschung der 1980er-Jahre wurden die Salons gelegentlich als Orte der Selbstverwirklichung der Frau betrachtet, auch als „verschwundene Höhepunkte einer weiblichen Kultur“. 32

Manche Strukturen, um deretwegen der jüdische Salon als Forum oder Agent der Emanzipation der Juden galt, sind den für den Salon angenommenen Geschlechterkonstellationen vergleichbar. Ähnlich wie die Frauenforschung attestierte auch die jüdische Historiografie den Berliner Salonièren, dass sie sich „mit dieser Form der Geselligkeit erstmals einen gesellschaftl. Raum [eröffnet haben], innerhalb dessen sie ihre [...] Forderung nach Gleichberechtigung realisieren konnten“. ${ }^{33}$ Nicht nur der Umstand, dass bürgerliche und adlige Männer jüdische Häuser ohne ökonomischen Zwang besuchten, wurde als Zeichen wegbrechender gesellschaftlicher Grenzen gedeutet, beziehungsweise als Zugangsmöglichkeiten zur deutschen Kultur (für die Juden) wie für erweiterte Bildung (für Frauen). Die - als hoch angenommene - Zahl der Konversionen und Eheschließungen mit adligen oder bürgerlichen Gästen wurde als Zwischenergebnis der Integration betrachtet, als individueller Kul-

31 Zum Salon als Ort weiblicher Literaturproduktion und -rezeption s. grundlegend Seibert 1993(a) und Renate Baader: Dames de lettres. Autorinnen des preziösen, hocharistokratischen und ,modernen' Salons (1649-1698). Mlle de Scudéry - Mlle de Montpensier - Mme d'Aulnoy, Stuttgart 1986.

32 Als wohl bekanntestes Beispiel dieses nostalgisierenden Ansatzes s. Heyden-Rynsch 1995. Auf ganz anderem Niveau: Carolyn Lougee: Le Paradis des Femmes. Women, Salons and Social Stratification in Seventeenth Century France, Princeton 1976. Auf wiederum anderer, geselligkeitstheoretischer Ebene überlegt Seibert, ob nicht eben die Neudefinition der Frauenrollen um 1800 spezifische „ihnen inhärente gesellige Möglichkeiten“ gebracht hätte: „Die Frau, indem ihr der Privatraum des Hauses zugewiesen wurde, hatte die Chance, Träger des Widerspruchs zu einer ständisch organisierten, sich durch Konventionen permanent selbst bestätigenden Gesellschaft zu werden." Seibert 1993(a), S. $161 \mathrm{f}$. 33 Helga Mandelartz-Kaußen: „Salons“, in: Julius H. Schoeps (Hrsg.): Neues Lexikon des Judentums, Gütersloh [u. a.] 1992, S. 405. Diese Formulierung lässt offen, ob sie nur die Forderung aussprechen oder Gleichberechtigung realisieren konnten. 
tursprung. ${ }^{34}$ Dabei wurde und wird der geschlechtsspezifisch unterschiedliche Zugang zur Bildung im Judentum betont, insofern die geringere religiöse Ausbildung Voraussetzung für eine schnellere Akkulturation der jüdischen Frauen gewesen sei. ${ }^{35}$ Neben dem potentiellen Beitrag der Salons zur Emanzipation der Salonièren wurde auch die Gegenfrage gestellt, ob die prominente Rolle kluger jüdischer Frauen in den Berliner Salons Einfluss auf die Einstellung der Gäste zur bürgerlichen Verbesserung der Juden hatte bzw. auf eine positive Einstellung gegenüber weiblichen Intellektuellen und damit emanzipierende Wirkung auf die Haltung der Gäste. So habe die Ausstrahlung der „kulturellen Begegnung“ im Salon „Einfluss auf die Entstehung und Verwirklichung der Idee der Judenemanzipation“ gezeitigt. ${ }^{36}$ Dass diese Idealgeschichte in der Forschung natürlich nicht unwidersprochen blieb, zeigt die Diskussion der im Folgenden skizzierten drei besonders umstrittenen Topoi.

\subsection{Topos 1 - Öffentlich, teilöffentlich oder privat - Der Salon als Ort „zwischen den Sphären”}

Spätestens seit der epochemachenden Untersuchung zum Strukturwandel der Öffentlichkeit durch Jürgen Habermas galt der Salon als Merkmal und Motor

34 Bzw. in negativer Deutung als Riss durch die jüdische Gemeinde, [s. III.2.3]. Die Tatsache, dass einige Salonfrauen konvertierten und christliche, zumeist adlige Männer heirateten, verschafft dem Salon auch immer wieder das Image eines „Heiratsmarktes“, zuletzt, allerdings in kritischer Verwendung, bei Jasper 2004, S. 80.

35 „Die Befreiung der Frau von vielen religiösen Pflichten des Mannes, brachte es mit sich, dass die religiöse Bildung der Frauen nur oberflächlich war.“ Dieser Ausschluss habe dazu geführt, dass Frauen weniger Hemmungen hatten, sich der Umgebungskultur anzupassen. Monika Richarz: In Familie, Handel und Salon. Jüdische Frauen vor und nach der Emanzipation der deutschen Juden, in: Karin Hausen / Heide Wunder (Hrsg.): Frauengeschichte - Geschlechtergeschichte (Geschichte und Geschlechter 1), Frankfurt/M. 1992, S. 57-66, hier S. 59 f. Ursula Isselstein argumentiert hingegen, dass auch die Männer der Familie nach Wegen suchten, „die traditionelle jüdische Kultur mit der modernen Zeit“ zu verbinden, sich oft widerwillig in die Karriere fügten und gleich ihren Schwestern Interesse (und Talent) zur Literatur hatten. Isselstein belegt dies am Beispiel der Familie Levin, in der nicht nur der Bruder Ludwig Robert, sondern auch Marcus literarische Ambitionen gehabt hatte, hält die These aber für ausdehnbar auf viele jüdische Bürgerfamilien. Ursula Isselstein: Emanzipation wovon und wofür? Das Beispiel der Familie Levin aus Berlin, in: Norbert Altenhofer / Renate Heuer (Hrsg.): Jüdinnen zwischen Tradition und Emanzipation (Jahrbuch des Archivs Bibliographia Judaica 1986/1987) Bad Soden 1990, S. $80-113$, bes. S. $84 \mathrm{f}$.

36 Monika Richarz: Einleitung, in. dies. (Hrsg.): Bürger auf Widerruf. Lebenszeugnisse deutscher Juden 1780-1914, München 1989, S. 11-55, hier S. 14. 
dieses Wandels, als Forum der Emanzipation des Bürgertums. ${ }^{37}$ Es muss dabei betont werden, dass Habermas sich explizit und ausschließlich auf den französischen Salon bezog. ${ }^{38}$ Die in der Salonforschung oft erfolgte Annahme, es sei auch der deutsche Salon mitgemeint, lässt sich rein quantitativ entkräften eine das Stadtbild prägende und verändernde Erscheinung wie das Kaffeehaus in London, von denen es im 18. Jahrhundert schon 3.000 gab, ist der Berliner Salon zu keiner Zeit gewesen, eine kulturhistorische entscheidende „Institution“ wie der Pariser Salon auch nicht. ${ }^{39}$ Vielmehr lässt sich fragen, ob nicht einige der von Habermas definierten Merkmale einer epochaltypischen Form von Öffentlichkeit auch für die Berliner Salons um 1800 zutreffen, wenn sie auch nicht eine Institution waren. ${ }^{40}$ Dazu zählen ein „Takt der Ebenbürtigkeit“, „eine der Tendenz nach permanente Diskussion unter Privatleuten“, und eine „prinzipielle Unabgeschlossenheit des Publikums““.41

$\mathrm{Zu}$ fragen ist aus der Berliner Perspektive auch noch, in welchem Verhältnis die jüdischen Salons und die seit den 1780er-Jahren neu entstehende jüdische Öffentlichkeit zueinander standen. Vereinzelte Hinweise gibt die neuere Forschung zur jüdischen Aufklärung, der Haskala; ${ }^{42}$ eine bessere Arbeits-

37 Habermas zeichnet den Übergang von der repräsentativen höfischen zur bürgerlichen Öffentlichkeit, die er als epochaltypische Kategorie begreift, in den drei Ländern England, Frankreich und Deutschland nach. Dabei sieht er in jedem Land die bürgerliche Öffentlichkeit - als der „Sphäre der zum Publikum versammelten Privatleute“ (Habermas 1990, S. 86) - paradigmatisch in einer anderen Form realisiert: In Frankreich gilt ihm der Salon als erster Ort, in England attestiert er den Coffeehouses die stärkste verändernde Kraft und in Deutschland den Vereinen, vor allem den Tischgesellschaften. Zu der bekannten Kritik an Habermas' Modell, dass er Öffentlichkeit zu monolithisch betrachtet und die plebejische oder eine spezifisch weibliche Öffentlichkeit außer Acht gelassen habe, s. sein Vorwort zur Neuauflage 1990. Aus Sicht der jüngeren Salonforschung s. Steven D. Kale: Women, the Public Sphere and the Persistence of Salons, in: French Historical Studies 25.1 (2002), S. 115-148. Kale sieht die französischen Salons, anders als Habermas, als primär aristokratisch in Herkunft und Ideal.

38 Die Pariser Salons wurden nicht nur als ein Zwischenraum zwischen Hof, Aristokratie und Stadtbürgertum untersucht, sondern ebenso als ein Raum zwischen den Philosophen, Künstlern und der allgemeinen Öffentlichkeit. Als nicht unwesentliche Beiträge der Pariser Salons zur Aufklärung gelten beispielsweise der Umstand, dass Madame Geoffrin die Autoren der „Encyclopédie“ finanziell und gesellschaftlich unterstützte, sowie die Tatsache, dass zahlreiche ausländische Philosophen und Schriftsteller die Pariser Salons besuchten. 39 Die Zahl der Kaffeehäuser und der Begriff Institution nach Habermas 1990, S. 92.

40 Habermas hatte auch explizit darauf hingewiesen, dass es neben den von ihm genannten frühen Institutionen der literarischen Öffentlichkeit ein „großes“ Publikum gegeben habe, das sich in Theatern, Museen oder als Zeitungspublikum bildete. Habermas 1990, S. 107. 41 Habermas 1990, S. 97.

42 Vor allem bei Shmuel Feiner: Haskala - Jüdische Aufklärung. Geschichte einer kulturellen Revolution, Hildesheim [u. a.] 2007, und Schulte 2002. 
grundlage ist von den verstärkt unternommenen biografischen Recherchen zu einzelnen ihrer Vertreter, den Maskilim zu erhoffen. ${ }^{43}$ In den grundlegenden Werken zur Verbürgerlichung der deutschen Juden tritt der jüdische Salon hingegen nicht in Erscheinung. Dabei scheinen der Begriff und die These einer deutsch-jüdischen „Subkultur“, die David Sorkin zwischen 1780 und 1840 entstehen sieht, eine informelle Gruppierung wie den Salon geradezu zu subsumieren. ${ }^{44}$ Insofern der Weg zur eigenen Subkultur nach Sorkin aber über die Adaption bürgerlicher Modelle der Mehrheitskultur führt, hat der Salon hier wirklich keine Funktion, da jüdische Bürger ihn nicht ,übernommen“ haben. Der Berliner Salon entstand, im umgekehrten Prozess, aus der spezifischen Lebenssituation der jüdischen Oberschicht der 1780er-Jahre, um im 19. Jahrhundert eine Geselligkeitsform des gehobenen Berliner Bürgertums zu werden.

Dass der Berliner Salon nicht zu den jüdischen „Wegen ins Bürgertum“45 im 19. Jahrhundert gerechnet wird, könnte erstens darauf hindeuten, dass im Salon eher der Lebensstil der Aristokratie gepflegt wurde, oder zweitens darauf, dass hier keine bürgerlichen, sondern romantische Lebenskonzepte vorweggenommen wurden, oder drittens darauf, dass der Salon doch einen exterritorialen, außerständischen Ort darstellte bzw. von den Forschern heute dafür genommen wird.46 Der Befund könnte viertens auch einfach mit der Tatsache korrelieren, dass der Salon um 1800 ein Phänomen für nur einen sehr kleinen Teil der späteren jüdischen Bürger darstellte.

Für die Einschätzung des Salons als „halböffentlichen“ Ort ist letztlich ein Paradigmenwechsel innerhalb der Frauen- und Geschlechterforschung besonders interessant. Bis in die 1980er-Jahre gehörte zu deren Kernthesen, dass die

43 Eine grundlegende neue Sicht auf die Vernetzungen eines Maskils bietet die Biografie von Andreas Kennecke: Isaac Euchel. Architekt der Haskala, Göttingen 2007.

44 David Sorkin: The Transformation of the German Jewry. 1780-1840, Oxford 1990. Eine Gruppe jüdischer Intellektueller, die er die Ideologen der Emanzipation nennt, habe ein neues Modell einer sich erneuernden jüdischen Gemeinde entworfen, das sowohl die Zuerkennung von Rechten als auch die Regeneration der Juden als solche beinhaltete. Sorkins zweite zentrale These lautet, dass diese neue jüdische Identität große Anleihen bei der Mehrheitskultur machte, und diese umformte, sodass eine deutsch-jüdische Subkultur entstand.

45 Auch Simone Lässig, die auf Sorkin aufbaut, aber als Ergebnis des Modernisierungsprozesses keine Subkultur, sondern eine rasante und erfolgreiche Verbürgerlichung der deutschen Juden sieht, erwähnt den Salon nicht. Simone Lässig: Jüdische Wege ins Bürgertum. Kulturelles Kapital und sozialer Aufstieg im 19. Jahrhundert, Göttingen 2004. 46 Die Exterritorialitätsthese kam mit der erstmals 1957 erschienenen Biografie Rahel Levin Varnhagens von Hannah Arendt in die Salonforschung: „Der jüdische Salon in Berlin war der soziale Raum außerhalb der Gesellschaft und Rahels Dachstube stand noch einmal außerhalb der Konventionen und Gepflogenheiten auch des jüdischen Salons.“ Arendt 2001, S. 71. 
Aufklärung den Frauen ein höchst ambivalentes Erbe hinterlassen habe, bzw. wurde, rückblickend vom 19. Jahrhundert, die sogenannte Sattelzeit als „Epochenschwelle [auch] der Geschlechterverhältnisse“ angenommen:47 Mit zunehmender Industrialisierung und Verlagerung der Erwerbsarbeit aus dem Haus habe sich die eher partnerschaftliche Familienökonomie aufgelöst und das Modell des öffentlich agierenden männlichen Ernährers etabliert, der sich in dem von der Frau gestalteten und bewahrten Zuhause regeneriere. ${ }^{48}$ In diesem Interpretationsmuster der getrennten Sphären ${ }^{49}$ galt der Salon lange als eine der wenigen Möglichkeiten für Frauen, an der männlich dominierten Öffentlichkeit zu partizipieren. Indem eine Frau Vertreter der literarischen oder politischen Öffentlichkeit in ihr Haus einlud, wurde ihr Wohn- oder Empfangszimmer zum halb- oder teilöffentlichen Raum.

Etwa seit den 1980er-Jahren im angloamerikanischen Raum und seit Beginn der 1990er auch in der deutschen Wissenschaftslandschaft begannen Vertreterinnen der Frauen- und Geschlechterforschung, einerseits das Narrativ vom Goldenen Zeitalter der Frau vor 1800 und ihrem anschließenden wirtschaftlich-gesellschaftlichen Niedergang zu hinterfragen und andererseits den Aufklärungsdiskurs und seine Reflektion durch die Geschlechter differenzierter $\mathrm{zu}$ betrachten und andere Möglichkeiten der Teilhabe von Frauen am Diskurs zu prüfen. Wie in II. erwähnt, konfrontieren neuere Ansätze das Bild der Muse

472004 tut das noch Cornelia Klinger: 1800 - eine Epochenschwelle im Geschlechterverhältnis?, in: Katharina Rennhak / Virginia Richter (Hrsg.): Revolution und Emanzipation. Geschlechterordnungen in Europa um 1800, Köln [u. a.] 2004, S. 17-32. Interessant ist allerdings ihr Ansatz, den Geschlechterdiskurs als frühe Form der Modernisierungskritik zu lesen.

48 Bei diesem Forschungsansatz wurde die von Karin Hausen geprägte Formulierung von der „Polarisierung der Geschlechtscharaktere“ oft zu absolut gedeutet und mit einer Polarisierung der Lebenswelten in eins gesetzt. Karin Hausen: Die Polarisierung der „Geschlechtcharaktere“. Eine Spiegelung der Dissoziation von Erwerbs- und Familienleben, in: Werner Conze (Hrsg.): Sozialgeschichte der Familie in der Neuzeit Europas, Stuttgart 1976, S. 363-393. Ihre 1992 vorgelegte kritische Auseinandersetzung mit den Kategorien Öffentlichkeit und Privatheit enthält die bis heute gültige Warnung, „daß die im Englischen noch viel handlichere und in der Wissenschaftssprache geradezu inflationäre Setzung publicprivate vermutlich völlig untauglich ist, um die in historischen Gesellschaften höchst unterschiedlich ausgebildeten sozialen Beziehungen zwischen den Geschlechtern angemessen wahrzunehmen“. Dies.: Öffentlichkeit und Privatheit. Gesellschaftspolitische Konstruktionen und die Geschichte der Geschlechterbeziehungen, in: dies. / Heide Wunder 1992, S. 81-88, hier S. 85.

49 Dies Modell wurde zurecht „eines der einflussreichsten Modelle der Frauengeschichte“ genannt. Leonore Davidoff: Regarding some "Old husbands' tales”: Public and Private in Feminist History, in: Joan B. Landes (Hrsg.): Feminism, the Public and the Private, Oxford University Press, Oxford 1998, S.164-194, S. 164. 
und Gastgeberin mit der tatsächlichen Schreibpraxis erfolgreicher Autorinnen um $1800 .{ }^{50}$

Gegen die „Separate-Spheres-Ideology“51 beziehungsweise das Alleinstellungsmerkmal des Salons lassen sich fünf wesentliche Gegenargumente ausmachen: Erstens lässt sich ein „Goldenes Zeitalter der mitarbeitenden Ehefrau“ gar nicht genau datieren bzw. wäre die Trennung der Sphären allein in England in jeder Region in einem anderen Jahrzehnt anzusetzen. ${ }^{52}$ Gegen eine dichotomische Weltsicht spricht zweitens der Umstand, dass Frauen de facto den ,privaten Raum“ zu allen Zeiten verließen, und sei es nur, um im „öffentlichen Raum“ der Gemeinde wohltätig zu werden, und „selbst der familiale Binnenraum der Privatheit blieb [...] durchzogen von der Öffentlichkeit der Dienstboten, der Gäste und dem öffentlichen Einfluss gesellschaftlicher Normen“. ${ }^{53} \mathrm{Zu}$

50 Einzeluntersuchungen zu schreibenden Frauen führten zur These, dass Autorinnen um 1800 durchaus Präsenz zeigten, sich keineswegs auf die ihnen zugestandenen „weiblichen“ Gattungen und „damenhaften“ Verhandlungstaktiken beschränkten. Grundlegend, besonders zum Drama, ist Susanne Kord: Sich einen Namen machen. Anonymität und weibliche Autorschaft 1700-1900, Stuttgart 1996. Generell wird zunehmend ein Prozess der „Aneignung“ angenommen, in dem Frauen Nischen im normativen Diskurs nutzten, zum Beispiel darauf bestanden, dass der vielfältige Rekurs auf die natürliche Bestimmung zur Mutterschaft sie zu Verfassern pädagogischer Literatur qualifiziere. Zum Paradigmenwechsel grundlegend Anne Fleig: Vom Ausschluss zur Aneignung. Neue Positionen in der Geschlechterforschung zur Aufklärung, in: Das Achtzehnte Jahrhundert 26, Heft 1, 2002, S.79-88. Zuletzt rekonstruierte Helen Fronius überzeugend Korrespondenzen zwischen Verlegern und Autorinnen, die sich keineswegs „im Schatten des Goetheschen Olymp“ bewegt hätten, sondern durch die Zahl ihrer Publikationen und ausgesprochenes Selbstbewusstsein beeindruckten. Helen Fronius: Determined Dilettantes. Women and Literature in the Goethe Era 1770-1820, Oxford 2007, hier S.3. Fronius' These, dass diejenigen Frauen selbstbewusster auftraten, die nicht im Umfeld männlicher etablierter Autoren schrieben, bietet eine mögliche Erklärung, warum Salonfrauen nicht mehr als Autorin in Erscheinung traten als andere Frauen, oder die Rolle der Autorin zeitlich der Rolle der Salonière folgen ließen. 51 Man muss natürlich selbstkritisch fragen, ob die Abwehr des Separate-Spheres-Modells nicht auch von der Hoffnung motiviert sei, dass Frauen um 1800 doch nicht so ausgeschlossen gewesen sind, wie vielfach vermutet worden ist - ähnlich der Begeisterung, mit der die Frauenbewegung Anfang der 1970er-Jahre vergessene Frauen der Geschichte als Leitbilder ausgrub. Nichtsdestoweniger gilt es immer, Modelle der Vergangenheit mit der komplexeren Realität zu konfrontieren und die traditionelle Geschichtsdeutung zu hinterfragen. Diesem feministischen Anliegen fühlt sich die Arbeit durchaus verpflichtet. 52 Dieses und andere Argumente gegen das Master Narrative werden überzeugend vorgebracht von Amanda Vickery: Introduction, in: dies.: The Gentleman's Daughter. Women's Lives in Georgian England, New Haven [u. a.] 1998, S.1-12.

53 Karin Hausen / Heide Wunder: Einleitung, in: dies. (Hrsg.) 1992, S. 9-20, hier S. 15. In den letzten zehn Jahren haben Arbeiten der Aufklärungs- und Geschlechterforschung daher an der Eindeutigkeit der Grenze zwischen öffentlich und privat im 18. und beginnenden 19. Jahrhundert zunehmend Zweifel angemeldet. 
fragen ist daher immer noch, ob und inwieweit sich das zeitgenössische Verständnis von „öffentlich“ und „privat“ mit unserem heutigen deckt. Forscherinnen verwiesen drittens auf die Kontinuitäten in den Lebensverhältnissen wie auch in den Weiblichkeitsvorstellungen der präskriptiven Literatur, die die Unterordnung des Weibes schon immer gefordert habe, und die um 1800 lediglich andere, verbrämtere Gestalt annahm. ${ }^{54}$ Umgekehrt ist der grundlegende Umstand, dass die Mehrheit öffentlicher Ämter in Männerhand ist und der Großteil der Haus- und Familienarbeit von Frauen bewältigt wird, ein bis heute gültiges Kontinuum und daher nicht als spezifisch historische Kategorie der Frühen Neuzeit zu betrachten. Mit Blick auf den umfassenden Textkorpus zur Geschlechterfrage um 1800 fragt viertens die jüngere feministische Forschung, ob die zahlreichen zeitgenössischen Texte über die natürliche Bestimmung für unterschiedliche Sphären nicht eine Reaktion auf eine zunehmende Verunsicherung statt einer Beschreibung des Status quo darstellten, so wie etwa Schiller im Lied von der Glocke eine Idylle des heimischen Herdes entwarf, in der der Mann sich von den Strapazen der Außenwelt erholen können soll - eine Idylle, die Zeitgenossen gleichermaßen zum Schwärmen wie zum Lachen brachte, aber nicht notwendigerweise als Alltagsbeschreibung verstanden wurde. ${ }^{55}$ Das fünfte Gegenargument gegen das Master Narrative vom Salon als „einer der wenigen Orte [...], der es Frauen gestattete, sich frei zu äußern“,56 ist die tatsächliche gesellige und kommunikative Lebenspraxis der Geschlech-

54 Im Vergleich der postrevolutionären Texte mit kirchlichen Ratgebern des 16. Jahrhunderts schreibt Hufton: „Die Botschaften, die von den Moralisten, den Richtern und den Medizinern [um 1800, H. L. L.] kamen, unterstützen also die traditionelle Rolle der Frau in einer patriarchalischen Familie, auch wenn die Gründe, die die Rolle der Frau rechtfertigen sollten, eine andere Akzentuierung und zum Teil ein neues Vokabular erhalten hatten." Olwen Hufton: Frauenleben. Frankfurt/M. 1998, S.683. Für Hufton besteht der Unterschied nur in einem „Schuß Empfindsamkeit und Naturrecht“. Sie weist auf die konfessionell gesteuerte Entwicklung des Diskurses hin und darauf, dass man in katholischen Ländern weiter an kirchlichen Ratgebern festhielt. Ebd., S. 679.

55 Neue Einzeluntersuchungen vor allem aus der Geschichtswissenschaft konfrontieren den veröffentlichten Diskurs mit Selbstaussagen der Geschlechter. In ihrer grundlegenden Untersuchung zum Hamburger Bürgertum fand Ann-Charlotte Trepp nicht nur keine polaren Ideale vertreten, sondern gemeinsame progressive Ideale erarbeitet. Dies.: Sanfte Männlichkeit und selbständige Weiblichkeit. Frauen und Männer im Hamburger Bürgertum zwischen 1770 und 1840 (Veröffentlichungen des Max-Planck-Instituts für Geschichte 123), Göttingen 1996.

56 Claude Dulong: Salonkultur und Literatur von Frauen, in: Georges Duby / Michelle Perrot (Hrsg.): Geschichte der Frauen, Bd. 3: Frühe Neuzeit, hrsg. von Arlette Farge und Natalie Zemon Davis, Frankfurt/M. 1997, S. 415-440, hier S. 415. 
ter um 1800. Aus verschiedenen Forschungsrichtungen wurden Stimmen laut, die den Salon als Ausnahmeerscheinung hinterfragten. ${ }^{57}$ Im jüngsten Forschungsbericht zum Berliner Salon forderte Ulrike Weckel daher die Rückbindung des Salons in die Geselligkeitsgeschichte Berlins und der Zeit. ${ }^{58}$ Diese Arbeit versteht sich als ein Schritt in diese Richtung.

Um sich von der post factum erfolgten Festlegung eines männlich-öffentlichen und weiblich-privaten Raumes zu lösen, zwischen denen der Salon sich etabliert habe, wird in dieser Arbeit am Beispiel des Salons gefragt, welches Verständnis von öffentlich und privat die Beteiligten selbst hatten und wo sie ihr geselliges Tun einordneten, welchen Handlungsspielraum sie für sich sahen und nutzten. ${ }^{59}$ Die These dieser Arbeit lautet: Der Salon ist nicht ein Ort „zwischen den Sphären“, der es den Frauen ermöglichte, aus einem geschützten Bereich des „weiblich geprägten Hauses“ an der „männlich geprägten Öffentlichkeit“ zu partizipieren, sondern er ist ein Beispiel dafür, dass diese Sphärenkonstruktion der Realität des 18. Jahrhunderts nicht notwendig entspricht. Damit soll in keiner Weise die Existenz geschlechtsspezifischer Ungleichheiten und Ungerechtigkeiten im Leben von Frauen und Männern um 1800 bezweifelt, sondern vielmehr der Blick dafür geöffnet werden, dass Frauen und Männer des 18. Jahrhunderts sich nicht in festgelegten Rollen und Sphären bewegten, sondern eine Vielfalt an Rollen und Verantwortlichkeiten durchlebten und sich abhängig vom Kontext und der Situation verschieden repräsentieren konnten und mussten.

57 Seit den 1990er-Jahren wiesen geschlechtergeschichtliche Arbeiten vor allem zur englischen Polite Society auf eine zunehmende Zahl Möglichkeiten der „Freizeitgestaltung“, die es auch Frauen ermöglichte, sich schicklich außerhäusig zu betätigen. Vgl. exemplarisch: Hannah Barker / Elaine Chalus (Hrsg.): Gender in Eighteenth Century England. Roles, Representations and Responsibilities, London 1997. Aus der Aufklärungsforschung sind Arbeiten interessant, die die Uneinheitlichkeit des aufklärerischen Diskurses und alternative Aneignungsformen der Geschlechtermodelle in den Blick nehmen. S. den Forschungsbericht in Frindte / Westphal 2005, S. 3-16.

58 Weckel 2000(a).

59 Begriff und Konzept des Handlungsspielraums wurden besonders vom Sonderforschungsbereich „Ereignis Weimar-Jena, Kultur um 1800“ als brauchbarer Maßstab für Geschlechterverhältnisse um 1800 diskutiert. Vgl. Frindte / Westphal 2005. Besonders überzeugend ist dabei die Frage nach der Gewichtung unterschiedlicher Faktoren, die Handlungsspielräume eröffnen oder begrenzen, und zu denen individuelle Talente und Ängste ebenso zu rechnen sind wie der gesellschaftliche Status der Akteure und zeitgenössische Diskurse. Ebd., S. 8. 


\subsection{Topos 2 - Konversion im Salon}

Welche Geschichte! [...] eine aus Ägypten und Palästina Geflüchtete bin ich hier und finde Hülfe, Liebe und Pflege von euch! [...]. Was so lange Zeit meines Lebens mir die größte Schmach, das herbste Leid und Unglück war, eine Jüdin geboren zu sein, um keinen Preis möcht' ich das jetzt missen. ${ }^{60}$ „Letzte Worte“ Rahel Levin Varnhagens

Vielfach thematisiert und bis heute umstritten sind die Motive und die Konsequenzen der Taufnahmen im Umfeld der Salons. Die zentralen Fragen sind erstens, welche Rolle die Konversion im Leben der Salonfrauen spielte und zweitens, ob der Salon die Konversionsrate im zeitgenössischen Berlin steigen ließ. Die Worte, die Rahel Levin Varnhagen auf ihrem Totenbett geäußert haben soll, bekamen spätestens dann Symbolwert, als Hannah Arendt ihre zum Klassiker gewordene Biografie damit einleitete und den Text dabei allerdings um die wesentliche zweite Hälfte verkürzte. Wie Michael A. Meyer treffend feststellte, haben in Arendts Nachfolge „die Interpreten, die den Versuch unternommen haben, Rahel Levin Varnhagen als ,Jüdin' zu verstehen, [...] den Schluß eben dieser Äußerung außer acht gelassen.“ Dieser lautete: „Mein Herz ist im Innersten erquickt; ich habe an Jesus gedacht [...], es so gefühlt, daß er mein Bruder ist. Und Maria, was hat die gelitten. [...] Das hätte ich nicht gekonnt, so stark wäre ich nicht gewesen [...]“.61

An diesem Zitat, in beiden Versionen, ließe sich die wechselvolle Rezeptionsgeschichte des Berliner Salons und seiner Konversionen verfolgen und festhalten, wie sehr vom 19. bis noch zum Beginn des 21. Jahrhunderts unterschiedliche Ansätze der Forschenden ebenso wie ihre gesellschaftspolitischen Interessen zu ganz verschiedenen Deutungen derselben Fakten und Textstellen führen können. Seit Mitte des 19. Jahrhunderts sahen sich jüdische Historiografen vor dem Dilemma, die zunehmenden Konversionen von „geistig so hochbegabten, und dennoch auf Abwege gerathenen Persönlichkeiten"62 in der Generation nach Moses Mendelssohn erklären zu müssen, ein Dilemma, das nicht

60 Rahel Levin Varnhagen, 2. 3. 1833, Notat von Karl August Varnhagen, in: GW I, S. 43. 61 Michael A. Meyer: Von Moses Mendelssohn zu Leopold Zunz. Jüdische Identität in Deutschland 1749-1824, München 1994, S.132. Hieraus auch das Schlusszitat. Das „doppelte Erbe“ Rahel Levin Varnhagens betont zuletzt Deborah Hertz: How Jews became Germans. The History of Conversion and Assimilation in Berlin, Berlin 2007, S. 215.

62 Meyer Kayserling: Die jüdischen Frauen in der Geschichte, Literatur und Kunst. Leipzig 1879 (Bibliothek des deutschen Judentums, hrsg. im Auftrag des Salomon Ludwig Steinheim Instituts für deutsch-jüdische Geschichte von Julius H. Schoeps. Abt. 5, Literatur- und Kulturgeschichte) Hildesheim 1991, S. VI. 
selten am Beispiel der dann prominenten Salonfrauen und dem Begriff „Mendelssohns Töchter" festgemacht wurde. ${ }^{63}$ Wegweisend bis weit ins 20. Jahrhundert wurde die elegante Lösung Ludwig Geigers, bekannte Salonfrauen als ,Ausnahmepersönlichkeiten' darzustellen, die aus schicksalhaften persönlichen Verwirrungen und jedenfalls pietätvoll die Taufe nahmen. ${ }^{64}$ Unter anderem mit Bezug auf ihre letzten Worte wird in dieser Lesart besonders für Rahel Levin Varnhagen meist eine Ausnahme gemacht, der man besonderes religiöses Empfinden zugestand. Bei Dorothea Mendelssohn Veit Schlegel wird in den meisten Darstellungen der Einfluss der Romantik, bei Henriette Herz eine innere Leere vermutet. ${ }^{65}$ Als neuere Entwicklung in der Motiv-Forschung sei festgehalten, dass, während ältere Interpreten oft noch einen wenn auch entschuldigenden Aspekt der Verführung der Salonfrauen durch männliche Denker einbringen, neuere Arbeiten eher dazu tendieren, den Frauen eine eigenständige religiöse Entwicklung zuzugestehen. ${ }^{66}$

63 Vgl. etwa den Ausruf: „Was ist aus der Nachkommenschaft unseres Moses geworden! Seine Tochter Dorothea küsste dem Papst den Pantoffel [...]. Es war damals die Zeit der Salons [...]. Für eine Grafenkrone, oder auch noch billiger, verkaufte man gern das bisschen Glauben, das noch vorhanden war." Nathan Samter: Berliner Judentaufen, in: Ost und West, 12 (1902), S. 811-820, hier S. 815 f. Der Begriff „Mendelssohns Töchter“ wurde am deutlichsten als Vorwurf diskutiert von Joseph Körner: Mendelssohns Töchter, in: Preußische Jahrbücher 214, Heft 2 (1928), S. 167-188. Gegen Körner und die These, dass Mendelssohn Verursacher der Taufen war: Bertha Badt-Strauß. Mendelssohns Tochter Dorothea, in: Der Morgen, 5. Jg., Nr. 3 (August 1929), S. 244-248.

64 Damit grenzten sie sich ab von einem allgemeinen Umsichgreifen von „Unsittlichkeit und Taufe“ unter den Juden. Ludwig Geiger: Geschichte der Juden in Berlin. Festschrift zur zweiten Säkular-Feier. Anmerkungen, Ausführungen, urkundliche Beilagen und zwei Nachträge (18711890). Mit einem Vorwort von Hermann Simon, Leipzig 1988, bes. S. 110-119, hier S. 110.

65 Die „verwirrende und umnebelnde Wirkung der Romantik auf das Geschlecht der Mendelssohntöchter" wird beispielsweise beklagt bei Badt-Strauß 1929, S. 248. Die Annahme einer „inneren Leere“ ist angesichts des recht umfänglichen Briefbestandes für die Zeit nach der Taufe Herz', der auf intensive Auseinandersetzung mit dem christlichen Glauben deutet, vor allem der Lesefaulheit einiger Forschender geschuldet.

66 Katz beispielsweise meinte, dass die Salonièren romantisches Gefühl mit Christentum gleichsetzten bzw. sich davon zu Christen hingezogen fühlten. Jakob Katz: Aus dem Ghetto in die bürgerliche Gesellschaft. Jüdische Emanzipation 1770-1870. Aus dem Englischen von Wolfgang Lotz, Frankfurt/M. 1986, S.136. Noch Michael A. Meyer schätzt die Bedeutung Schleiermachers für die Taufe Henriette Herz', und Fichtes für die Christianisierung Rahel Levin Varnhagens als hoch ein. Meyer 1994, S. 127 f. Deborah Hertz betont hingegen die komplexen Strategien und Kämpfe der Frauen, persönliche Entscheidungen und Familieninteressen bewusst zu verbinden. Hertz 2007, bes. S. 146-148. Shmuel Feiner kehrt partiell wieder zur alten Interpretation zurück, er sieht zwar „keinen Grund, diese sensible und einfühlsame Deutung abzulehnen, doch aus der Perspektive der jüdischen Gesellschaft [...] bedeutete diese Erscheinung in ihrer letzten Konsequenz die Aufgabe des Judentums.“ Feiner 2007, S. 391. 


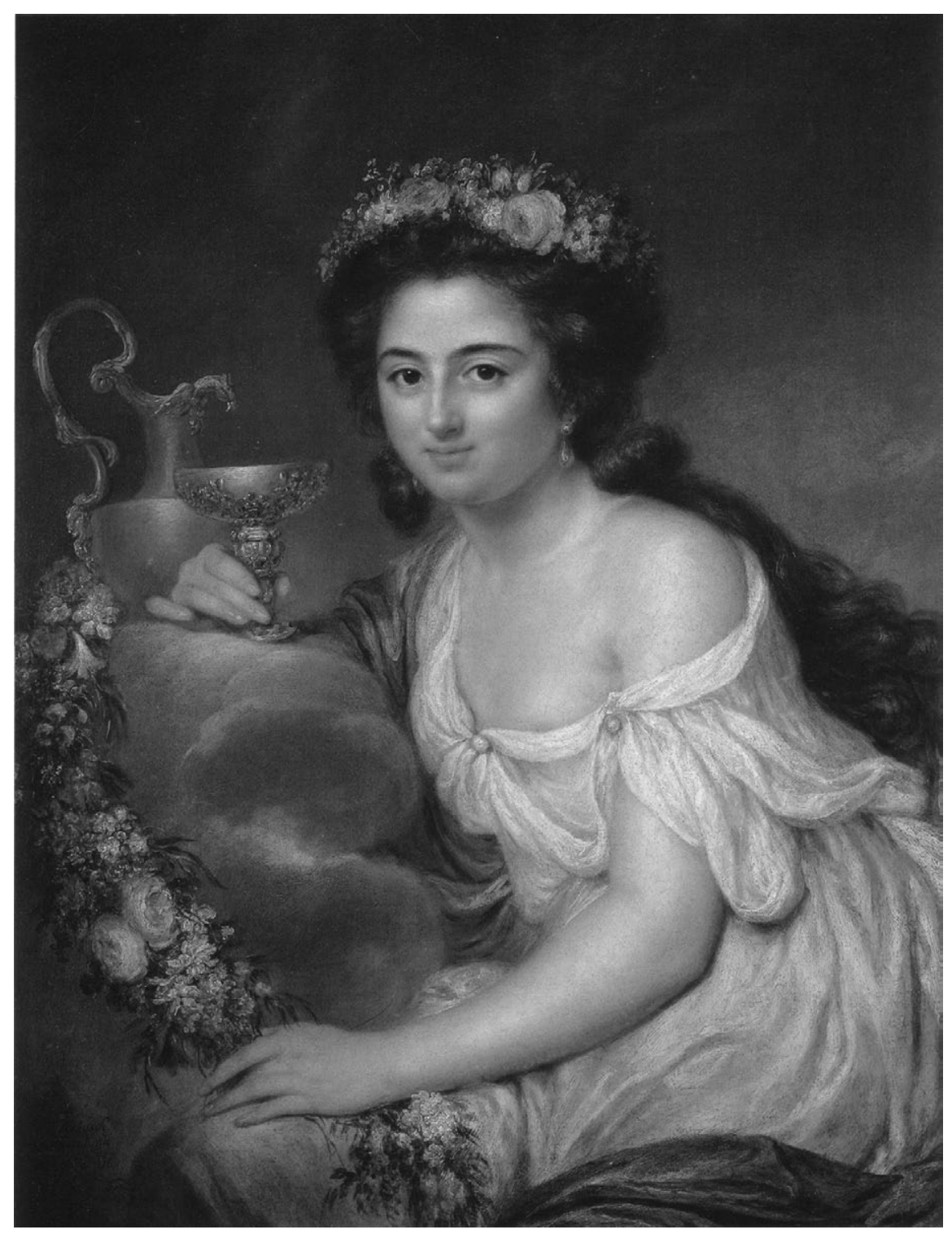

Abb. 6: Ein mehrfacher Konventionsbruch? Henriette Herz (1764-1847), 1778 als Göttin Hebe gemalt von Anna Dorothea Therbusch.

In Bezug auf die Konsequenzen der Konversionen hingegen ist die Fama der Vorbildwirkung bzw. ,Gefahr' der Übertritte im Salon bis heute, trotz grundlegender Gegendarstellungen bei Honigmann oder Lowenstein, immer noch weit 
verbreitet. ${ }^{67}$ Letzterer betont die Notwendigkeit, zwischen dem publizistischen Aufruhr um die Konversionen und den tatsächlichen Statistiken zu unterscheiden, denn, obwohl „Frauen sich in ihrem Handeln nicht wesentlich von ihren männlichen Religionsgenossen unterschieden, zog der Umstand, dass sie überhaupt öffentlich agierten, das Interesse derjenigen - meist männlichen - Personen auf sich, die ihre Eindrücke vom Leben der Gemeinde schriftlich überlieferten". 68

Dass das Thema der Konversionen auch und gerade von Salonfrauen für die Forschung bis heute Brisanz hat, zeigt die Tatsache, dass in jüngster Zeit von ausgewiesenen Forscherinnen der deutsch-jüdischen Geschichte zwei Monografien erschienen, die sich aus ganz unterschiedlicher fachlicher und methodischer Perspektive mit der Identität getaufter Jüdinnen auseinandersetzen und dabei Salonfrauen an prominenter Stelle diskutieren.69 In ihrem 2002 erschienenem Buch Die Jüdin Pallas Athene analysiert Barbara Hahn Texte von und über schriftstellerisch tätigen Jüdinnen aus zwei Jahrhunderten. ${ }^{70}$ Gendertheoretische Ansätze mit kulturwissenschaftlichen Fragestellungen verbindend, zeigt Hahn die deutschsprachige Jüdin als eigenständigen Kulturtypus,

67 Die Frage, ob der Umgang in Salons Taufen en masse befördert habe, wurde sowohl auf personeller Ebene bejaht, zum Beispiel implizit bei Geiger 1988, S.106-110, wie auf abstrakt kulturtheoretischer sowie statistischer Ebene. Bis weit ins 20. Jahrhundert hielt sich Heinrich Graetz' Verdikt, dass in den ersten drei Jahrzehnten des 19. Jahrhunderts die Hälfte der Berliner jüdischen Gemeinde übergetreten sei, obwohl diese Zahl schon in der zweiten Auflage vom Herausgeber hinterfragt wurde. Ironischerweise beruhte Graetz Aussage u. a. auf einem Briefzitat Rahel Levin Varnhagens. Zur Problematik der Graetzschen Angaben und der möglichen Zählungen siehe: Peter Honigmann: Jewish Conversions - A Measure of Assimilation. A Discussion of the Berlin Secession Statistics of 1770-1941, in: Leo Baeck Institute Year Book 34 (1989), S. 3-45. Eine grundlegende geschlechterspezifische Auseinandersetzung mit der Frage, wie Frauen und Männer der jüdischen Gemeinde unterschiedliche auf die Veränderungen reagierte, bietet das immer noch nicht genügend rezipierte Buch von Steven M. Lowenstein: The Berlin Jewish Community. Enlightenment, Family, and Crisis, 1770-1830. New York [u. a.] 1994, bes. S. 162-176.

68 Lowenstein 1994, S. 176. (Übersetzung H. L. L). Lowenstein weist nach, dass sich, nach Phasen unterschieden, mal mehr Männer, mal mehr Frauen, haben taufen lassen und fragt nach geschlechtsspezifisch unterschiedlichen oder vergleichbaren Motiven.

69 Diese beiden Bücher zusammengenommen, dürften sowohl alle bekannten Quellen als auch die wesentlichen Forschungsmeinungen zur Konversion und potentiellen Identitätskonflikten von Rahel Levin Varnhagen, Sara Meyer Grotthus und Marianne Meyer Eybenberg offen vorlegen und sind hiermit Interessenten zur weiteren Erforschung persönlicher Motivlagen nachdrücklich empfohlen.

70 Hahn beginnt mit der Gräfin Cosel 1765 und endet 1966 mit dem Tod von Margarete Susman. Das Buch verbindet ältere Aufsätze zum Salon mit neueren Überlegungen zu der grundlegenden These, daß sich deutsche Jüdinnen zwischen dem ausgehenden 18. Jahrhundert und 1945 in einer eigenen hochparadoxen intellektuellen Landschaft bewegten. 
den sie an prominenten Beispielen verschiedener Epochen diskutiert. Bedeutsam sind dabei die Traditionslinien, die sie aufdeckt, die Bezugnahmen auf Jüdinnen in vermeintlich vergleichbarer Situation über Jahrhunderte hinweg etwa wenn Hannah Arendt den Wunsch äußert, „Rahels Lebensgeschichte so nachzuerzählen, wie sie selbst sie hätte erzählen können“. ${ }^{71}$

Deborah Hertz untersucht zum Teil dieselben Protagonistinnen in einem disziplinär ganz anders gelagerten, sozialhistorischen Buch. Die 2007 erschienene Studie How Jews became Germans. The History of Conversion and Assimilation in Berlin arbeitet schwerpunktmäßig mit der „Judenkartei“, dem von Nationalsozialisten erarbeiteten Verzeichnis konvertierter Juden in Berlin.72 Ausgehend von diesem Material und dem explizit benannten persönlichen Interesse an Motivforschung, stellt Hertz zahlreiche Fallstudien zwischen 1645 und $1833 \mathrm{zu}$ einer Kollektivbiografie zusammen,73 in der die Salonfrauen eine prominente Rolle einnehmen. ${ }^{74}$ Die Biografie Rahel Levin Varnhagens deutet Hertz in der Nachfolge Hannah Arendts im Wesentlichen als wiederholten Versuch, aus dem Judentum herauszukommen.75

Die abschließenden Wertungen der genannten grundlegenden Arbeiten sind trotz ähnlicher Analysen sehr divergent: Während Hannah Arendt festgehalten hatte, dass Rahel ,Jüdin und Pariah geblieben“ sei, spricht Michael A. Meyer davon, dass Rahel Levin Varnhagen nie „irgendeine Übereinstimmung mit dem Judentum empfunden" habe und ihrer Herkunft nur erkenntnistheoretisch dankbar gewesen sei: „Jude zu sein bedeutete für Rahel, am Rande der Gesellschaft zu leben, frei von ihren Heucheleien und Lügen, eben weil man

71 Arendt 2001, S.12. Hahn baut ihre Analyse auf diesem „merkwürdige[n] Konjunktiv“ auf. Hahn 2002, S. 207-209. Ebd. Eine andere von ihr beschriebene Entwicklungsgeschichte ist die Nahida Remys, die über der Studie über jüdische Frauen sich selbst zum Judentum hin bewegte und schließlich konvertierte. Ebd., S. 105-110.

72 Zur Geschichte der so genannten „Judenkartei“, einer Sammlung Notizbücher mit Aufzeichnungen zu Juden in Berlin, die zwischen 1645 und 1933 zum Protestantismus konvertiert waren, s. Hertz 2007, S.1-16.

73 Gewissermaßen wird hier die Geschichte der Juden in Berlin und Preußen in einer Reihe von Einzelfällen, wie etwa dem bekannten Duell zwischen Moritz Itzig und Achim von Arnim oder den Biografien der Kinder Mendelssohns, nacherzählt.

74 Hertz gleicht dabei sowohl in ihrer biografisch-individuellen Herangehensweise wie in ihrem erkenntnisleitenden Interesse der grundlegenden Studie Michael A. Meyers, da auch sie die Voraussetzungen und die Bedeutungen einer jüdischen Identität hinterfragt. Vgl. die Kernfragen: „Was bedeutetet es für den einzelnen, daß er Jude ist?“ Meyer 1994, S.9. und „I have written this book, because I cannot decide, whether a passionate ethnic identity is necessary for personal happiness." Hertz 2007, S. ix.

75 Bei diesem ganz individuellen Vorhaben hätten bürgerliche Rechte nicht im Vordergrund gestanden, daher sei sie auch an der politischen Gleichstellung der Juden als jüdische Bürger nicht interessiert gewesen. 
nicht wirklich dazu gehörte“. ${ }^{76}$ Deborah Hertz kommt zu dem Schluss, dass sie eine fragmentierte Identität gehabt haben müsse, ${ }^{77}$ und Barbara Hahn hingegen beschreibt Levin Varnhagen gewissermaßen als Urfassung eines Kulturtypus, in dem sich verschiedene Identitäten verbinden. ${ }^{78}$

Mit dem Verweis auf die genannten Arbeiten und die darin verhandelten Quellen, die tiefergehende Studien zur individuellen Motivforschung erlauben und fordern, sucht die vorliegende Arbeit Antworten auf die Fragen, wie die Salongesellschaft mit dem Thema der Konversion umging, welche Funktion und Bedeutung dem Schritt zugemessen wurde.

\subsection{Topos 3 - „Deutsch-jüdischer Dialog“ im Salon}

Ich bestreite, daß es ein deutsch-jüdisches Gespräch in irgendeinem echten Sinne als historisches Phänomen je gegeben hat.

Gershom Scholem ${ }^{79}$

Männer, selbst die ausgezeichnetesten wollen das die Frauen nur von Allem wie die Schmetterlinge kosten sollen, die ganze wirkliche Nahrung schöner und gesunderüchte soll für sie bleiben, wenn sie mit Weibern raisoniren, so soll das Gesagte oder Gefragte sie neu mit der eignen Tiefe und Gründlichkeit nur mehr bekant machen $u$ durch den Contrast vergewißern daher mögen sie keine philosophisch denkende Frau.

Sara Meyer Grotthus an Rahel Levin Varnhagen ${ }^{80}$

76 Arendt 2001, S. 237; Meyer 1994, S. 131 und 126. Wie schon Ludwig Geiger wählt auch Michael A Meyer aus dem Dilemma der Konversionen einerseits und der angenommenen historischen Bedeutung der Person für die jüdische Geschichte andererseits den eleganten Ausweg, die Abkehr vom Judentum mit einem aufrichtigen religiösen Suchen zu begründen, bzw. mit einer besonders starken Persönlichkeit.

77 „Rahel's deathbed utterances reveal her uneven, fragmented, brittle identity.“ Hertz 2007, S. 215. Im jüngsten Aufsatz zum Thema diskutiert Hertz verschiedene Stadien der Identitätsveränderung am Beispiel Levin Varnhagen und nennt sie zusammenfassend „still identifiably Jewish“. Hertz 2011, S. 76.

78 Barbara Hahns Buch ist unter den hier vorgestellten Arbeiten das einzige, dass den doppelten Ausschluss von Jüdinnen als Jude und als Frau explizit thematisiert. Wie in ihren vorangegangenen Arbeiten diskutiert Hahn den Salon als noch nicht verstandenes Experiment, gleichermaßen aus der Perspektive ungedruckter Quellen sowie mit deutlicher Forschungskritik am bisher in den Salon Hineininterpretierten. Auswirkungen der im Salon stattgehabten Konversionen auf die Umgebungsgesellschaft diskutiert sie nicht, weil sie dem Salon eine prominente Position in der Berliner Gesellschaft abspricht.

79 Scholem 1995 (a), S. 7. Der Text war ein offener Brief an Manfred Schlösser und erschien erstmals 1964. Hervorhebung im Original.

80 Sara Meyer Grotthus an Rahel Levin Varnhagen, 27.1. 1825, SV 78, in etwas anderer Lesart der Handschrift auch in Hahn 1990(b), S. 35. 
Letztlich ist die Betrachtung der Konversionen von der Diskussion um einen Dialog in Scholems Verständnis natürlich nicht $\mathrm{zu}$ trennen, da ein wesentliches Motiv der Taufnahme die Hoffnung auf gesellschaftliche Integration war sei es über Studien oder Berufe, die nur Christen offen standen, sei es durch die Eheschließung mit christlichen Adligen und Bürgern. In der fortgesetzten Debatte um die Bewertung der Emanzipationsepoche, ${ }^{81}$ die vielfach unter dem Stichwort „deutsch-jüdischer Dialog“82 geführt wird, scheint der Salon auf den ersten Blick ein klassisches Gegenbeispiel gegen Scholems Verdikt. Nach der Definition der Forschung war der Berliner jüdische Salon ein Treffpunkt verschiedener Konfessionen und die wesentliche Aktivität war das Gespräch. Wie Scholem allerdings in einer seltener zitierten Nachschrift selbst erläuterte, zielte sein Verdikt nicht auf die Tatsache, dass keine Gespräche und „historische Beziehungen“ zwischen einzelnen Individuen stattgefunden hätten, sondern richtete sich gegen den Mythos der Akzeptanz der Juden als Juden in einer wirklichen „geistigen Auseinandersetzung“.83 In der bis heute währenden Forschungsdiskussion kommt es dennoch immer wieder zu Missverständnissen wegen der mal faktischen und mal metaphorischen Verwendung der Begriffe Dialog und Gespräch.

Dass der vermehrte Umgang zwischen Juden und Nichtjuden schon die Zeitgenossen bewegte und auch verunsicherte, ist unter anderem an vielfältigen, allerdings noch nicht systematisch analysierten satirischen Äußerungen zum Thema abzulesen, die statt eines Dialogs eher Sprachverwirrung abbilde-

81 Was David Sorkin 1990 feststellte, dass die Geschichtsschreibung der deutsch-jüdischen Geschichte wie seit Anbeginn so bis dato auf dem Begriff Emanzipation fokussierte und Forscher sich entweder als Verteidiger der Akkulturationsleistung oder als Ankläger eines Prozesses positionieren, der den Antisemitismus vorbereitet habe, gilt im weitesten Sinne noch heute. Der deutsche Weg der Judenemanzipation, der die - schrittweise - Gewährung von Rechten von dem Erfolg der (Um-)Erziehung der Juden abhängig machte, wurde besonders nach 1945 dahin gedeutet, dass er die Selbstaufgabe der Juden impliziert habe, die zu Selbsthass, Missachtung, einem Staatsbürgertum zweiter Klasse und letztlich zum modernen Antisemitismus geführt habe. Scholems bekannte Intervention gegen die Verherrlichung einer „deutsch-jüdischen Symbiose“ 1964 hat die Forschung erneut mit der Frage konfrontiert, ob und unter welchen Voraussetzungen eine gleichberechtigte geistige Auseinandersetzung zwischen Juden und Nichtjuden überhaupt möglich war.

82 Eine Positionierung zur Haltung Scholems gehört bis heute zu den Anforderungen an Wissenschaftler, die sich mit der deutsch-jüdischen Geschichte beschäftigen. Der jüngste Forschungsbericht zum Thema konstatiert, dass die Frage, ob und in welcher Form ein verstehendes Gespräch zwischen Juden und Vertretern der nichtjüdischen Mehrheitsgesellschaft stattgefunden habe, ebenso zentral bleibt, wie sie widersprüchlich beantwortet wird. Abigail Gilman: Beyond Dialogue. New Scholarship in German-Jewish Studies, in: prooftexts. A Journal of Jewish Literary History 23, 2. (2003), S. 242-258. 83 Scholem 1995 (b), S. 12 f. 
ten, und von denen angenommen wird, dass sie Anspielungen auf die Salongesellschaft enthalten. ${ }^{84}$ In der Historiografie der deutsch-jüdischen Geschichte wurde der Berliner Salon dann oft an prominenter Stelle für eine gelungene oder vergebliche Annäherung diskutiert. Autoren, deren Fokus auf dem Verlust jüdischer Identität im „langen 19. Jahrhundert“ lag, sahen im Salon ein illustres Beispiel verfehlter Anbiederung. Eine wesentliche Rolle spielten bei dieser Beurteilung eine oft fälschlich angenommene Prominenz und Einfluss des Salons (i. e. eine stattgehabte Verständigung zwischen Juden und Nichtjuden), etwa wenn Leon Poliakov „Henriette Herz [als] die Madame Du Deffand des ganzen philosophischen und literarischen Berlin“ darstellte. ${ }^{85}$ Ebenso streitbar ist die Interpretation der Konversionsrate im Umfeld der Salons. ${ }^{86}$ Historiker, die in dem Salon eher ein Produkt der Emanzipation als ihren Agenten sahen, schätzten auch seinen Effekt als gering ein, er wurde „das gelegentliche Abenteuer von marginalem Charakter“ .87

Nach dem Holocaust konnte die Geschichte der Juden in Deutschland nicht mehr ungebrochen erzählt werden. Dennoch oder deswegen blieb der Topos Emanzipation eine zentrale Frage der Geschichtsschreibung und auch in Nachkriegsdarstellungen wurde dem Salon mit vergleichbarem Nachdruck emanzipatorisches Potential zu- und abgesprochen. Bis in die 1960er-Jahre überwog vor dem Hintergrund ihres Endes die Suche nach den Glücksmomenten deutsch-jüdischer Geschichte, ablesbar an dem dann verwendeten Begriff der „deutsch-jüdischen Symbiose“.88 Ein Forschungsbericht hat nachgewiesen, wie besonders nach 1945 der Topos von „Rahels Dachstube“, in der schranken-

84 Vgl. exemplarisch Isaak Euchel: Reb Henoch. Oder: Woß tut me dermit, 2004, Textedition von Marion Aptroot / Roland Gruschka, Hamburg 2004. Das Drama erschien erst posthum, wird aber von der Forschung auf das Jahr 1793 datiert. Satiren mit direktem Bezug auf Salons sind etwa Daniel Jenisch „Diogenes Laterne“ von 1799 [s. V] und der 1797 anonym erschienene „Mücken-Almanach“ [s. III].

85 Léon Poliakov: Geschichte des Antisemitismus, Bd. V: Die Aufklärung und ihre judenfeindliche Tendenz, Worms 1983, S. 224.

86 Dieselben Faktoren wurden auch in antisemitischer Darstellung als Argumente für die Gefährlichkeit der „Drahtzieher“ im Salon als Ort einer „großen Verschwörung“ angeführt. Fervers 1989, S. 19.

87 Katz 1986, S. 69.

88 Als Ende 1960 der Süddeutsche Rundfunk das Thema der Begegnung zwischen Juden und Christen erstmals als solches wieder aufgriff, wurde der Begriff „Symbiose“ unkritisch verwendet. Vgl. exemplarisch in der Dokumentation der Sendung: Carlo Schmid: Wir Deutschen und die Juden, in: Hans Jürgen Schultz (Hrsg.): Juden, Christen, Deutsche, Stuttgart 1961, S. 13-29. Den Begriff nutzt auch noch, allerdings nicht ohne ihm einen deutlichen Endpunkt zu setzen, Selma Stern 1971: „Das Gespräch zwischen Deutschen und Juden hat mit dem Gespräch zwischen Lessing und Mendelssohn seinen Anfang genommen [...]. Das Gespräch endete im Jahre 1933, als die Symbiose sich noch nicht ganz vollzogen 
überwindende Begegnungen möglich gewesen seien, zur Verklärung des Phänomens beitrug. ${ }^{89}$

$\mathrm{Zu}$ einem Paradigmenwechsel kam es mit den Arbeiten von Hannah Arendt und vor allem Gershom Scholem. Arendts Biografie Rahel Levin Varnhagens ist ebenso symbolisch wie von großer nachhaltiger Wirkung für die Geschichtsschreibung der jüdischen Salons im 20. Jahrhundert.90 1929 in Berlin begonnen, wurde das Buch 1957 aus dem amerikanischen Exil veröffentlicht, für den Untertitel der deutschen Ausgabe musste der Begriff „Jüdin“ erstritten werden. ${ }^{91}$ Eine wesentliche These Arendts war, dass Rahel Levin Varnhagen sich dem Leben in ihrer Position bewusst ungeschützt ausgesetzt habe, wie einem „Wetter ohne Schirm“, um das Leben selbst wie ein Kunstwerk zu gestalten. ${ }^{92}$ Die Bemühungen, aus dem Judentum herauszukommen, werden als vergeblich geschildert: Der gesellschaftlichen Außenseiterin Rahel Levin Varnhagen nahm man ihren Aufstieg übel, sie wurde vom „Pariah zum Parvenu“. Um sie als solche zu kennzeichnen, wurde nach ihrer Konversion verstärkt von der Jüdin Levin Varnhagen gesprochen. ${ }^{93}$

Wesentlich an Scholems Intervention war neben der Abwehr der Idee eines „unzerstörbaren Gesprächs“ auch seine Interpretation einer großen „Bereitschaft zur Selbstaufgabe“ auf Seiten der Juden, „die das Irreale und Gespenstische an diesem Gespräche weitgehend mitbedingt“ habe. ${ }^{94}$ Bis spätestens in die frühen 1990er-Jahre existierten der positive und der negative Interpretationsstrang nebeneinander. Die letzte intertextuelle Auseinandersetzung zum Berliner Salon als Ort der „deutsch-jüdischen Symbiose“ fand sich zwischen dem Germanisten Horst Meixner, der dem Salon sowohl im Bereich der Frauen-

hatte, aber ,eine reale Möglichkeit' gewesen war." Selma Stern: Der Preußische Staat und die Juden. Band 3: Die Zeit Friedrichs des Großen (Schriftenreihe wissenschaftlicher Abhandlungen des Leo Baeck Instituts, 24), 2. Abt., Tübingen 1971, 1. Abt, S. 421.

89 Vgl. Hahn 1997(a).

90 Zur Werkgeschichte der Biografie siehe v. a. die Neuedition durch Weissberg, Arendt 2000.

91 Der Titel war letztlich ein Kompromiss zwischen Arendt und dem Verleger Klaus Piper, der den Begriff „jüdisch“ ursprünglich vermeiden wollte. Siehe dazu die Dissertation von Christophersen 2003.

92 Dies glauben zu können nennt Arendt einen durchaus romantischen Irrtum. Arendt 2001, S. 13.

93 Hannah Arendt sieht Wilhelm von Humboldts Kommentar zur Eheschließung Rahel Levins mit Karl August Varnhagen, „es ist nichts, was die Juden nicht erreichen“, als kennzeichnend für die Einstellung der Umgebungsgesellschaft zu getauften Juden als „Parvenus par excellence“. Arendt 2001, S. 211.

94 Scholem 1995(b), S. 17. Zur Auseinandersetzung zwischen Arendt und Scholem s. Hannah Arendt: Brief an Gerhard Scholem (Juli 1963), in: dies.: Ich will verstehen, Selbstauskünfte zu Leben und Werk. Mit einer vollständigen Bibliografie. Herausgegeben von Ursula Lutz, München 2005, S. 31-38. Hannah Arendt nannte Scholem zeitlebens Gerhard. 
emanzipation wie der Judenemanzipation Potential attestierte und dem Historiografen der Juden in Preußen, Albert Bruer, der Meixners Interpretation vehement ablehnte. ${ }^{95}$

Neuere Forschungen deuten auf einen grundlegenden Perspektivenwechsel in der deutsch-jüdischen Historiografie. 1992 formulierte Trude Maurer in einem Forschungsbericht zum Thema die Forderung, nicht länger eine „Leistungsbilanz“ der Beiträge der Juden zur Kultur zu ziehen, sondern eher in Wechselbeziehungen und Akkulturation als Prozess des Kulturwandels zweier Kulturen zu denken. ${ }^{96}$ Ähnlich und ironisch äußerte sich Steven Lowenstein über die „Beitrags-Historiographie“, die ein „kollektives Unternehmen“ der Juden voraussetzte, „mit dem Ziel die deutsche Mehrheit zu beschenken“. ${ }^{97}$ Gleichzeitig wird die rein teleologische Sicht (eines notwendigen Scheiterns des Emanzipationsprozesses) zunehmend infrage gestellt, weil man damit den Juden erneut nur die Rolle der Opfer zuweise. ${ }^{98}$ Mit der Überlegung, dass

95 Meixners Formulierungen sind an Positivismus kaum zu übertreffen, so „erscheinen die um Berliner Jüdinnen zentrierten Kreise an der Wende vom 18. zum 19. Jahrhundert als Lichtblicke, in denen jenseits der bloßen Koexistenz und diesseits der Assimilation die Möglichkeit der Symbiose aufscheint“ und „Judenemanzipation und Frauenemanzipation gehen eine Verbindung ein, wie sie in dieser Art später nie mehr herstellbar war." Horst Meixner: Berliner Salons als Ort deutsch-jüdischer Symbiose, in: Walter Grab: Gegenseitige Einflüsse deutscher und jüdischer Kultur von der Epoche der Aufklärung bis zur Weimarer Republik (Jahrbuch des Instituts für Deutsche Geschichte, Beiheft 4) Tel Aviv 1982, S. 97-109, hier S. 99 f. Bruer kritisiert zurecht die Darstellung Meixners als Überhöhung, lässt sich aber bei seiner Gegendarstellung, nach der Levin Varnhagen ihre „persönliche Erlösung im Hochzeitsbett eines preußischen Aristokraten“ gesucht hätte, ebenfalls zu unnötigen Klischees verleiten. Albert Bruer: Geschichte der Juden in Preußen (1750-1820), Frankfurt/M. 1991, S. 224.

96 Maurer 1993, S. 179.

97 Steven M. Lowenstein: Der jüdische Anteil an der deutschen Kultur, in: ders. / Paul Mendes-Flohr [u. a.] (Hrsg.): Deutsch-jüdische Geschichte der Neuzeit, Band 3: Umstrittene Integration 1871-1918, München 1997, S. 302-332, hier S. 303.

98 Vergleichbar wies Schoeps darauf hin, dass es ,ungerecht [sei], denjenigen, die an Emanzipation geglaubt haben, den Vorwurf zu machen, sie seien einem Irrtum aufgesessen“. Julius H. Schoeps: Zur Geschichte des deutsch-jüdischen Verhältnisses, in: ders. 1992, S. 117-119, hier S. 119. Ein anderer Ansatz kam aus der Forschung zum deutsch-jüdischen Bürgertum, etwa mit der Programmatik Till van Rahdens, dass ein Dialog nicht zu suchen sei zwischen einer dominanten (ob konfessionell, ob national bestimmten) Mehrheitskultur und Minderheiten, sondern dass Jüdischsein eine von vielen Partikularidentitäten sei, die an der Entwicklung des „bürgerlichen Wertehimmels“ beteiligt gewesen sei. Ders.: Von der Eintracht zur Vielfalt: Juden in der Geschichte des deutschen Bürgertums, in: Andreas Gotzmann / Rainer Liedtke / Till van Rahden: Juden, Bürger, Deutsche. Zur Geschichte von Vielfalt und Differenz 1800-1933, Tübingen 2001, S.9-32, hier S. 27. Auch Simone Lässig geht von einer interaktiven Konstituierung der bürgerlichen Kultur aus, an der Juden wie andere gesellschaftliche Gruppen beteiligt waren. Lässig attestiert dem deutschen Weg der Emanzipation wieder positive Auswirkungen, da er durch Modernisierungsdruck zur erfolgreichen Verbürgerlichung der Juden beigetragen habe. Lässig 2004. 
sowohl das Modell der Symbiose wie das ihres notwendigen Scheiterns auf einem Zwei-Sphären-Modell basieren, welches die vielen Interaktionen zwischen jüdischen und deutschen Traditionen außer Acht lässt, plädiert die neuere Forschung für eine Überwindung dieser Dichotomie. Der von Julius $\mathrm{H}$. Schoeps eingeführte Begriff der „missglückten Emanzipation“ erlaubt, das positive Engagement für die Integration und das letztliche Scheitern zusammenzudenken. ${ }^{99}$

In Bezug auf die Salons lautet eine heute zunehmend verwendete Formel, Emanzipation sei hier höchstens auf individueller Ebene vollzogen oder als kurzzeitige Illusion gelebt worden, was die Attraktivität des Modells ausgemacht habe. ${ }^{100}$ An diesem Punkt wird der Unterschied besonders deutlich zwischen Arbeiten, die den Salon im Gesamtzusammenhang der deutsch-jüdischen Geschichte sehen, und denen, die ihn unter die Lupe der Salonforschung ziehen, und hier, vor allem im städte- oder länderübergreifenden Vergleich, das Positive und Möglichkeiten betonen, die dieser „eigene Raum“ Frauen, auch jüdischen Frauen, gebracht habe.

\title{
2.5 Vom Ausschluss zur Aneignung? Berührungspunkte der Forschungsdiskurse
}

\author{
Das Schiller'sche Biederweib denkt und sorgt nur für das eigene Haus, \\ die jüdische Hausfrau hat auch noch für Andere Etwas übrig. \\ Nahida Remy, 1894
}

[Rahel Levin Varnhagen] selbst vertritt als höchstausgebildeter Typus die zeitgenössischen Phasen jener beiden Culturentwickungen, die sich in den Schlagworten der geistigen Emancipation des Weibes und der gesellschaftlichen Emancipation des Judenthums zusammenfassen lassen.

Allgemeine Deutsche Biographie, 1895101

99 Wider das Zwei-Sphären-Modell s. Willy Goetschel: Mendelssohn and the State, in: Modern Language Notes 122 (2007), S. 472-492, hier S. 473. Schoeps 1996 und 2002. 100 „Während zahlreiche Philosophen und Beamte mehr Rechte für die jüdische Bevölkerung forderten, vermittelte der Salon die Illusion einer Emanzipation, die noch nicht stattgefunden hatte.“ Liliane Weissberg: Nachwort, in: Dorothea Schlegel: Florentin. Roman. Fragmente. Varianten. Hrsg. und mit einem Nachwort versehen von Liliane Weissberg, Frankfurt 1987, S. 205-238, hier S. 208. Sich an Weissberg anschließend nennt Klaus Berghahn den Salon ein „utopisches Modell eines Judentums [...], das sich durch die kulturelle Assimilation in die bürgerliche Gesellschaft emanzipierte.“ Klaus L. Berghahn: Grenzen der Toleranz. Juden und Christen im Zeitalter der Aufklärung, Köln 2000, S. 260 f. 101 Remy 1892, S. 160; Oskar F. Walzel: „Varnhagen von Ense, Rahel“ in: ADB, Bd. 39 (1895), S. 780-789, hier S. 780 f. Bemerkenswert ist hier, dass zwischen einer geistigen Emanzi- 
Wie im Master Narrative erwähnt, wurde das Phänomen einer zwiefachen Emanzipation der Frau und Jüdin durch den Salon in der Literatur mehrfach, wenn nicht bewiesen, so aber angenommen. ${ }^{102}$ Der Eintrag in der ADB zeigt beispielhaft, dass Salonfrauen dabei nicht notwendig als Symbol einer vollzogenen Emanzipation gesehen wurden, sondern als Repräsentation der ,zeitgenössischen Phasen“, in der sich die jeweiligen Emanzipationsbewegungen befanden. ${ }^{103}$ Seit den 1990er-Jahren erscheinen, vor allem von Wissenschaftlerinnen, die auf dem Gebiet deutsch-jüdischer Frauengeschichte arbeiten, Untersuchungen, die nicht die gleichzeitige Überwindung zweier Grenzen, sondern vorrangig die doppelte Ausgrenzung als Frau und Jüdin thematisieren. ${ }^{104}$

pation der Frauen und einer gesellschaftlichen der Juden unterschieden wurde. 1895 war das allgemeine Frauenwahlrecht noch über 20 Jahre entfernt, und auch bei geistiger Emanzipation kann nicht das Frauenstudium gemeint sein, das in Preußen erst 1908 legalisiert wurde.

102 So belegten manche Darstellungen von Vertreterinnen der frühen Frauenbewegung am Salon die „Kulturmission“ gerade der jüdischen Frau. Auch wenn heute fragwürdig klingt, dass die Salonfrauen „durch Eigenschaften ihrer Rasse originell“ gewesen seien, hatte schon Ludwig Geiger vergleichbar formulierend bei Rahel Levin Varnhagen eine Kombination von Vorzügen diskutiert: Sie habe das „Erbteil ihres Stammes“, den Witz und als „Erbteil ihres Geschlechts“ die Anmut in sich vereinigt. Ella Key: Rahel. Eine biographische Skizze. Einzig autorisierte Übertragung aus dem schwedischen Manuskript von Marie Franzos, Halle 1912, S. 14f; Ludwig Geiger 1988, S. 112.

103 Die anschließende Charakterisierung dieser beiden Bewegungen zeigt den Verfasser Walzel als geradezu begeistert vom Einfluss Mendelssohns auf die Bildung einer neuen „Gesellschaftsschicht“ unter den Juden sowie vom Frauenbild der Romantik, worunter er eine geistige „Ebenbürtigkeit“ der Geschlechter verstand. Er zählte Rahel Levin Varnhagen neben den beiden Schlegelfrauen zu den „Begründern der Frauenemancipation“ in diesem Sinne, „freilich hat sie mit ihren Genossinnen auch die weniger erfreuliche Gestalt des Blaustrumpfs auf dem Gewissen“. Walzel 1895, S. 781.

$104 \mathrm{Im}$ Bereich der Salonforschung haben vor allem Barbara Hahn und Liliane Weissberg mit diesem Konzept gearbeitet. Die Frau im Salon sei das „doppelt Andere: Frau und exotische Jüdin zugleich“, heißt es so bei Weissberg 1987, S. 209. Vgl. Hahn 2002. Interessant müsste der Salon daher nicht nur für Forschungen zur bürgerlichen, jüdischen und weiblichen Emanzipation sein, sondern auch für die jeweiligen Schnittstellen, Forschungen zur Entwicklung des deutsch-jüdischen Bürgertums und zum Geschlecht als Kategorie der jüdischen Geschichte. Hier sind allerdings die Kommentare zur Rolle des Salons, seiner vermeintlichen Popularität wegen, ebenso redundant wie im Einzelnen knapp, in der Art: „eine Ausnahme waren die berühmten Salons ...“. Ein wichtiger Schritt in diese Richtung war 2009 die Konferenz „Salondamen und Dienstbotinnen. Jüdisches Bürgertum aus weiblicher Sicht“ des Instituts für jüdische Geschichte Österreichs, die die Salons in die jüdische Geschlechtergeschichte rückband. Einen interessanten Ansatz, der sicher auch für Salons gilt, vertreten Stefanie Schüler-Springorum und Kirsten Heinsohn: Obwohl Männer bei der Abkehr von religiöser Tradition die Avantgarde bildeten, wurden die Ängste auf Frauen projiziert und „die Kritik an Aufklärung und religiöser Reform zu einer Kritik an den Frauen“ umgeschrieben. Kirsten Heinsohn / Stefanie Schüler-Springorum: Einleitung, in: dies. 2006, S. 7-24, hier S. $14 \mathrm{f}$. 
Methoden und Konsequenzen des Ausschlusses werden verglichen, ebenso wie die Lösungsversuche der jüdischen Frauen. Dabei wird auch die Frage nach einem möglicherweise ähnlichen Ausgrenzungsmuster, des Weiblichen und des Jüdischen als „des internen Anderen“ aufgebracht. Diese für literarische Texte entwickelte Formulierung Sigrid Weigels für diese Arbeit übernehmend, ${ }^{105}$ lautet der Arbeitsauftrag, die Brieftexte daraufhin zu befragen, welche Vorstellungen von einem jeweiligen Anderen sich aus den Korrespondenzen schließen lassen. Eine zweite Frage ist, wann und wie die Tendenz, Differenzen verschwinden zu machen, durch die gegenläufige Tendenz, Differenz zu betonen, abgelöst wurde.

Wie dargestellt wurde, findet in beiden Forschungsdiskursen, zur deutschjüdischen Geschichte und zur Geschlechtergeschichte der Aufklärung, ein Umdenkprozess statt, der sich in der Bezeichnung „Aneignung“ fassen lässt. Statt Exklusionsmechanismen zu beschreiben, geht es in jüngeren Arbeiten darum, vielleicht ungewöhnliche, alternative, aber aktive Formen der Teilhabe und Mitgestaltung (wieder) zu entdecken. ${ }^{106}$ Man kann in beiden Disziplinen von einer zunehmenden Abwendung von dichotomischer Denkweise sprechen. In dem Moment, wo die Grenzen zwischen männlicher und weiblicher bzw. jüdischer und nichtjüdischer Lebenswelt weniger absolut gedacht werden, verliert der Salon seine Ausnahmestellung als einziger grenzenüberschreitender Treffpunkt. Auch dieser Befund führt zu der Überlegung, mit einer detaillierteren Untersuchung des Berliner jüdischen Salons vor dem Hintergrund der Entwicklungen in der Berliner Gesellschaft um 1800 Aneignungs- und Ausschlussprozesse neu zu sichten. Das Zitat von Sara Meyer Grotthus macht die grundsätzliche Problematik einer abschließenden Bewertung des Dialoges und der Begegnung im Salon deutlich: insofern und so oft Grenzen im Salon überwunden wurden, so oft also Vertreter und Vertreterinnen verschiedener Stände, Schichten, Konfessionen oder Geschlechter miteinander ,raisonnierten‘, eben so oft ist auch zu fragen, inwieweit das miteinander Reden eine Verständigung bedeutete, bzw. eine Verständigung wirklich gewünscht war. In dieser Arbeit werden anhand einiger ausgewählter „Briefgespräche“ sowohl neue Details des praktischen Umgangs (als Fundament eines Dialogs) wie diskursive Formen der Annäherung über mehrere Jahrzehnte offen gelegt und exemplarisch nach der Bereitschaft gefragt, mit Frauen als denkenden Wesen, oder dem Juden als

105 Vgl. Sigrid Weigel: „Frauen“ und „Juden“ in Konstellationen der Modernisierung Vorstellungen und Verkörperungen der „internen Anderen“, in: dies. / Sabine Schilling / Inge Stephan (Hrsg.): Jüdische Kultur und Weiblichkeit in der Moderne (Literatur-KulturGeschlecht, 2), Köln [u. a.] 1994, S. 333-351.

106 Vergleichbar formuliert van Rahden: „Zur Diskussion steht hier das Moment des Aneignens, Umdeutens und Verhandelns." Rahden 2001, S. 27. 
Juden zu sprechen bzw. Juden als Juden zu akzeptieren, und damit nach der Bereitschaft, das Gegenüber nicht primär als das Andere zu begreifen.

\section{Die zeitgenössischen Debatten um Emanzipation und die Berliner Salons}

\subsection{Die Geschlechtscharakterdebatte}

Das Recht des halben Menschengeschlechts ist der höchste Gegenstand der Moral, der von allen Seiten betrachtet werden muß, um es endlich von der rechten zu werden, und dazu trägt nichts so zwekmäßig bei als die mannigfache Darstellung durch verschiedene Individuen. Esther Gad, Salonière und Publizistin, $1798^{107}$

Im Rahmen der frühneuzeitlichen „Querelle des Femmes“108 waren der Geschlechtsunterschied bzw. Charakteristik und Aufgaben von Frau und Mann immer wieder Themen für die europäische Gelehrtenrepublik. In den Jahren von 1770 bis $1810^{109} \mathrm{kam}$ es im deutschsprachigen Raum dann noch mal zu

107 [Esther Gad]: „Einige Aeußerungen über Herrn Kampe’ns Behauptungen die weibliche Gelehrsamkeit betreffend“, in: Der Kosmopolit. Eine Monatsschrift zur Beförderung wahrer und allgemeiner Humanität, hrsg. von Ch. D. Voß, Bd. 3, Halle 1798, S. 557-590, hier S. 577. 108 Die „Querelle des Femmes“ als gesamteuropäisches Phänomen bezeichnet einen die Frühe Neuzeit durchziehenden umfassenden Streit zwischen den Geschlechtern und über die Rollen der Geschlechter. Als Austragungsorte dieser Debatte gelten die verschiedensten Medien, vor allem dialogische und polemische Texte, aber auch Akademiewettbewerbe, satirische und ikonografische Bilder. Der Begriff knüpft an zeitgenössische Terminologie an, ist aber als Fachterminus ein Begriff der Forschung. Grundlegend dazu Gisela Bock und Margarete Zimmermann: Die Querelle des Femmes in Europa. Eine begriffs- und forschungsgeschichtliche Einführung, in: Gisela Bock (Hrsg.): Die europäische Querelle des Femmes. Geschlechterdebatten seit dem 15. Jahrhundert (Querelles 2), Stuttgart 1997, S.938. Zuletzt zur Querelle im internationalen Vergleich: Friederike Hassauer (Hrsg.): Heißer Streit und kalte Ordnung. Epochen der Querelle des femmes zwischen Mittelalter und Gegenwart, Göttingen 2008. Hier auch ein aktueller Forschungsüberblick, S. 12 ff. Grundlegend und interessant für die Überkreuzung von Geschlechterdebatte und (englischem) Salon: Ina Schabert: Englische Literaturgeschichte. Eine neue Darstellung aus der Sicht der Geschlechterforschung, Stuttgart 1997.

109 Die zeitliche Begrenzung der Debatte ist in Abhängigkeit vom Interpretationsansatz der Analysierenden leicht variabel. Für die deutsche Debatte sind die Interpreten sich weitgehend darin einig, dass auf eine Phase der intensiven und kontroversen Auseinandersetzung um 1800 eine der Verwissenschaftlichung bzw. der Stabilisierung der konservativen Modelle bis 1850 tritt. Volker Hoffmann sieht die intensive Debatte von 17701805 andauern, worauf eine Phase der Integration der Entwürfe in größere Modelle und Populärliteratur folgte. Volker Hoffmann: Elisa und Robert oder das Weib und der Mann, wie 
einer diskursiven Verdichtung, einer auffälligen Zunahme der Veröffentlichungen sowie der Bezugnahmen der Autoren und Autorinnen aufeinander, sodass von einer spezifischen „Geschlechtscharakteristik der Goethezeit“ oder von der „Geschlechtscharakterdebatte“ gesprochen wird. ${ }^{110}$ Der Begriff Geschlechtscharakter ${ }^{111}$ bezeichnet dabei ein in dieser Zeit entwickeltes Denkmodell, nach dem das biologische Geschlecht einer Person Auswirkungen auf ihre moralische Konstitution und damit Konsequenzen für ihre Rolle in der Gesellschaft habe. In der prägnanten Formulierung eines der Debatteure: „Ist nicht das Weib kleiner, zarter, schwächer geformt? [...] Stärke ist nicht die Gabe der Weiber. Sie können daher nicht beschützen, folglich sind sie nicht zum Herrschen gemacht" .112

Die disziplinäre Spannbreite sowie die thematische Vielfalt der Debatte ${ }^{113}$ äußerten sich unter anderem in anatomisch-physiologischen Untersuchungen

sie sein sollten. Anmerkungen zur Geschlechtercharakteristik der Goethezeit, in: Karl Richter / Jörg Schönert (Hrsg.): Klassik und Moderne. Die Weimarer Klassik als historisches Ereignis und Herausforderung im kulturgeschichtlichen Prozeß. Walter Müller-Seidel zum 65. Geburtstag, Stuttgart 1983, S. 80-97, hier S. 83. Claudia Honegger betrachtet die Jahre 1785-1850 als Zeit für verschiedene „Aufschwünge zu einer endgültigen Ontologie der Geschlechtlichkeit“, wobei die Debatte aber im „späten 18. Jahrhundert noch einigermaßen unentschieden und gleichsam auf scholastischem Niveau hin- und herzutorkeln scheint“. Claudia Honegger: Die Ordnung der Geschlechter. Die Wissenschaften vom Menschen und das Weib 1750-1850. Campus, Frankfurt/M. 1991, S. 6 und S. 4.

110 Für den Begriff und eine klassisch gewordene Analyse der „Geschlechtscharakteristik der Goethezeit“ siehe Hoffmann 1983. In der Forschung ist uneindeutig, ob die Geschlechterdebatte um 1800 als Endpunkt der „Querelles des Femmes“ oder als neues Aufflammen eines alten Themas unter neuem Gesichtspunkt zu betrachten sind. Bock / Zimmermann 1997, S. 20 ff.

111 Zur Analyse und Geschichte des Begriffs s. den zum Klassiker gewordenen Aufsatz Hausen 1976.

112 [Ernst Brandes]: Über die Weiber, Leipzig 1787. S. 39 f. Man kann sagen, um 1800 entwickelte sich eine „positive Legende der bloßen Naturauslegung“, die bis heute Wirkung zeigt. Honegger 1991, S. ix. Wie die von „Meisterdenkern“ vorformulierten Modelle unter das Publikum gebracht wurden, zeigt exemplarisch Pia Schmid: „0, wie süß lohnt das Muttergefüh!!“ Die Bestimmung zur Mutter in Almanachen für das weibliche Publikum, in: Claudia Opitz / Ulrike Weckel / Elke Kleinau: Tugend, Vernunft und Gefühl. Geschlechterdiskurse der Aufklärung und weibliche Lebenswelten, Münster [u. a.] 2000, S. 107-125. 113 Hoffmanns Phaseneinteilung wurde zurecht als selektiv und zu literarisch orientiert kritisiert, allerdings wurden die von inm erwähnten Ambivalenzen des literarischen Diskurses auch oft überlesen. Für eine alternative Darstellung mit dezidiert politischer Wertung und Einbeziehung internationaler Texte s. das Nachwort von Sigrid Lange in: dies. ( $\mathrm{Hg}$ ): Ob die Weiber Menschen sind? Geschlechterdebatten um 1800, Leipzig 1992, S. 411-431. Honegger 1991 bietet eine Paralleldarstellung literarisch-politischer und anthropologischer Entwicklungen und unterfüttert so die Genese einer weiblichen Sonderanthropologie auch 
zur Gehirngröße oder dem Einfluss des Uterus, ${ }^{114}$ kulturhistorischen Überlegungen zur Rolle der Frau in Gesellschaft und Geselligkeit, zahlreichen Traktaten zu den richtigen Prämissen der Erziehung und - wenigen - Plädoyers für die Ausweitung von Bürgerrechten auf Frauen. ${ }^{115}$ Die Zentrierung auf ,Frauenfragen' ist historisch vorgegeben, denn obwohl Charakteristika und Rollen beider Geschlechter zur Debatte standen, fokussierte die überwiegende Mehrheit der Texte auf die Festlegung der Frauen. Gleichermaßen überwogen im literarischen Diskurs die Präsentationen des Weiblichen. ${ }^{116}$

\section{Etappen der Debatte}

Gerade im Hinblick auf die sich entfaltende Wirkungsmacht des polaren Geschlechterbildes im 19. Jahrhundert sind für den Ablauf der Debatte die eher progressiven Texte aus der Anfangszeit der 1770er-Jahre interessant, in denen überkommene Ehevorstellungen und biblische Texte in kritisches Licht gerückt wurden. ${ }^{117}$ Nach 1787 kam es dann, ausgelöst von der Veröffentlichung des

mit medizinischen Entwicklungen. Eine umfassende Darstellung, die auch weibliche Beiträger berücksichtigt, bei Juliane Jacobi: „Geschlecht“, in: Dietrich Brenner / Jürgen Oelkers (Hrsg.): Historisches Wörterbuch der Pädagogik, Weinheim [u. a.] 2004, S. 422-442. Immer noch sehr lesenswert als Analyse der hinter den Idealen liegenden Ausschlussstrategien: Silvia Bovenschen: Die imaginierte Weiblichkeit. Exemplarische Untersuchungen zu kulturgeschichtlichen und literarischen Repräsentationsformen des Weiblichen, Frankfurt/M. 1979.

114 Für einen Einstieg in den in seiner Wirkmächtigkeit nicht zu unterschätzenden Diskurs über den weiblichen Körper siehe Évelyne Berriot-Salvadore: Der medizinische und andere wissenschaftliche Diskurse, in: Duby / Perrot 1997, Bd. 3, S. 367-413.

115 Wenn die jüngste Forschung diese kontroverse, multidisziplinäre Auseinandersetzung über die Rolle/n der beiden Geschlechter auf die paradoxe Formel vom „heißen Streit und kalter Ordnung“ bringt, heißt das, nicht nur gerieten hier scheinbar entfernte Disziplinen miteinander ins Gespräch, sondern hinter scheinbar klaren Argumenten ging es immer auch um dahinterliegende Machtverhältnisse. Vgl. Hassauer 2008.

116 Die Unterscheidung zwischen literarischen und pragmatischen Texten ist bei den Beiträgen der Debatte oft nicht möglich, da sich vielmehr oft in einem Text die Gattungen mischen und auch die enthaltenen Geschlechterentwürfe nicht selten in sich widersprüchlich sind.

117 In einer von Hoffmann so benannten ersten Phase diskutierten Anfang der 1770er-Jahre die ostpreußischen Literaten August Wilhelm Hupel, Theodor Gottlieb von Hippel, Johann Georg Hamann und Johann Gottfried Herder die aus der Antike überlieferten Geschlechtertheorien ebenso wie zeitgenössische Gesetze neu, sachlich kritisch oder ironisierend. Exemplarisch war das Unterfangen von August Wilhelm Hupel: Vom Zwecke der Ehen. Ein Versuch, die Heurath der Castraten und die Trennung unglücklicher Ehen zu verteidigen, Riga 1771. In Faksimile wiedergegeben, mit einer Biografie des Autors und rechtsgeschichtlichen Erläuterungen versehen von Clausdieter Schott, Frankfurt/M. 1985. 
Traktats Über die Weiber ${ }^{118}$ des Juristen Ernst Brandes zu einem ersten diskursiven Höhepunkt. ${ }^{119}$ Motiviert unter anderem durch die Verhältnisse in Frankreich polemisierte der Autor darin gegen die falsche Position der Frauen in der gegenwärtigen Gesellschaft. ${ }^{120}$ Deutlich war Brandes' Geschlechtertrennung als Warnung und Wunschdenken formuliert, nicht als Beschreibung eines IstZustandes: So müsse der Mann sich gelegentlich mit Wissenschaft beschäftigen - „Das Weib darf das nicht“..121

Eine dezidierte Gegenschrift $\mathrm{zu}$ Brandes verfasste der Militärschriftsteller Jakob Mauvillon, wobei er sich vor allem gegen die ebenfalls von Brandes vorgetragene These verwehrte, dass dem schwächeren Körperbau schwächere Nerven und Fähigkeiten abzuleiten seien. ${ }^{122}$ In einer Art Präventivtheorie riet er allerdings den gleich befähigten Frauen, sich dennoch zu untergeben, um einen „Streit wegen der Oberherrschaft“ zu verhindern. ${ }^{123}$ In gewisser Hinsicht war er darin Joachim Heinrich Campe vergleichbar, der im Vätherlichen Rath an meine Tochter 1788 die Ungleichheit zwischen den Geschlechtern genau benannte, um anschließend die freiwillige Unterwerfung der Tochter zu fordern, da ihr Geschlecht „nach unserer jetzigen Weltverfassung, in einem abhängigen und auf geistige sowohl als körperliche Schwäche abzielenden Zustande lebt““ ${ }^{124}$ Mit einer Veränderung dieser Weltverfassung hatte der Pädagoge anscheinend auch in den postrevolutionären Folgeauflagen nicht gerechnet, stattdessen ermun-

118 Brandes 1787. Eine Neubearbeitung erschien 1802 unter dem Titel: „Betrachtungen über das weibliche Geschlecht und dessen Ausbildung in dem geselligen Leben“.

119 Manche Interpreten deuten das Buch auch als eigentlichen Beginn der „modernen deutschen Geschlechterfrage“. Honegger 1991, S.47. Unabhängig davon, ob man die Geschlechtscharakterdebatte mit Volker Hoffmann chronologisch in Phasen einteilt oder sie nach thematischen Entwicklungssträngen strukturiert, werden die 1790er-Jahre als ihr Kulminationspunkt betrachtet.

120 Obwohl Brandes mit Sanftmut und Ergebenheit als der vernachlässigten „Eigenheit des Geschlechts“ argumentierte, leitete er sie, anders als Humboldt später, noch nicht wissenschaftlich her, sondern nahm sie als traditionelle, tradierte Setzung.

121 Brandes 1787, S. 184. Seine Thesen wurden in den Folgejahren weiterentwickelt vom Popularphilosophen Meiners und vom Erfahrungsseelenkundler Pockels. Christoph Meiners: Geschichte des weiblichen Geschlechtes, 4 Bde., Hannover 1788-1800; Carl Friedrich Pockels: Versuch einer Charakteristik des weiblichen Geschlechtes. Ein Sittengemälde des Menschen, des Zeitalters und des geselligen Lebens, 5 Bde., Hannover 1799-1802. 122 [Jakob Mauvillon]: Mann und Weib nach ihren gegenseitigen Verhältnissen geschildert, Leipzig 1791.

123 Mauvillon 1791, S. 25 f. Letztendlich appellierte Mauvillon an die Ritterlichkeit der Männer, die zweifelhafte Lage der Frauen diesen leichter zu machen, für eine Aufhebung des Zustandes plädiert er nicht.

124 Joachim Heinrich Campe: Väterlicher Rath für meine Tochter. Ein Gegenstück zum Theophron. Der erwachsenen weiblichen Jugend gewidmet, Braunschweig 1791, S. 19. 
terte er die Frau mit dem prägnanten Bild „er die Eiche, sie der Epheu“: „Geduld erträgt, was nicht zu ändern ist; Sanftmuth entwaffnet den männlichen Starrsinn durch milde Freundlichkeit [...] und Gewöhnung an Selbstverläugnung giebt zu allem die erforderliche Seelenkraft““.125

Als Vertreter eines wirklichen progressiven Entwurfs kann hingegen Theodor Gottlieb von Hippel gelten, der mit seiner Schrift Über die Bürgerliche Verbesserung der Weiber 1792 ein leidenschaftliches Plädoyer für die Staatsbürgerrechte für Frauen veröffentlichte, in der er zur „Zerstörung der galanten Bastillen, der häuslichen Zwinger und bürgerlichen Verließe“ aufrief und damit die Verbindung zwischen politischer und häuslicher Neuordnung eindeutig benannte. ${ }^{126}$ Auch wenn er einzelne Geschlechterstereotype in seine Argumentation einflocht, ${ }^{127}$ sah Hippel den wesentlichen Unterschied der Geschlechter in der bisher stattgehabten unterschiedlichen Erziehung, nicht in der Verschiedenheit des Wesens: „Man räume ihnen Kanzeln und Lehrstühle ein, und es wird sich zeigen, ob sie [...] nicht ebenso gut unsere Überzeugung zu gewinnen wissen“.128 In Frankreich hatte kurz zuvor und ähnlich pointiert Olympe de Gouges angemerkt, dass Frauen, die das Recht haben, das Schafott zu besteigen, auch das Rednerpult besteigen dürfen müssten. ${ }^{129}$ Dass de Gou-

125 Campe 1791, S. 21 u. 188. Mit Recht stellt Claudia Honegger fest: „Die lärmende Rhetorik, die Campe einsetzen musste, um seine Tochter von der Erhabenheit ihrer weiblichen Bestimmung in Kenntnis zu setzen, zeigt, dass es in dieser Zeit noch keineswegs ausgemacht war, ob die ,politische Unzufriedenheit' vieler Weiber ins deutsche Hausfrauentum einmünden würde." Honegger 1991, S. 68. Campe wird, vermutlich der Gattung Hausväterliteratur wegen nicht immer zur Geschlechterdebatte gerechnet, ist aber in seiner Wirkungsmacht nicht zu unterschätzen. Darin ist er Knigge vergleichbar, der es in seinem vielgelesenen „Ratgeber“ „salontauglich“ machte, weiblicher Gelehrsamkeit mit sprichwörtlich gewordenem „Fieberfrost“ zu begegnen. Adolph Freiherr von Knigge: Über den Umgang mit Menschen, hrsg. von Gert Ueding. Mit Illustrationen von Chodowiecki und anderen, Frankfurt 1977, S. 201.

126 Hippel 1977, S.17f. Explizit forderte er die Französische Nationalversammlung auf, die Bürgerrechte auf Frauen auszudehnen, argumentierte sowohl mit dem Einsatz der Pariserinnen für die Revolution wie mit der Aufgabe der Frauen als Erzieherinnen künftiger Bürger, für die sie vorbereitet und ausgebildet sein müssten. Ebd., S. 121.

127 Beispielsweise argumentierte er mit einer größeren Emotionalität der Frauen. Interessant ist bei Hippel die Entwicklung der frauenpolitischen Argumente zwischen seiner 1775 erschienen Schrift „Über die Ehe“ und dem Traktat von 1792.

128 Hippel 1977, S. 151.

129 Olympe de Gouges (1748-1793), französische Revolutionärin und Autorin. De Gouges hatte in ihrer „Erklärung der Rechte der Frau und Bürgerin“ u. a. gefordert: „Keine/r darf verfolgt werden wegen ihrer / seiner Meinung, wie grundsätzlich auch immer; die Frau hat das Recht das Schafott zu besteigen, sie hat gleichermaßen das Recht, die Tribüne zu besteigen [...].“ in: Olympe de Gouges: Mensch und Bürgerin. „Die Rechte der Frau“ 1791, herausgegeben, eingeleitet und kommentiert von Hannelore Schröder, Aachen 1995, S.111. 
ges 1793 selbst hingerichtet wurde, war keine Ironie der Geschichte, sondern ein sichtbares Zeichen dafür, dass politische Einmischung von und für Frauen nicht erwünscht war.

Zeitgenössische Gegner Hippels zogen eine Parallele eher zur britischen Autorin Mary Wollstonecraft ${ }^{130}$ und lehnten beide als schädlich[!] ab. Wollstonecraft hatte 1790 zunächst eine Verteidigung der Französischen Revolution und der Menschenrechte veröffentlicht, der sie 1792 eine Vindication of the Rights of Woman folgen ließ, die im Wesentlichen auf verbesserte Erziehung der Frau als vernunftbegabtem Wesen abzielte. ${ }^{131}$ Die Abwehrrhetorik der konservativen Theoretiker ist bezeichnend, weil diese sich sowohl im Falle Hippel wie Wollstonecraft weniger auf die Begründung, das Argument der gleichen Fähigkeiten und staatsbürgerliche Aufgaben beider Geschlechter, als auf die Konsequenz ihrer Forderungen, eine gefürchtete gesellschaftliche Unruhe, bezogen und die Autorität der Fordernden durch Hinweise auf deren Biografien zu untergraben suchten. ${ }^{132}$

1794/1795 bekam die Debatte erneut eine andere Stoßrichtung durch die Veröffentlichung zweier ganz unterschiedlicher Werke, die jedes für sich die Polarität der Geschlechtscharaktere propagierten und zahlreiche Folgeschriften auslösten. Wilhelmine Karoline von Wobeser veröffentlichte den Erfolgsroman Elisa oder das Weib wie es sein sollte, ein ironiefreies Hohelied auf die Entsa-

130 Mary Wollstonecraft (1759-1797), politische Autorin. Wollstonecrafts Forderungen nach verbesserter Mädchenerziehung und der Revision Rousseauscher Maximen führten auch deswegen zu anhaltenden Debatten, weil sie vor dem Hintergrund des Lebenswandels der Autorin gelesen wurden, die 1794 in das revolutionäre Paris zog. Ebenso wie diese „Grenzüberschreitung“ oder unverheiratetes Zusammenleben trug ihre journalistische Arbeit in als „männlich“ definierten Genres, wie der bezahlten Rezension und dem politischem Tagesjournalismus, dazu bei, dass ihr von Zeitgenossen zahlreiche diffamierende Schimpfnamen angehängt wurden, unter denen Horace Walpoles „Hyäne in Petticoats“ der bekannteste war und später in der feministischen Rezeption entsprechend gewürdigt wurde. 131 Nichtsdestotrotz war Wollstonecrafts Buch 1792 in Deutschland vom Pädagogen Salzmann beworben worden und erschien 1793 in dessen Übersetzung im Verlag der Erziehungsanstalt, wenn auch mit dezent relativierendem Vorwort. Mary Wollstonecraft: Rettung der Rechte des Weibes. Übersetzt von Christian Gotthilf Salzmann, Schnepfenthal 1793/1794. S. a. III.

132 Zur Rezeption beider s. Ulrike Weckel: Gleichheit auf dem Prüfstand. Zur zeitgenössischen Rezeption der Streitschriften von Theodor Gottlieb von Hippel und Mary Wollstonecraft in Deutschland, in: Opitz / Kleinau / Weckel 2000, S. 209-247. Auch die einflussreichste Kulturzeitschrift der Zeit verglich Hippels Text den „Herzenserleichterungen der Maria Wolstoncraft“ und spekulierte „mit mühsam kaschierter klammheimlicher Schadenfreude“, ob nicht die beiden Autoren auch Angst vor der Guillotine haben müssten. Journal des Luxus und der Moden 8, Dezember 1793, S.615. Die Wertung nach: Weckel 2000(b), S. $210 \mathrm{f}$. 
gung, dessen Protagonistin an das weibliche Geschlecht appellierte: „Warum sollten Sie nicht das in Ihrer Sphäre werden, was der Mann in der seinigen ist?";133 Wilhelm von Humboldt schrieb für Schillers Journal Die Horen die Beiträge Über den Geschlechtsunterschied und seinen Einfluss auf die organische Natur sowie Über die männliche und weibliche Form. ${ }^{134}$ Während Hippel noch unter Verweis auf anatomische Untersuchungen festgehalten hatte: „Der Geschlechtsunterschied kann nicht zur Antwort dienen, wenn die Frage ist: ob das männliche Geschlecht mit wesentlichen körperlichen und geistigen Vorzügen vor dem weiblichen ausgestattet worden sei?“,135 trat Humboldt an, genau diesen Zusammenhang $\mathrm{zu}$,beweisen“ und explizit den Unterschied der Geschlechter aus der Natur und einer Dialektik der Zeugung wissenschaftlich herzuleiten [s. III.4]. Bedeutsam ist an Humboldts Ansatz, dass er über die traditionelle Dichotomie der Geschlechter hinausging, sie als gegensätzlich, aber aufeinander bezogen betrachtete (Polarität) und ihnen eine prinzipielle Gleichwertigkeit zugestand. ${ }^{136}$

Wie man hingegen aus dem Geschlechtergegensatz eine rechtliche Unterordnung der Frau herleiten konnte, zeigte im Folgejahr Johann Gottlieb Fichte, der im Grundriß des Familienrechts ebenfalls die Fortpflanzung als Grundprinzip der Natur betrachtete, zu deren Gewährung er jedem Geschlecht einen Naturtrieb zuerkannte, dem Manne den allgemeinen Geschlechtstrieb, der Frau die Liebe und daraus folgernd die „Unterwerfung“: „Die Ruhe des Weibes hängt davon ab, daß sie ihrem Gatten ganz unterworfen sei, und keinen andern

133 Wilhelmine K. von Wobeser: Elisa oder das Weib wie es sein sollte [1794] / Christian August Fischer: Über den Umgang der Weiber mit Männern [1800]. Mit einem Nachwort von Lydia Schieth, Hildesheim [u. a.] 1990 (Frühe Frauenliteratur in Deutschland, hrsg. von Anita Runge, 8), Hildesheim [u. a.] 1990, S. VII und VIII. Hervorhebung im Original. Die Auffassung Volker Hoffmanns, dass Wobeser einem anderen Strang der Debatte zuzuordnen sei als Humboldt, kann ich nur stilistisch, nicht inhaltlich teilen.

134 Wilhelm von Humboldt: Über den Geschlechtsunterschied und dessen Einfluss auf die organische Natur, in: Albert Leitzmann (Hrsg.): Wilhelm von Humboldts Werke. Erster Band. 1785-1795 (Wilhelm von Humboldts Gesammelte Schriften Bd. I), Berlin 1903, S. 311-334, und ders.: Über die männliche und weibliche Form, in: ebd., S. 335-369. Hoffmann sieht mit diesen Werken die vierte und entscheidende Phase der Geschlechtscharakterdebatte eingeläutet.

135 Denn: „Die Natur scheint bei Bildung der beiden Menschengeschlechter nicht beabsichtiget zu haben, weder einen merklichen Unterschied unter ihnen festzustellen, noch eins auf Kosten des anderen zu begünstigen.“ Hippel 1977, S. 26. Hervorhebung H. L. L. 136 Während „Dichotomie“ den Gegensatz bezeichnet, nimmt „Polarität“ auf den Umstand Bezug, dass hier einzelne Eigenschaften der Geschlechter, konträr gesetzt, einander als Ergänzung dienen sollen. 
Willen habe, als den seinigen“. ${ }^{137}$ Humboldt und Fichte waren dabei nur zwei besonders prägnante Vertreter eines weit verbreiteten Dreischritts der Geschlechterhierarchie, durch den eine Physik der Gleichheit (1. die Geschlechter sind von Natur verschieden, aber gleichwertig), über einen „sophistischen Salto mortale zur Metaphysik der sozialen Ungleichheit“ wird, denn da 2. das männliche Geschlecht stark und das weibliche schwach ist, brauchen 3. die Weiber Schutz und Anleitung der Männer. ${ }^{138}$

Im Gegensatz dazu stand Friedrich Schlegels Begriffspaar von „sanfter Männlichkeit“ und „selbständiger Weiblichkeit“, das er erstmals 1795 in die Debatte warf. ${ }^{139}$ Unter anderen durch Schlegels Replik herausgefordert, untermalte Friedrich von Schiller das polare Geschlechtermodell seines Freundes Humboldt mit Versen wie „Ehret die Frauen, sie flechten und weben / Himmlische Rosen ins irdische Leben“. Dabei verteilte er Humboldts polare Geschlechtscharaktere auf deutlich getrennte Lebenswelten. ${ }^{140}$ Als Gegenentwurf $\mathrm{zu}$ Schillers Gedichten wiederum muss nicht nur August Wilhelm Schlegels direkte Parodie „Ehret die Frauen, sie stricken die Strümpfe“ gelesen werden, ${ }^{141}$ sondern auch, und in seiner Radikalität bis heute bedeutender, Friedrich Schleiermachers Katechismus der Vernunft (1798), ${ }^{142}$ der liturgische Texte feminisierte und Frauen explizit dazu aufforderte, sich bisher männlich dominierte Reservate zu erobern, zum Beispiel im „10. [Gebot]: Laß Dich gelüsten nach der Männer Bildung, Kunst, Weisheit und Ehre“..143

137 Johann Gottlieb Fichte: Grundriss des Familienrechts (als erster Anhang des Naturrechts), in: ders.: Werke 1797-1798 (FGA I,4), Stuttgart 1970, S.95-149, hier S. 99 und 103. 138 Lange 1992, S. $421 \mathrm{f}$.

139 Dies Begriffspaar erschien zuerst in Schlegels Aufsatz „Über die Diotima“, in: Berlinische Monatsschrift 26 (1795), und wurde später wieder verwendet in „Über die Philosophie“, in: Athenäum Bd.2/1 (1799). Dazu gehören auch die Rollentauschmotive in der Lucinde. Zur Rezeption Schlegels s. V.

140 Er sprach den Männern die Welt zu: „Ewig aus der Wahrheit Schranken / Schweift des Mannes Wilde Kraft“ und den Frauen das Haus: „In der Mutter bescheidener Hütte / Sind sie geblieben mit schamhafter Sitte“. Friedrich von Schiller: Ehret die Frauen [1795], Vers 7/8 und 18/19, in: ders.: Sämtliche Werke in 5 Bänden, Bd. 1: Gedichte Dramen I, hrsg. von Albert Meier, München [u. a.] 2004, S. $218 \mathrm{f}$.

141 August Wilhelm Schlegel: Ehret die Frauen [1796], in: ders.: Sämmtliche Werke, 10 Bde., hrsg. von Eduard Böcking, Leipzig 1846-47, Band 2, S. 171-173. Weniger bekannt ist die ebenfalls in der Parodie formulierte Warnung: „Der moralische Phantast / Macht uns Männer den Frauen verhaßt.“ Ebd.

142 Die „Ideen zu einem Katechismus der Vernunft für edle Frauen“, erschienen 1798 zunächst im Athenäum.

143 Friedrich Daniel Ernst Schleiermacher: Ideen zu einem Katechismus der Vernunft für edle Frauen, in: Lange 1992, S. 359-361, hier S. 360. 
1799 brachte schließlich Friedrich Schlegel den Roman Lucinde auf den Markt, der lange als Gegenentwurf zur Geschlechterpolarität betrachtet wurde, da die beiden Hauptfiguren der Erzählung den Rollentausch, zumindest in der sinnlichen Liebe, einfordern [vgl. IV]. ${ }^{144}$

Trotz dieser kontroversen Diskussion erwies sich das polare Geschlechterbild letztlich als das Erfolgsmodell, zumindest in der Rezeptionsgeschichte. Nach der Jahrhundertwende und vor allem mit einsetzendem Biedermeier kam es zunehmend zur Integration der Geschlechterpolarität in die theoretischen Systembildungen sowie $\mathrm{zu}$ ihrer Umformung in Rollenklischees in der Lyrik und Belletristik und sogar in der Musik. ${ }^{145}$ Es lässt sich, unter anderem anhand von Lexikoneinträgen, nachzeichnen, dass die um 1800 erstmals eingebrachten geschlechterpolaren Formulierungen im 19. Jahrhundert bald zur Allgemeinbildung wurden. ${ }^{146}$

\subsection{Zur Kritik und Erweiterung der Debatte - Texte von Autorinnen}

Kennzeichnend für alle Modelle, auch und besonders die dichotomische Geschlechtercharakteristik, war um 1800 die in sich widersprüchliche Argu-

144 Der Titel der Originalausgabe lautete: Lucinde. Ein Roman von Friedrich Schlegel. Erster Theil, Berlin 1799.

145 Als Beispiel für die Integration in eine Weltanschauung wird meist Hegel angeführt, der u. a. in den „Grundlinien der Philosophie des Rechts“ der Geschlechterdifferenz einen „systemimmanenten Platz“ angewiesen habe. Hoffmann 1983, S.95, Fn. 42. Die Zuschreibung von „männlich“ und „weiblich“ auf Musikstücke, unter Bezugnahme auf u. a. Humboldts Vokabular, analysiert erstmals Matthew Head: „Like Beauty Spots on the Face of a Man“. Gender in $18^{\text {th }}$-Century North-German Discourse on Genre, The Journal of Musicology, Vol. 13, No. 2 (Spring 1995), S.143-167.

146 Besonders deutlich wird die Durchsetzungskraft des Humboldtschen Modells im mehrseitigen Artikel von Dr. Karl Hermann Scheidler: „Geschlechtscharakter“, in: Allgemeine Encyclopädie der Wissenschaften und Künste, Erste Section A-G, 63. Theil:

Geschlechtsapparat-Gesen, Leipzig 1856, S. 29-44. Der Hinweis, dass sich die Geschlechter nur „durch die Behauptung ihrer Besonderheit und zugleich durch ihre gegenseitige Verbindung und Ergänzung“ verwirklichen können, findet sich bei Carl Theodor Welcker: „Geschlechterverhältnisse“, in: Karl von Rotteck / ders. (Hrsg.): Staatslexicon oder Encyclopädcie der Staatswissenschaften Bd. 6, Altona 1838, S. 642, zit. nach: Hausen 1976, S. 377. Romantisch fasste es zur selben Zeit ein Lexikon für Damen: „Die Allmacht hat, um das Ideal der Meschheit zu erzielen, die Idealität in beiden Geschlechtern ausgeprägt; nur die Vereinigung beider, ihrer gleich großen, wenn auch verschiedenen Anlagen und Fähigkeiten, [...] bilden das Meisterwerk der Schöpfung.“ Artikel „Frau“, in: DamenConversations-Lexikon, hrsg. im Verein mit Gelehrten und Schriftstellerinnen von Carl Herloßsohn [1834-1836]. Neu vorgestellt und mit einer Nachrede versehen von Peter Kaeding, Berlin 1989, S. 87-91, hier S. 87 u. 91. 
mentation. Überwiegend wurde dem Mann ein kraftvolles, aber gespaltenes Wesen zugesprochen, dem die Frau als passives Natur- bzw. Einheitswesen gegenüberstand. Andererseits flossen in diese „Einheit“ Frau viele verschiedene Weiblichkeitsimaginationen ein, Naturwesen und Verführerin, Mutter ebenso wie Jungfrau. Wie Volker Hoffmann nachweist, wurden der Frau in verschiedenen Polaritätsmodellen einzelne Talente „wie Verstand oder Fantasie bald ab-, bald zugesprochen, im letzteren Fall dann gern mit einer zusätzlichen Spezifizierung (z. B. schöner, nicht tiefer Verstand)“ ${ }^{.147}$ Dass es sich hier um Anthropologie in pragmatischer Absicht gehandelt hat, verbirgt sich kaum.

Ein Erfolgsmodell war die Geschlechterpolarität gewissermaßen auch in der Forschung, insofern eine gewisse Kanonisierung der so genannten grundlegenden Texte der Geschlechtscharakterdebatte festzustellen ist. ${ }^{148}$ Unter Berufung auf einen Deutschen „Sonderweg“ der Geschlechterdebatte, die Ausbildung einer weiblichen Sonderanthropologie, wurden ausländische Texte lange wenig berücksichtigt. ${ }^{149}$ Auch wird Schlegels Lucinde oft noch pauschal als androgynes Modell betrachtet und die feministische Kritik an Schlegels Frauenbild nicht immer berücksichtigt. Andere zeitgenössische Kritik an Humboldt, die beispielsweise von Friedrich Nicolai oder Immanuel Kant geübt wurde, wurde kaum behandelt, sodass der - historisch nicht ganz korrekte - Eindruck entstand, dass erst die Romantiker Gegenentwürfe zu Humboldt formuliert hätten. Ein im Zusammenhang mit dieser Arbeit wesentliches und noch überraschend wenig beleuchtetes Forschungsfeld ist der Anteil weiblicher Stimmen an der Debatte. 150 Von einem scheinbar naiven, aber umso berechtigteren Standpunkt aus wäre zu fragen, warum Schlegels Lucinde als Kerntext der

147 Hoffmann 1983, S. 85.

148 Wilhelm von Humboldts „Horen-Aufsätze“ beispielsweise gelten als Wendepunkt der Debatte, sein „Plan einer vergleichenden Anthropologie“ aus derselben Zeit, der das Frauenbild in größerem Zusammenhang betrachtet, wird selten gelesen oder zitiert. Wilhelm von Humboldt: Plan einer vergleichenden Anthropologie, in: Albert Leitzmann (Hrsg.): Wilhelm von Humboldts Werke. Erster Band. 1785-1795 (Wilhelm von Humboldts Gesammelte Schriften Bd. I), Berlin 1903, S. 377-410. Diese Sonderstellung verdanken die „HorenAufsätze“ vermutlich den Analysen von Hausen 1976 und Hoffmann 1983. Der „Plan“, posthum veröffentlicht, steht in engem Denkzusammenhang mit den Aufsätzen und rückt die Geschlechterpolarität in ein anderes Licht.

149 Während die Rousseaurezeption in Deutschland umfänglich erforscht ist, gingen Lange 1992 und Honegger 1991 mit ihren Hinweisen auf Mary Wollstonecraft und Olympe de Gouges relativ neue Wege.

150 Eine frühe, wenig verfolgte Schrift zum Bild der Frau und zu Autorinnen im Zeitschriftendiskurs ist Frank Schubert: Die Stellung der Frau im Spiegel der Berliner Monatsschrift (Abhandlungen zur Philosophie, Psychologie und Pädagogik 150), Bonn 1980. Dagegen gibt es einige neuere Arbeiten, die briefliche Auseinandersetzungen zwischen Mann 
Debatte gelesen wird, der im Folgejahr erschienene Roman Florentin seiner Lebenspartnerin, der ebenfalls alternative Geschlechterrollen entwarf, aber nicht? ${ }^{151}$ Kaum genannt und noch weniger auf ihre intertextuellen Bezüge zu den männlichen Schriften analysiert wurden Werke von Emilie von Berlepsch, ${ }^{152}$ Amalia Holst ${ }^{153}$ oder Marianne Ehrmann,, ${ }^{154}$ um nur drei damals aktive Publizistinnen $\mathrm{zu}$ nennen. ${ }^{155}$ Ohne die Durchschlagkraft weiblicher

und Frau zu den zeitgenössischen Geschlechterbildern auf unterschiedliche Aneignungsmuster analysieren. Vgl. exemplarisch: Petra Wulbusch: Therese Huber und Emil von Herder. Zum Geschlechterdiskurs um 1800, Tübingen 2005. Zu der Frage, wie Frauen auf die Entwürfe der Aufklärer zu den ,privaten“ Themen Ehe, Mutterschaft und Körperlichkeit reagiert haben, s. den Sammelband Opitz / Weckel / Kleinau 2000. Mehr Aufmerksamkeit verdienen auch solche Texte um 1800, die Cross-Dressing und Rollentausch thematisieren. Als Pionierarbeit dazu Elizabeth Crimmer: In the Company of Men. Cross-Dressed Women around 1800, Detroit 2004.

151 Neuere Arbeiten der feministischen Literaturwissenschaft diskutieren „Florentin“ als Gegenstück zu „Lucinde“ bzw. als Parodie auf die Geschlechterideologie des zeitgenössischen Bildungsromans, Darstellungen der Geschlechterdebatte schließen inn dennoch kaum ein. [Dorothea Schlegel]: Florentin. Ein Roman herausgegeben von Friedrich Schlegel. Erster Band. Lübeck [u. a.] 1801. Vgl. exemplarisch: Inge Stephan: Weibliche und männliche Autorschaft. Zum „Florentin“ von Dorothea Schlegel und zur „Lucinde“ von Friedrich Schlegel, in: dies.: Inszenierte Weiblichkeit. Codierung der Geschlechter in der Literatur des 18. Jahrhunderts, Köln 2004, S. 233-250. Zu „Florentin“ als Parodie: Barbara Becker-Cantarino: Schriftstellerinnen der Romantik. Epoche - Werk - Wirkung, München 2000, S. 138-141.

152 Dorothea Friderika Aemilia von Berlepsch, geb. von Oppel (1755-1830), verfasste u. a. Gedichte, Sachtexte und Theaterreden.

153 Johanne Pauline Amalie Holst, geb. von Justi (1758-1829), Pädagogin.

154 Marianne Ehrmann, geb. Brentano (1755-1795), Schauspielerin und Schriftstellerin, Herausgeberin von Frauenzeitschriften.

$155 \mathrm{Zu}$ den Texten, die schon im Titel auf debattenrelevante Themen Bezug nehmen gehören das Traktat von Ehrmann: „Philosophie eines Weibs. Von einer Beobachterin. O. 0 [Kempten] 1784, und das ebenfalls für Vernunfterziehung votierende Schauspiel „Leichtsinn und Gutes Herz, oder Folgen der Erziehung“, Strasbourg 1786. Holst veröffentlichte 1802 „Über die Bestimmung des Weibes zur höheren Geistesbildung“, Emilie von Berlepsch „Ueber einige zum Glück der Ehe nothwendige Eigenschaften und Grundsätze“, in: Neuer Teutscher Merkur, 5. und 6. Stück 1791, S.63-102; 113-134. Viele dieser Texte sind nicht oder nur schwer zugänglich. Eine gute Zusammenstellung weiblicher Argumentationsstränge bietet Claudia Honegger, bezeichnet sie allerdings als ein wenn auch nicht zu vernachlässigendes „Gemurmel“ in der Debatte. Honegger 1991, S. 13-45, hier S. 44. Zu Marianne Ehrmann s. die Dissertation von Britt-Angela Kirstein: Marianne Ehrmann. Publizistin und Herausgeberin im ausgehenden 18. Jahrhundert, Wiesbaden 1997, hier auch Nachdruck einiger Originaltexte. Warum zum Beispiel der Aufsatz Frau von Berlepschs über die Ehe, der 1791 in Wielands Merkur erschien und explizit auf oben erwähnte Thesen der Autoren Brandes und Pockels zum Thema Bezug nahm, nicht in die Debatte miteingerechnet wird, ist fraglich. Ein Hinweis auf diesen Aufsatz findet sich bei Honegger 1991, S. 266, eine umfassende Textanalyse steht noch aus. 
Stimmen in diesem Diskurs letztgültig einschätzen zu können, muss man sagen, dass pauschale Ausschlussformeln der Geschlechterdebatte als „Männerphantasien über Frauenwirklichkeit"156 weniger die historische Realität abbilden, als die Erwartungshaltung der Forschenden spiegeln, dass zu Sanftmut ermahnte Frauen sich gar nicht erst beteiligt hätten. Zur Realität gehört vielmehr sogar der Umstand, dass eine Salonfrau wie Esther Gad ${ }^{157}$ durch Einige Aeußerungen über Herrn Kampe'ns Behauptungen erkennbar als weibliche Stimme und polemisch mitstritt. ${ }^{158}$ Eine umfassende Analyse von Zeitungsartikeln, besonders anonymer oder weiblicher Beiträger zum Themenbereich Geschlechterfragen, könnte hier neue Erkenntnisse vermitteln.

Schon der kleine Teilstrang der Debatte zum Thema Geselligkeit zeigt, dass Frauen durchaus ihre Stimmen erhoben und Texte veröffentlicht haben, die explizit auf den Diskurs Bezug nahmen. Die rhetorischen Mittel der Kontrahenten wurden dabei ebenso oft genau benannt wie von den Frauen selbst erfolgreich angewendet. Interessant im Zusammenhang dieser Arbeit ist dabei, dass in fast allen männlichen Beiträgen, die für eine Geschlechtertrennung im öffentlichen oder geselligen Leben plädierten, französische Salons, die „Bureaux d'esprit“ explizit oder implizit als Übertreibungen gegeißelt wurden.159 Auch Autorinnen nahmen Bezug auf die französischen Salonièren. Allerdings sahen sie diese, im exakten Unterschied zu den männlichen Interpreten, als positives Beispiel.

156 So formuliert Sigrid Lange, trotzdem sie selbst mehrere Frauenstimmen wieder zugänglich gemacht hat. Lange 1792, S. 423.

157 Esther Gad, verheiratete Esther Bernard, spätere Lucie Domeier (1770-1827) ist bekannt geworden als Schriftstellerin und Freundin Rahel Levin Varnhagens, die sie bei Berliner Aufenthalten besuchte und mit der sie im Briefwechsel stand.

158 Gad 1798. Als Autorinnenkürzel war „C. B., geb. G.“ angegeben. Der Text ist neu ediert in: Elke Kleinau / Christine Mayer (Hrsg.): Erziehung und Bildung des weiblichen Geschlechts. Eine kommentierte Quellensammlung zur Bildungs- und Berufsbildungsgeschichte von Mädchen und Frauen, 2 Bde., Weinheim 1996, Bd.1, S.53-64. Unlängst wurden auch die Texte der in Berlin und Königsberg wirkenden Salonière Elisabeth von Stägemann (17611835) als Beiträge zur Geschlechterdebatte gedeutet, auch wenn sie erst posthum veröffentlicht wurden. Elisabeth von Stägemann: Erinnerungen für edle Frauen. Nebst Lebensnachrichten über die Verfasserin und einem Anhange von Briefen, hrsg. von Wilhelm Dorow, Leipzig 1846. Zu der These ihres möglichen Eingreifens in die Debatte s. Caroline Vogel: Geschlechterdiskurs und Lebensrealität. Elisabeth von Stägemann, ihr literarisches Leben und ihr Salon, Regensburg 2001.

159 Besonders detailliert bei Carl Friedrich Pockels: Über Gesellschaft, Geselligkeit und Umgang, 2 Bde., Hannover 1813, Bd. 2, S. 50 f., Fn. Die Salons seien von Molière zu recht satirisiert worden. Molières Werke, „Femmes savantes“ und „Précieuses ridicules“, werden nochmals empfohlen, namentlich genannt noch die Salonfrauen Rambouillet, Longueveille und Lenclos. 
Schon Brandes hatte die Pariser Salons, in denen „man dem andern Geschlechte ein Richteramt in Sachen der Philosophie, der Erziehung, des Geschmacks, der Literatur eingeräumt“ habe, als Beispiel für eine gesellschaftliche Fehlentwicklung genommen. ${ }^{160}$ Sein Plädoyer für reine Männerzirkel fand, was die Forschung oft verschweigt, eine zeitgenössische Rezension aber belegt, in „gemischten Gesellschaften“ unterschiedliche Aufnahme: „Dem weiblichen Geschlecht hat dieses Buch durchgängig misfallen. Bey Männern hingegen hat es viel Beyfall gefunden“ - dieser sei aber in Gegenwart von Damen nicht immer laut vertreten worden. ${ }^{161}$ Zur Ausführung eines spielerisch(?) geforderten Gegenentwurfs „Über die Kerls“ seitens einer weiblichen Autorin ist es leider nicht gekommen. ${ }^{162} \mathrm{Zu}$ den Kritikerinnen, deren Beitrag aber rekonstruierbar ist, gehört Emilie von Berlepsch, die 1791 zwar, gleich männlichen Kollegen, einen unangenehmen Ton in gemischten Gesellschaften konstatierte, dies allerdings als Konsequenz der zeitgenössischen Misogynie ansah. ${ }^{163}$ Statt für getrennte Geselligkeiten plädierte sie dann nachhaltig für einen liebe- und respektvolleren Umgang zwischen den Geschlechtern. ${ }^{164}$

160 Brandes 1787, S. 10, und 100 f. (bes. Fn.). Brandes' Ausgangspunkt war die angenommene falsche Position der Frau in der Geselligkeit. Frauen würden, u. a. durch Komplimente und falsche Lektüre, falsch erzogen, hätten in einigen Bereichen zuviel Einfluss. Vor gemischten Geselligkeiten wäre außerdem zu warnen, da Frauen ohne Interesse an ernsthaften Gesprächen in Gesellschaft immer die Begierde der Männer reizten. Ebd., S. 125 161 Mauvillon 1791, S. 4.

162 Honeggers Analyse macht, in den Fussnoten, deutlich, dass eine noch ausstehende Rezeptionsgeschichte der Debatte, inklusive Leserinnenmeinungen, ein anderes Bild von der Wirkungsmächtigkeit der Texte zeigen würde. Beispielsweise überlieferte gerade ein Verteidiger der Brandesschen Schrift die ablehnenden Reaktionen: „Einige Thörinnen fanden es sonderbar, daß der Verfasser die Weiber - Weiber genannt hatte [...]. Eine behauptete sogar, daß man auch ein Buch über die Männer unter dem Titel: Ueber die Kerls! schreiben müsste!! Genug, das Buch machte große Sensation in der vornehmen Weiberwelt, und die meisten überfällt noch jetzt ein kleiner Schauder, wenn sie an das aus so edlen Absichten geschriebene Werk denken." Pockels 1799, Bd. 2, S. 432 ff, zit. nach: Honegger 1991, S. 222, Fn. 54.

163 An dieser Stelle muss betont werden, dass schon Zeitgenossen Frauenfeindlichkeit als diskursives Phänomen, als „Modeerscheinung“ geißelten. z. B. in: „Etwas über die heutige Mode-Misogynie. Ein Dialog.“ in: Hannoversches Magazin, 69 (1788), zit. nach: Fronius 2007, S. 10 .

164 Auf Brandes, und in seiner Nachfolge vielleicht Meiners, Bezug nehmend, schrieb Berlepsch zunächst einschränkend: „Freylich beschuldigen uns die Männer nicht ganz zu Unrecht, daß wir uns zu hohe Begriffe von dem Werth unserer Bestimmung machen“, betonte dann aber den Unterschied zwischen übertriebener Anbetung und dem rechtschaffenen Anspruch eines Individuums auf Wohlwollen und Enthusiasmus der anderen. Berlepsch 1791, S. 83 f. Misogynen Autoren wies sie mit guter Textkenntnis selektive Rousseaurezeption nach. 
Die Pädagogin Amalie Holst ${ }^{165}$ mischte sich 1802 mit einem längeren Traktat explizit aus dem Grund in die Debatte ein, dass noch kaum ein Weib dagegen protestiert habe, was ,seit kurzem [...] so viel über die weibliche bestimmung geschrieben. männer wagten es, unserm geiste die linie vorzuziehen, über welche im felde des wissens er nicht hinüber schreiten dürfe“. ${ }^{166}$ Ihr Hauptargument war, Wollstonecraft vergleichbar, dass in einem wohlgeordneten Gemeinwesen alle Menschen das Recht und die Pflicht hätten, ihre Talente auszubilden, und zur Geselligkeit der „Hausfrau“ Geist gehöre. ${ }^{167}$ Dem Buch von Brandes widmete Holst nur eine Fußnote, bei ihm wie bei Rousseau vermutete sie gekränkte Eigenliebe, die auch zur Verurteilung der französischen gelehrten Frauen geführt habe. ${ }^{168}$ Stattdessen empfahl sie nachdrücklich die Lektüre des progressiven Hippel. Die Reaktionen auf Holsts Buch zeigen, wie sehr um 1802 ein Hinweis auf die „Natürlichkeit“ ausreichte, um gut begründete Forderungen abzuwiegeln: „Will das Weib eine Gelehrte von Profession sein, so muss es auf den Namen der Gattin und Mutter und noch mehr der Hausfrau Verzicht leisten. Verbieten kann ihm dies Niemand als - die Natur“.169

Die Diskussion über Frauen in der geselligen Öffentlichkeit ist natürlich nicht zu trennen von der über Gelehrsamkeit bei Frauen, deren Gegner ebenfalls als letztgültiges Argument zunehmend die Natur der Frau heranzogen. Von besonderer Nachhaltigkeit war auch hier ein Beitrag Schillers, der 1788 die Salonière Ninon de l'Enclos als Zerrbild präsentierte:170 „Ein starker Geist

165 Amalie Holst geb. von Justi: Über die Bestimmung des Weibes zur höhern Geistesbildung, Vorwort und Nachwort von Berta Rahm, Zürich 1984, S. 167. (Holsts Vater, der Aufklärer Johann Heinrich von Justi, hatte 1760 einen kaum noch bekannten Vorschlag zur Einrichtung einer Akademie für Frauenzimmer veröffentlicht.)

166 Holst 1984, S. 16 f. In der Ausgabe, dem bisher einzigen Nachdruck, wird die Kleinschreibung angewandt.

167 „gibt sie gastmähler, so wird das gebildete weib [...] die grosse pflicht der geselligkeit recht lebhaft fühlen. [...] und so wird auch dann die unerschöpfliche quelle ihres geistes hilfsmittel darbieten.“ Holst 1984, S. 126.

168 Holst vermutete, und machte sich dabei die schmähende Abwehrstrategie der Konservativen zu eigen, eine „kokette“ habe Rousseau versetzt und dann habe er geschrieben. Holst 1984, S. 22, Fn. Allerdings kritisiert sie die Salonfrauen zugleich dafür, dass sie sich bei ihren „unbestimmten, aber grossen vorrechten“ zu wohl befunden und Olympe de Gouges' Anliegen nicht unterstützt hätten. Ebd., S. 25.

169 [anon.]: Rezension zu Holst, in: Zeitschrift zur Geschichte der Zeit, der Sitten und des Geschmacks, Hamburg, hrsg. von Franz Nestler, 1802, zitiert nach: Holst 1984, S. 142. Hervorhebung im Original.

170 Friedrich von Schiller: Die berühmte Frau. Epistel eines Ehemanns an einen andern [1788], in: ders.: Gedichte, Auswahl, hrsg. von Eike Middell, Leipzig 1984, S.125-129. Weibliche Autorschaft wird hier schlimmer „empfunden“ als Ehebruch und Prostitution, denn „die berühmte Frau“ „wird [...] in allen Buden feilgeboten“ und müsse vor Kunstrichtern „auf 
in einem zarten Leib / Ein Zwitter zwischen Mann und Weib.“ Am Beispiel einer Salonfrau machte Schiller damit alles andere als subtil deutlich: Frauen, die ihre zugewiesene Rolle verlassen, verlieren ihren ,natürlichen Geschlechtscharakter‘. Weniger bekannt, aber ebenso prägnant ist der Text, mit dem eine Berliner Salonfrau genau diese Verknüpfung als unzulässig ablehnte. Esther Gad bekommt hier, anders als in der historischen Debatte, das letzte Wort: „Unverantwortlich, wenn ein Mann [...] Meinungen a priori, öffentlich hinwirft, die durch die anerkannte Autorität eines solchen Mannes, zu Gesezzen gestempelt werden“. ${ }^{171}$

\subsection{Die Debatte über die Emanzipation der Juden}

Die Sache ganz von der Nähe betrachtet, bewegt zum Unwillen oder zum laut lachen. Halb Europa führt Krieg, aber zur Wiederherstellung des lieben Landfriedens ist kaum so viel geredet und geschrieben worden, als jetzt über die ganz unwahrscheinliche Bekehrung eines berlinischen Juden. ${ }^{172}$ August Wilhelm Hupel, 1771

Die lebensgeschichtliche Situation der Juden im Preußen des 18. Jahrhunderts ist in einschlägigen Untersuchungen detailliert geschildert worden. ${ }^{173} \mathrm{Im}$ Zusammenhang mit den Emanzipationsdebatten muss hier nur daran erinnert werden, dass die Berliner Salonfrauen in eine jüdische Gemeinde hineingeboren wurden, deren Zusammensetzung und -leben von zahlreichen diskriminierenden Einzelbestimmungen wie Leibzoll, Heiratssteuer und Solidarhaftung

den Pranger“ gehen. Nicht nur erniedrige sie ihren Ehemann und vernachlässige die Familie - „(Laut hört man in der Kinderstube weinen)“ schob Schiller das bekannte Schreckensbild wie eine Theaterkulisse in Klammern ein -, sie verliere letztendlich ihre Weiblichkeit.

$171 \mathrm{Gad}$ 1798, S. 581. Ihre Kritik bezog sich auf die Person Campes, zugleich aber auf das methodische Vorgehen, Unbeweisbares als Naturvorgabe zu behaupten. „Meinungen a priori“ bedeutet unbewiesene Argumente. Für ihr Plädoyer für Frauenbildung argumentierte sie ex negativo: „Wenn Kenntnisse und Gelehrsamkeit diejenige so despotisch beherrschten, die sich ihnen widmen, so müste der Staat, wo oft Gelehrte das Ruder führen, ebenso zerfallen als die Haushaltung eines Privatmanns, dessen Frau sich mit Kenntnissen der Wissenschaften abgiebt.“ Gad 1798. S. 579.

172 [August Wilhelm Hupel]: Dienstfreundliches Promemoria an die, welche den Herrn Moses Mendelssohn durchaus zum Christen machen wollen, oder sich doch wenigstens herzlich wundern, daß er es noch nicht geworden ist, Riga 1771, S. 6.

173 Exemplarisch sei verwiesen auf Bruer 1991. Grundlegend für die Zeit bis 1786 immer noch Stern 1971. 
der Gemeinde ${ }^{174}$ sowie vom friderizianischen Generalprivileg 1750 bestimmt wurde, welches die Zahl der aufenthaltsberechtigten Juden beschränkte und diese in sechs Klassen teilte. ${ }^{175}$ Die prekäre Situation der Juden in Preußen wurde nicht zu unrecht häufig symbolisch in der Figur Moses Mendelssohns gefasst, der als international geachteter Philosoph an seinem Arbeitsort nur geduldet und lange von seiner beruflichen Anstellung bei einem „ordentlichen Schutzjuden“" abhängig war. ${ }^{176}$

Als Beginn der Judenemanzipation in Preußen wird das Werk Über die bürgerliche Verbesserung des Juden Christian Wilhelm Dohms betrachtet, das 1781 erschien und in einer breiten publizistischen Debatte den Toleranzdiskurs der Aufklärung von einer philosophisch-literarischen auf die politische Ebene verlagerte. ${ }^{177}$ Dohm verlieh der vor allem durch die Aufklärung bedingten neuen Sicht prägnant Ausdruck, dass die rechtlich eingeschränkte und gesell-

174 Leibzoll bedeutete, dass ein Jude, der in Gebiete reiste, für die der Schutzbrief nicht galt, Gebühren zahlen musste. Die solidarische Haftung galt für die Gemeinde, die für Vergehen Einzelner bezahlen musste. Zu zahlreichen beruflichen Einschränkungen kamen Gebühren, die bei wichtigen Ereignissen, wie Heiraten, an den Staat zu zahlen waren; besonders berüchtigt wurde die Zwangsabnahme von schwer verkäuflichen Waren der Königlichen Porzellan-Manufaktur seit 1769.

175 Die Familien der meisten bekannten Salonièren gehörten zur Oberschicht der ersten zwei Klassen. Die umfassendsten Klassen waren 5. die Geduldeten und Tolerierten, die nur zeitlich begrenzt bleiben durften und 6. die Privatdienstboten, deren Aufenthalt an eine Anstellung in einem Haushalt der oberen Klassen gebunden war.

176 Als Mendelssohn auf seine Eingabe hin 1763 das Bleiberecht gewährt wurde, durfte er es nicht vererben. Das dauernde Aufenthaltsrecht für sich und ihre Kinder erlangte Fromet Mendelssohn erst von Friedrich Wilhelm II. Dass Mendelsohn überhaupt das Privileg eines Schutzjuden erhielt, war höchstwahrscheinlich auf den Einspruch des in Berlin lebenden Marquis d'Argens zurückzuführen, der Mendelssohns Eingabe mit der Formulierung unterstützte, die auf die Vorlieben Friedrichs II. zugespitzt war, der zwar nicht die Juden, aber Pointen schätzte: „Un Philosophe mauvais catholique supplie un Philosophe mauvais protestant de donner le privilège à un Philosophe mauvais juif. Il y a trop de philosophie dans tout ceci pour que la raison ne soit pas du côté de la demande." Vgl. Julius H. Schoeps: Der König und der Philosoph. Friedrich II. und Moses Mendelssohn, in: ders. (Hrsg.): Moses Mendelssohn, die Aufklärung und die Anfänge des deutsch-jüdischen Bürgertums (Menora 15), Hamburg 2006, S. 81-96.

177 Man kann sagen, die Debatte um die bürgerliche Verbesserung der Juden hat ihre Vorläufer oder Wurzeln in mehreren Toleranzdebatten des 18. Jahrhunderts, etwa der Debatte um Lessings Drama „Die Juden“ 1754 oder der Mendelssohn-Lavaterdebatte 1769. Zur Rolle Mendelssohns bei der Entstehung des Dohmschen Textes s. Gerda Heinrich: „Juden müssen sich also gar nicht einmischen ...“ Mendelssohn als Initiator und Mentor der Debatte um die „bürgerliche Verbesserung der Juden“ 1781 bis 1786, in: Julius H. Schoeps / Karl E. Grözinger/Gert Mattenklott (Hrsg.): Haskala und Öffentlichkeit (Menora 12), Berlin 2001, S. 39-65. 
schaftlich marginalisierte Lage der Juden weder gottgewollt noch unveränderlich sei, sondern durch eine spezifische historische Entwicklung, konkret durch die bisherige Judenpolitik, hervorgebracht worden sei. Daraus konnte er folgern, dass durch veränderte staatspolitischen Behandlung auch der sittliche Charakter der Juden sich ändern würde: „Wenn ihn [den Juden] die Drückung, in der er Jahrhunderte gelebt, sittlich verderbter gemacht hat; so wird eine gerechtere Behandlung ihn wieder bessern“. ${ }^{178}$ Der Titel und die Argumentation Dohms waren kennzeichnend für die Grundhaltung der preußischen Judenemanzipation: „Bürgerliche Verbesserung“ bedeutete die schrittweise Erhebung in den Bürgerstand bei Nachweis sittlich-moralischer Besserung. Die preußische und spätere deutsche Konzeption unterschied sich damit wesentlich von der französischen Herangehensweise, bei der 1791, wenn auch nach heftigen Debatten, alle Juden mit nur einem Gesetz zu Staatsbürgern wurden. ${ }^{179}$

Dohms Ratschläge zur schrittweisen Integration zog eine Flut von Kommentaren und Gegenschriften nach sich. ${ }^{180}$ Trotz einiger deutlicher Gegenstimmen war sich die Mehrheit der Debatteure in der Notwendigkeit der „Verbesserung“ als solcher einig, strittig waren das Tempo und die Methode des Vorgehens. ${ }^{181}$

178 Dohm 1973, I, S. 87.

179 Es war bereits im Dezember 1789 debattiert worden, ob Juden Franzosen seien oder eine Nation eigenen Rechts. 1791 erklärte die Nationalversammlung alle Juden Frankreichs zu Staatsbürgern. Die Forschung unterscheidet seitdem zwischen einem aufgeklärt-etatistischen Modell der Judenemanzipation, wie Preußen es vollzog, und einem liberal-revolutionären Konzept wie dem Frankreichs. Allerdings wurden, wie Rürup zurecht betont, beide Konzepte nicht konsequent durchgehalten. Rürup 1987, S. 23 und 40. Die neueste Forschung betont statt unterschiedlicher Modelle die Zusammenarbeit jüdischer Aufklärer in verschiedenen Ländern: Michael Brenner / Vicki Caron / Uri R. Kaufmann: Jewish Emancipation Reconsidered. The French and German Models, Tübingen 2003.

180 In gut aufgeklärter Tradition veröffentlichte er bei seiner Wiederauflage 1783 einige davon mit und kommentierte sie. Dohm 1973, II.

181 Dohm selbst plädierte für eine völlige rechtliche Gleichstellung unter staatlicher Kontrolle und Lenkung der Emanzipationsobjekte, beispielsweise weg vom Handel hin zur Landwirtschaft. Kanzleidirektor von Diez lehnte staatliche Einmischung ab. Freiherr von Schuckmann formulierte hingegen, dass bis die völlige Emanzipation erreicht sei, man die Absonderung der Juden zu befördern habe, denn „so lange das Vorurteil wider sie noch in den Herzen" sei, könnten Gesetze allein die Juden nicht schützen. Heinrich Friedrich von Diez: Ueber Juden, An Herrn Kriegsrath Dohm in Berlin, Dessau [u. a.], 1783, Friedrich von Schuckmann: Über Judenkolonien. An Hrn. Geheimen Rath Dohm, in: Berlinische Monatsschrift, Bd. 5, 1785, S. 55 f., zit. nach: Rürup 1987, S. 20. Hier wurde ein wesentliches Problem des preußischen Emanzipationsmodells vorweggenommen, auf das unter Zeitgenossen später nur Humboldt deutlich hinweisen sollte: Schrittweise Emanzipation, „eine allmählige Aufhebung bestätigt die Absonderung [...], verdoppelt [...] die 
Als Gegenstimme mit Autorität argumentierte der Theologe und Orientalist Johann David Michaelis 1782, dass das mosaische Recht jüdischen Separatismus bedinge und die Bürgerwerdung durch das biblische Gesetz verhindert sei. ${ }^{182}$ Zugleich formulierte er klimatisch-rassistisch, dass unter den Juden als „ungemischte Race eines südlichern Volks [...] wenig wohlgewachsene Männer“ seien, die in ihrer körperlichen Konstitution schon den Militärdienst in Preußen, den Dohm unter anderem gefordert hatte, nicht leisten würden können. ${ }^{183}$ Auch Angst vor ,Überfremdung‘ klang an, wenn er davor warnte, dass sich Juden prinzipiell schneller vermehrten als Christen, ${ }^{184}$ und vorschlug, die Juden als ein „abgesondertes Volk“ besser auf „Zuckerinseln“ im südlichen Klima zu halten. ${ }^{185}$ Da sich bei solchen Entwürfen Parallelen zum 20. Jahrhundert aufdrängen, soll hier mit Erb / Bergmann festgehalten werden, dass die Geschichte der Emanzipation immer durch eine Geschichte der Abwehrversuche dieser „kulturellen Immigration“ ergänzt werden muss. Zwar wurden um 1800 durchaus auch anderen Bevölkerungsgruppen vergleichbare SeparationsFantasien gewidmet, ${ }^{186}$ aber Michaelis' Idee einer jüdischen Kolonie war nicht die einzige, sondern einer von über 40 solcher Vorschläge, die zwischen 1774

Aufmerksamkeit auf die noch bestehende Beschränkung“, und befördert so alte Vorurteile. Wilhelm von Humboldt: Über den Entwurf zu einer neuen Konstitution für die Juden. 17. Juli 1809, in: ders.: Studienausgabe in 3 Bänden, hrsg. von Kurt Müller-Vollmer, Bd. 2: Politik und Geschichte, Frankfurt/M. 1971, S. 114-128, hier, S. 115.

182 Johann David Michaelis: Hr. Ritter Michaelis Beurtheilung. Ueber die bürgerliche Verbesserung der Juden von Christian Wilhelm Dohm. In: Orientalische und exegetische Bibliothek 19 (1782): S. 1-40, wieder abgedruckt in und hier zitiert nach: Dohm 1973, II, S. 31-72. Michaelis galt, als Autor eines Standardwerkes zum Thema und Herausgeber der „Orientalischen Bibliothek“, als Autorität auf dem Gebiet und vor dieser Rezension auch als Verteidiger des mosaischen Rechts. Dohm selbst hatte inn mehrfach zitiert, umso nachhaltiger musste der Gegenangriff wirken. Zu Michaelis s. ausführlich Anna-Ruth Löwenbrück: Judenfeindschaft im Zeitalter der Aufklärung. Eine Studie zur Vorgeschichte des modernen Antisemitismus am Beispiel des Göttinger Theologen und Orientalisten Johann David Michaelis (1717-1791), Frankfurt/M. 1995. Löwenbrück geht davon aus, dass Michaelis wusste, dass er Dohms Argumenten nicht politisch beikommen würde, und daher alten Vorurteilen dies neue Vokabular gab.

183 Michaelis in Dohm 1973, II, S.51. Ausführlich zu dem Thema, auch zur Debatte um den Kriegsdienst am Sabbat: Ludwig Geiger: Die deutschen Juden und der Krieg, Berlin 1915.

184 Dabei schreckte er nicht vor antisemitischen Klischees zurück, wie dem, dass Juden kaum fremd gingen, weil Ehebruch mit Christen sie zuviel Geld, welches ihnen „über alles lieb“ sei, kosten würde. Michaelis in Dohm 1973, II, S. 44.

185 Michaelis in Dohm 1973, II, S. 41.

186 Dazu zählen etwa die Nichtzulassung von Katholiken an protestantischen Universitäten, die Deportation von Verbrechern und der Verkauf von Armen in überseeische Kolonien. 
und 1819 veröffentlicht wurden. ${ }^{187}$ Einige wurden sogar praktisch umgesetzt. ${ }^{188}$

Radikal klingende Formulierungen ${ }^{189}$ äußerten in der Debatte um die Judenemanzipation nicht nur die Gegner der Emanzipation, die zum Teil alte antijüdische Vorurteile auf die Spitze trieben, sondern auch Befürworter einer Integration, sofern sie konkrete Beweise für die ernste Absicht zur bürgerlichen Verbesserung wollten. Zwei immer wiederkehrende Forderungen waren die Abschaffung der Zeremonialgesetze (etwa die Regelungen zum Sabbat oder zur Schächtung) und der Übertritt zum Christentum. 1782 veröffentlichten Moses Mendelssohn und Markus Herz die Übersetzung einer historischen Schrift, Rettung der Juden, um das Vorurteil gegen die Juden, das „die Gestalten aller Jahrhunderte annimmt“, als zeitlos anzuprangern. ${ }^{190}$ Mendelssohns Vorrede brachte die Widersprüchlichkeit der Gegner auf den Punkt: „Man bindet uns die Hände und macht uns zum Vorwurf, dass wir sie nicht gebrauchen“.191 1783 wieder einmal persönlich zum Übertritt herausgefordert, ${ }^{192}$ veröffentlichte

187 Zahlen nach Jonathan M. Hess, Sugar Island Jews? Jewish Colonialism and the Rhethoric of "Civic Improvement", in: Eighteenth-Century Studies 32.1. (1998), S.92-100, hier S. 94. Als Überblick über diese Veröffentlichungen auch Jakob Toury: Emanzipation und Judenkolonien in der öffentlichen Meinung Deutschlands (1775-1819), in: Jahrbuch des Instituts für deutsche Geschichte 11 (1982), S.17-53.

188 So gründete der ,Vater' der Toleranzgesetzgebung, Joseph II., einige landwirtschaftliche Judenkolonien im habsburgischen Reich, die allerdings keinen Bestand hatten, weil man ihnen nicht dieselbe technische Unterstützung gewährt hatte wie anderen Ansiedlungen. 189 Die Sprache der Emanzipation ist ein eigenes Untersuchungsfeld. 1781 konnte Dohm noch von den Juden als „unglücklichen asiatischen Flüchtlinge[n]“ sprechen. Dohm 1973, I, S. 8. Es setzte sich im Laufe der Debatte die Überzeugung durch, dass der Begriff „Jude“ im Verständnis der Zeit abwertend sei. Daher wurde von oberster Stelle, sowohl von der jüdischen Gemeinde wie den preußischen Behörden, die Frage nach einer alternativen Bezeichnung „Israelit“, oder „Mosaist“ aufgeworfen. Diese von Hardenberg in die Gesetzvorlage eingebrachte Überlegung wurde von Friedrich Wilhelm III. wieder gestrichen. Vgl. Erb / Bergmann 1989, S. 18, Fn. 12.

190 Manasseh Ben Israel: Rettung der Juden. Aus dem Englischen übersetzt. Nebst einer Vorrede von Moses Mendelssohn. Als ein Anhang zu des Hrn. Kriegsrath Dohm Abhandlung: Ueber die bürgerlicher Verbesserung der Juden. Berlin 1782, in: Moses Mendelssohn: Schriften zum Judentum II, in: ders.: Gesammelte Schriften (Jubiläumsausgabe), [im Folgenden JubA], Bd. 8, Stuttgart 1983, S.1-71. Mendelssohn hatte Herz gebeten, die „Vindicatio Judaeorum“ von 1656 zu übersetzen und schrieb eine gegenwartsbezogene Vorrede.

191 Moses Mendelssohn, Vorrede, in: Ben Israel 1983, S. 3-25, hier S. 6.

192 Die Vorrede zur Rettung der Juden führte zur konkreten Provokation durch den Kriegsrat und Satirenschreiber Cranz, der Mendelssohn unterstellte, auf dem Weg zum Christentum zu sein. Hinzu kam, daß Cranz die Autorschaft so inszenierte, dass Mendelssohn annehmen 
Mendelssohn dann mit Jerusalem oder über religiöse Macht und Judenthum, eine grundlegende Abhandlung, in der er die Trennung von Staat und Kirche postulierte bzw. die These aufstellte, dass nur Handlungen, die für das Gemeinwesen relevant sind, vom Staat kontrolliert werden sollten, nicht Meinungen oder Konfessionen. ${ }^{193}$ Zugleich beharrte er auf der Gleichberechtigung der Religionen, dem Respekt vor dem Gewissen des Einzelnen, und auf der Möglichkeit der Bürgerwerdung ohne vorherige Konversion: „Wenn die bürgerliche Vereinigung unter keiner andern Bedingung zu erhalten sei, als wenn wir von dem Gesetze abweichen, das wir für uns noch für verbindlich halten; so thut es uns herzlich leid [...]““.194

Brisant an der Debatte um die Emanzipation der Juden war das gelegentlich deutliche Ineinandergreifen textlicher und politischer bzw. gesellschaftspolitischer Maßnahmen gegenüber dem Ausbleiben politischer Konsequenzen an anderer Stelle. So bestärkten die allerersten wirklichen Emanzipationsmaßnahmen auf europäischem Boden, die Toleranzpatente Kaiser Josephs II. von Österreich seit 1781,195 die damit beschäftigten preußischen Beamten in der Veröffentlichung ihrer Stellungnahmen. ${ }^{196}$ Übersetzungen des Dohmschen Tex-

musste, er sei von einem berühmten Staatsmann angesprochen worden. Vgl. Alexander Altmann, Einleitungen, in: Moses Mendelssohn: Schriften zum Judentum II: in JubA, Bd. 8, Stuttgart 1983, S. IX-XCI, hier S. XXIIIff. [Friedrich August Cranz]: Das Forschen nach Licht und Recht in einem Schreiben an Herrn Moses Mendelssohn auf Veranlassung seiner merkwürdigen Vorrede zu Manasseh Ben Israel, Berlin 1783.

193 Moses Mendelssohn: Jerusalem oder über religiöse Macht und Judenthum, Berlin 1783, in: ders.: Schriften zum Judentum II, in: JubA, Bd. 8, Stuttgart 1983, S.99-204. Beispielhaft die folgende Formulierung: „Weder Staat noch Kirche haben also ein Recht, die Grundsätze und Gesinnungen der Menschen irgendeinem Zwang zu unterwerfen.“ Ebd., S. 138.

194 Mendelssohn 1983, S. 200. Sein Festhalten am Zeremonialgesetz brachte Mendelssohn unter christlichen wie jüdischen Aufklärern besonderen Widerspruch, sein Plädoyer einer „unbeschränkten Gewissensfreyheit“ trug ihm andererseits ein Kompliment Kants ein. Für eine Zusammenfassung der zeitgenössischen Aufnahme s. Altmann 1983, S. LIX-LXXXVIII. Immanuel Kant an Moses Mendelssohn, 16. 8. 1783, Ebd., S. LXII.

195 Beginnend mit dem 19. Oktober 1781 wurde eine Reihe von Toleranzpatenten erlassen. Mit dem expliziten Ziel, Juden „dem Staate nützlicher und brauchbarer zu machen“, wurden Provinz für Provinz weltliche Schulbildung gefordert und ermöglicht, sowie verschiedene Handelsbeschränkungen und Kleiderordnungen aufgehoben. Wilma Iggers: Das mährische Toleranzpatent Josephs des Zweiten, in: Günter Sternberger (Hrsg.): Die Juden. Ein historisches Lesebuch, München 1995, S. 210-215, hier S. 211. Zur Judenemanzipation in Österreich detailliert: Louise Hecht / Albert Lichtblau / Michael L. Miller: Österreich, Böhmen und Mähren, in: Kotowski / Schoeps / Wallenborn 2001, Bd.1, S. 101-134.

196 Das Verhältnis zwischen preußischer und österreichischer Judenemanzipation zu diesem Zeitpunkt wird von der Forschung unterschiedlich eingeschätzt. Gerda Heinrich argumentiert, 
tes waren ihrerseits Mitauslöser der 1787 in Metz ausgelobten Preisfrage, ob es Mittel gebe, die Juden in Frankreich ,glücklicher und nützlicher“ zu machen. ${ }^{197}$ Die folgende Debatte blieb sicher nicht ohne Einfluss auf die Gedankenwelt der Abgeordneten der französischen Nationalversammlung. Das Gesetz zur sofortigen Gleichstellung der Juden in Frankreich 1791 hingegen zeitigte keinen Einfluss auf die Obrigkeit in Preußen, die an ihrem Konzept festhielt, Emanzipation ,gewähren` zu wollen. Zwar war mit dem Tod Friedrich II. 1786 eines der größten Hindernisse zur Judenemanzipation in Preußen von der politischen Bühne verschwunden, doch die verschiedenen Reformversuche, welche die jüdische Gemeinde bis 1800 initiierte, scheiterten an der allgemeinen „Erstarrung“ des Beamtenwesens. ${ }^{198}$ Bezeichnend ist, dass ebenfalls anno 1791 in Berlin ein Naturalisationspatent an den reichsten und einflussreichsten Juden, Daniel Itzig, erging, das ihn den christlichen Bürgern gleichstellte, ein Patent, das angesichts der Itzigschen Verdienste um den Preußischen Staat und seine Finanzen zurecht als „Abschlagszahlung“ der Emanzipation bezeichnet wurde. ${ }^{199}$ Von dieser speziellen Form der bürgerlichen Verbesserung gibt es eine Querverbindung zu den Salons: Der ,Bürgerbrief' für Itzig erstreckte sich auf seine „ehelichen Descendenten beyderley Geschlechts“, damit bekamen auch seine Töchter, darunter die drei Salonièren Fanny von Arnstein, Cäcilie Wulff Eskeles und Sara Levy, zehn Jahre früher als alle anderen Juden in Preußen, ,alle Rechte christlicher Bürger in Unsern gesammten Staaten“.200

dass das Vorhaben Josephs im preußischen Departement des Auswärtigen, wo Dohm tätig war, durch diplomatische Kontakte früh bekannt war. Heinrich 2001, S. 42. Fn. Alexander Altmann nennt es hingegen nur eine „glückliche Fügung“. Altmann 1983, S. XIII. Heinrich stellt die These auf, dass die große Breitenwirkung der Emanzipationsdebatte zu nicht geringem Teil auf die Publikationsstrategie Mendelssohns zurückging, mehrheitlich nichtjüdische Autoren zur Agitation für jüdische Verbesserung zu gewinnen und die Frage permanent im Bewusstsein der allgemeinen Öffentlichkeit zu halten. Heinrich 2001, S. 39 f. und 44.

197 Von den elf eingesandten Schriften waren zwei antisemitisch, zwei schienen der Akademie preiswürdig. Als bedeutsam gilt das Buch des Abbé Henri Grégoire, der sich später auch für die Befreiung der Sklaven in den französischen Kolonien einsetzen sollte. 198 Nur einige kleinere Erleichterungen, wie die Aufhebung des Leibzolls 1787, konnten durchgesetzt werden. Bruer argumentiert, an der allgemeinen „Erstarrung“ des preußischen Beamtenwesens vor den Reformen seien auch die verschiedenen Eingaben und Vorschläge der jüdischen Gemeinde zur Aufhebung einzelner Sondergesetze gescheitert. Bruer 1991, S. $166-173$.

199 Rürup 1987, S. 22.

200 Naturalisationspatent vom Mai 1791, zit. nach: Spiel 1962, S. 171. Vergleichbar wurde argumentiert, die Schwestern Sara Meyer Grotthus und Marianne Meyer Eybenberg seien ein Beispiel dafür, dass es einzelnen jüdischen Familien vor 1800 gelang, an die Spitze der Gesellschaft zu gelangen und dabei mehr Freiheiten zu erreichen, als das Edikt von 1812 
Anfang der 1790er-Jahre politisierte sich die Debatte. 1793 erschienen, in unmittelbarer zeitlicher Nähe zum Terreur in Frankreich, zwei Texte von Vertretern ganz unterschiedlicher, wenn nicht gegensätzlicher politischer Positionen, die sich mit den Voraussetzungen der Einbürgerung von Juden beschäftigten und beide als einzige Möglichkeit metaphorisch deren Enthauptung forderten. ${ }^{201}$ Johann Gottlieb Fichte formulierte sein berüchtigt gewordenes Diktum vom jüdischen „Staat im Staate“, und ergänzte in einer Fußnote: „Ihnen Bürgerrechte zu geben, dazu sehe ich wenigstens kein Mittel, als das, in einer Nacht ihnen allen die Köpfe abzuschneiden, und andere aufzusetzen, in denen auch nicht eine jüdische Idee sei“. ${ }^{202}$ Der jüdische Aufklärer Lazarus Bendavid nannte in Etwas zur Characteristick der Juden das Judentum eine Hydra, der alle Köpfe zugleich abzuschlagen seien.203

Obzwar diese Texte vor dem politischen Hintergrund und der sprachlichen Entwicklung der Zeit zu lesen sind - und abgesehen von der ähnlichen Metapher zwei ganz unterschiedlichen Weltanschauungen entstammen ${ }^{204}$ markieren sie einen Wendepunkt in der Debatte, weg von den Prämissen der Aufklärung zu einer qualitativ neuen Begründung der Gegnerschaft zum

vorsah. Gerhard Lauer: Die Rückseite der Haskala. Geschichte einer kleinen Aufklärung, Göttingen 2008, S. 311.

201 Für eine vergleichende Textanalyse Fichtes und Bendavids siehe die Analyse von SvenErik Rose, dessen wesentliches Argument lautet, beide Philosophen hätten ihre Überzeugung aus der kantischen Philosophie weiterentwickelt. Sven-Erik Rose: Lazarus Bendavid's and J. G. Fichte's Kantian Fantasies of Jewish Decapitation in 1793, in: Jewish Social Studies 13.3 (2007), S. 73-102.

202 Das Zitat heißt weiter: „Um uns vor ihnen zu schützen, dazu sehe ich wieder kein anderes Mittel, als ihnen ihr gelobtes Land zu erobern, und sie alle dahin zu schicken.“ Johann Gottlieb Fichte: Beitrag zur Berichtigung der Urtheile des Publikums über die französische Revolution, in: ders.: Werke 1791-1794, J.-G.-Fichte-Gesamtausgabe [im Folgenden FGA], Bd. I,1, Stuttgart 1962, S. 193-404, hier S. 292 f. Als Theorie der Weltverschwörung wurde Folgendes gelesen: „Fast durch alle Länder von Europa verbreitet sich ein mächtiger, feindseelig gesinnter Staat, der mit allen übrigen im beständigen Kriege steht, das Judenthum.“ Ebd., S. 292.

203 Lazarus Bendavid: Etwas zur Characteristick der Juden, Leipzig 1793, S. 55. In der Formulierung Roses hatte sich der Argumentationsstrang, von einer „Leidensgeschichte“ des Judentums in Dohms Text, bei Bendavid in eine „Krankengeschichte“ verwandelt, der nur durch eine Radikalkur beizukommen war. Rose 1998, S. 78.

204 Während Fichte als Schlagwortgeber einer neuen Judenfeindschaft betrachtet werden kann, war für Bendavid die Emanzipation des Judentums ein zentrales Anliegen und seine Enthauptungsmetapher richtete sich vor allem gegen einen von ihm verabscheuten, durch die Geschichte entstandenen „Sklavensinn voriger Jahrhunderte“, den er anders als Dohm nicht als sich selbst verbessernd betrachtete. Zu Bendavids Text als schonungsloser jüdischer Selbstkritik, die nichtsdestoweniger nichts mit „Selbsthass“ zu tun hat, s. Schulte 2002, bes. S. 107-114. 
Judentums. ${ }^{205}$ Einer der wenigen, der diese neue Qualität zeitnah erkannte und benannte, war der jüdische Aufklärer Saul Ascher. Als wesentlichen Unterschied benannte Ascher weitsichtig die Absicht Fichtes, mit seiner Schrift den Judenhass nicht mehr religiös und kirchengeschichtlich, sondern politisch rassistisch untermauern $\mathrm{zu}$ wollen. ${ }^{206}$

1799 bekam die Debatte um die Integration der Juden neue Impulse durch einen anonymen offenen Brief „von einigen Hausvätern jüdischer Religion“, in dem diese einen Vorschlag zur formellen Konversion der preußischen Juden unterbreiteten. ${ }^{207}$ Dieses Sendschreiben an den liberalen Propst Teller bot als möglichen Schritt zur Gewinnung der Bürgerrechte die Aufgabe der jüdischen Zeremonialgesetze und sogar die Taufnahme an, wenn den ,neuen' Christen einige Elemente des Christentums, wie etwa die Annahme der Dogmen, erlassen werden könne. Das Sendschreiben, dessen Autorschaft durch David Friedländer bald bekannt wurde, löste eine Flut von Gegenschriften von christlicher und jüdischer Seite aus. Mit seiner Distanz gegenüber den Zeremonialgesetzen und dem Messiasglauben entfernte sich Friedländer 16 Jahre nach Jerusalem deutlich von den Überzeugungen seines Lehrers Mendelssohn. Die Antwort des Propstes mag hingegen als typisch für die fortgesetzte preußische Dialektik gelten: Er begrüßte das Vorhaben als Theologe, hielt sich aber in Fragen des Staatsrechts deutlich zurück. ${ }^{208}$ Die Reaktionen auf Friedländers Initiative wie-

205 Bruer spricht von drei Phasen der Debatte. In der ersten von 1780 bis etwa 1793 dominierten Fragestellungen, die von Mendelssohn, Lessing und Dohm vorgegeben waren. In einer zweiten Phase bis 1799 war die Aufklärung nicht mehr die dominierende Position, es wurden unterschiedliche Antworten auf die Integrationsfrage gegeben, vor allem unter dem Einfluss der Frühromantik und der kantischen Philosophie. Die dritte Phase 1799-1803 habe dann den Niedergang der Aufklärung belegt. Bruer 1991, S.174 ff. Wenn auch Fichte die Formel „Staat im Staate“ auf verschiedene Bevölkerungsgruppen anwandte, die einer Reform im Wege stünden, so zum Beispiel der Aristokratie, war die Separierung der Juden seiner Meinung nach ,naturgegeben', da sie durch die Religion bestimmt sei. Tatsächlich diente Fichtes Zitat dem Antisemiten Grattenauer zehn Jahre später als wesentlicher Beleg einer Verschwörungstheorie. [C. W. F. Grattenauer]: Wider die Juden. Ein Wort der Warnung an alle unsere christliche [sic] Mitbürger. Berlin 1803, S. 8.

206 Saul Ascher: Eisenmenger der Zweite. Nebst einem vorangesetzten Sendschreiben an den Herrn Professor Fichte in Jena, in: ders.: 4 Flugschriften. Eisenmenger der Zweite Napoleon - Die Germanomanie - Die Wartburgfeier. Berlin 1991, S. 5-80. Zu Aschers Rolle in der zeitgenössischen Publizistik vgl. Schulte 2002, bes. S. 185 ff. S. a. die Rehabilitierung Aschers als „Vernunftdoktor“ bei Peter Hacks: Ascher gegen Jahn. Ein Freiheitskrieg, in: Peter Hacks: Werke, Bd. 14: Die Maßgaben der Kunst II, Berlin 2003, S. 321-448.

207 [David Friedländer]: Sendschreiben an seine Hochwürden, Herrn Oberconsistorialrath und Probst [Wilhelm Abraham] Teller in Berlin. Von einigen Hausvätern jüdischer Religion, Berlin 1799.

208 In der Forschung wurde das Sendschreiben sehr unterschiedlich interpretiert: Die jüdische Geschichtsschreibung des 19. Jahrhunderts kritisierte Friedländer für die 
sen darüber hinaus auf eine deutliche Tendenzwende in der zeitgenössischen Interpretation des Verhältnisses von Staat und Religion. ${ }^{209}$ Friedrich Schleiermacher, der anonym, aber deutlich antwortete, betonte den Stellenwert ,wahrer' religiöser Empfindung und lehnte Friedländers Angebot rundweg ab.210

Die Zahl der Schriften ging zurück, ${ }^{211}$ bis die Debatte in den Jahren 1803 bis 1805 - besonders durch die Schriften des Antisemiten Carl Wilhelm Grattenauer - in derartigen Pamphletismus ausartete, dass die Obrigkeit einschritt und weitere Publikationen verbot. ${ }^{212}$

Wirkliche Veränderungen für die Juden in Preußen brachten die Stein-Hardenbergschen Reformen seit 1808. ${ }^{213}$ Bedeutsam ist die Diskussion um die Judenemanzipation in Vorbereitung des so genannten Emanzipationsediktes, da einige der Gutachten weit über die schließlich gewährten Rechte hinausgin-

angenommene Absage an das Judentum. In jüngeren Interpretationen wird hingegen diskutiert, ob Friedländer sich seiner Provokation wohl bewusst war und sie einsetzte, um Zeitgenossen ihre Situation drastisch vor Augen zu führen. Feiner 2007, S. 401. Schoeps sieht das Sendschreiben als beispielhaft für die vielfältigen Bemühungen der Juden, die Anpassungsforderungen der christlichen Umwelt zu „entschärfen“. Julius H. Schoeps: Tradition und Neubeginn. Innerjüdische Reformen 1750-1870, in: ders. / Grözinger/ Mattenklott 2001, S. 15-38, hier S.16. Michael A. Meyer weist auf das Paradox hin, dass in dieser scheinbaren Absage an das Judentum großes jüdisches Selbstbewusstsein zum Ausdruck komme und liest es daher als Apologie. Meyer 1994, S. $81 \mathrm{f}$.

209 Den Begriff Tendenzwende für diesen Zusammenhang übernehme ich von Bruer 1991, S. $201 \mathrm{f}$.

210 [Friedrich Schleiermacher]: Briefe bei Gelegenheit der politisch theologischen Aufgabe und des Sendschreibens jüdischer Hausväter, Berlin 1799. Die Forderung, dass vor den Bürgerrechten die Konversion stehen müsse, schade dem Christentum. Es müsse daher eine Möglichkeit geben, Staatsbürger zu werden und Jude zu bleiben (wobei er den angebotenen Abstand von den Zeremonialgesetzen deutlich begrüßte). Vermutlich ist Meyers Deutung richtig, dass Schleiermachers Hinweis, wie weit die Juden sich von den Forderungen Mendelsohns bereits verabschiedet hätten, für Friedländer schmachvoll gewesen ist. Meyer 1994, S. $90 \mathrm{f}$.

211 Eine zeitgenössische Sammelrezension formulierte bedauernd: „Wenn nun auch die Akten noch nicht ganz geschlossen seyn sollten; so scheinen sie doch reponirt zu seyn; indem der Staat [...] noch gar keine Notiz davon genommen hat, und die Hauptpersonen noch keine weiteren Schritte gethan haben.“ [Anon.]: „Protestantische Gottesgelahrtheit“, in: Neue allgemeine deutsche Bibliothek, Bd.57, 2. St. (1801), S. 270-293, S. 271.

212 Der Preußische Justizkommissar Grattenauer publizierte 1803 mindestens drei antisemitische Pamphlete. Auf „Wider die Juden“ folgte noch eine „Erklärung an das Publikum über meine Schrift: Wider die Juden von C. W. F. Grattenauer, Berlin 1803 und C. W. Grattenauer's Erster Nachtrag zu seiner Erklärung über seine Schrift „Wider die Juden“, Berlin 1803. Der erste Band, eine polemische Ansammlung antijüdischer Stereotype, schaffte 1803 allein sechs Auflagen. Die Gegenstimmen waren wenig durchsetzungsstark.

213 Die Städteordnung von 1808 machte es beispielsweise möglich, dass auch jüdische Bürger städtische Ehrenämter erlangten, so wurde David Friedländer Stadtrat. 
gen. ${ }^{214}$ Im Zusammenhang mit dieser Arbeit ist der Entwurf Wilhelm von Humboldts doppelt interessant, da hier ein ehemaliger Salongast die liberalsten Forderungen formulierte, sich gegen eine Erziehungsfunktion des Staates ebenso deutlich aussprach wie gegen eine schrittweise Emanzipation. ${ }^{215}$ Weitsichtig begründete Humboldt die Notwendigkeit sofortiger Gleichstellung: „Mag das Volk auch noch so viele gut geartete Juden sehen; es wird nie leicht dadurch $\mathrm{zu}$ anderen Meinungen über die Juden als solche selbst kommen, sondern die Einzelnen nur immer als Ausnahme betrachten“. ${ }^{216}$ Bemerkenswert ist Humboldts Gutachten auch deswegen, weil es einen grundsätzlichen Glauben an das Konzept des Nationalcharakters der Juden mit Forderungen nach gleichen Rechten für alle verband, und diffamierende Gerüchte, wie die von Michaelis beschworene „Gefahr, dass die Juden die Christen verdrängen würden“, deutlich in den Bereich des „Chimärischen“ verwies. ${ }^{217}$ In das Spannungsfeld zwischen Salons und Emanzipation im Reformzeitalter gehört aber nicht nur Humboldts Gutachten, sondern auch die eher unentschiedene Haltung des mehrjährigen Innenministers Graf Alexander von Dohna-Schlobitten, der ebenfalls Gast jüdischer Salons und langjähriger Verehrer von Henriette Herz gewesen war. ${ }^{218}$ Und in dieses Umfeld gehört auch die Gründung der Deutschen Tischgesellschaft 1811, eines nationalkonservativen Vereines, der auch als Gegenentwurf zum Salon gedeutet wurde, da seine Statuten Juden, „Philister“ und Frauen explizit ausschlossen. ${ }^{219}$ Die Tischgesellschaft, zu deren

214 Verschiedene von der Regierung angefertigte Gesetzesentwürfe gingen drei Jahre zwischen einzelnen Behörden zur Begutachtung hin und her. Die wohl ausführlichste Darstellung der Entstehungsgeschichte findet sich bei Alfred Stern: Abhandlungen und Aktenstücke zur Geschichte der preußischen Reformzeit 1807-1815, Leipzig 1885, S. 227262.

215 Rürup nennt Humboldts Gutachten „eines der bedeutendsten Dokumente emanzipatorischen Denkens überhaupt“ Rürup 1987, S. 38. Wesentlich ist, dass Humboldt den Staat grundsätzlich nicht als Erziehungs-, sondern Rechtsinstitution betrachtete und das Konzept der stufenweisen Emanzipation ausdrücklich ablehnte. Der Staat müsse mit vorurteilsloser Denkungsart beispielhaft vorangehen bzw. diese befördern. Die Betrachtung von Menschen nicht als Individuen sondern als „zu einer Race gehörig und gewisse Eigenschaften gleichsam notwendig mit ihr teilend“, nannte Humboldt „inhuman“. Ebd. Wie Erb und Bergmann betonen, wies Humboldt „mit einmaliger Klarheit“ nach, dass ein Staat die Bürgerwerdung gar nicht überprüfen könne, denn mit Tabellen, wie viele Juden Soldaten geworden seien, wäre es nicht getan. Erb / Bergmann 1989, S. 37, Fn. 78.

216 Humboldt 1971, S. 115. Humboldt führt Gründe der Gerechtigkeit sowie politische und pragmatische Gründe an.

217 Humboldt 1971, S. 119.

218 Zu Graf von Dohna, der der verwitweten Henriette Herz mehrere Heiratsanträge gemacht haben soll, s. Bruer 1991, S. 278.

219 Als umfassende Monografie dazu Nienhaus 2003, sowie zuletzt, mit guter politischer Analyse und allerdings veralteter Sicht auf den Salon, Puschner 2008, S. 268-298. 
Mitgliedern auch ehemalige Salonbesucher wie Graf Dohna, Friedrich Schleiermacher, Achim von Arnim und Clemens Brentano gehörten, wurde für ihre deutlich antijüdischen Texte bekannt. ${ }^{220}$ Wie sehr nicht nur in der Junkerschaft, sondern auch im progressiv arbeitenden Beamtenapparat noch Vorurteile gegen das Judentum bestanden, zeigt die Kontinuität der Formulierungen. Noch 1808 wurde ein Entwurf zur gesetzlichen Verbesserung der Juden erbeten als Mittel, um die Juden „zwar unblutig, jedoch auf einmal todtzuschlagen“.221

Das so genannte Emanzipationsedikt vom 11.3.1812 gehörte in den Gesamtzusammenhang der ,Revolution von oben'.222 Das Gesetz machte alle Juden mit sofortiger Wirkung zu „Einländern“ und preußischen Staatsbürgern, die speziellen Auflagen und Beschränkungen wurden aufgehoben, Zugang zu akademischen Berufen gesichert.223 Der Zugang zu Staatsämtern allerdings blieb späteren Regelungen vorbehalten, eine Beratung mit den Juden über die Anpassung ihrer religiösen Praxis und Erziehung wurde angeraten. ${ }^{224}$ Da in einzelnen Staaten unter französischer Besatzung bzw. nach den Reformen den Juden unterschiedliche Rechte zugesprochen worden waren, wurde die Judenemanzipation Teilthema des Wiener Kongresses. Allen Bemühungen Einzelner zum Trotz einigte sich der Wiener Kongress letztlich nur auf eine Gewährung der von den einzelnen Bundesstaaten gewährten Rechte, nicht der in ihnen existierenden. Damit war die Gleichstellung in den Ländern, in denen sie unter französischer Besatzung eingeführt worden war, faktisch annulliert. So war vorerst das letzte gesetzliche Wort zur Judenemanzipation gesprochen, es folgte eine Phase der allgemeinen Reaktion, die vor allem polemische Worte und viele Rücknahmen des bisher Errungenen in Einzelstaaten mit sich brachte. ${ }^{225}$

Die Salonfrauen erlebten 1819 noch ein erneutes Aufflackern tätlicher Ausschreitungen gegen die jüdische Bevölkerung, die so genannte „Hep-Hep-

220 Sodass sie gewissermaßen als literarisch verbrämte Reaktion auf Reformbestrebungen vor allem im landwirtschaftlichen Besitzrecht angesehen werden kann, da u. a. Juden nun Güter besitzen dürfen sollten.

221 So Minister von Schrötters Aufforderung an Kriminalrath Brandt 1808, zitiert bei Stern 1885, S. 228.

222 Walter Grab hat argumentiert, dass „die aus taktischen Gründen der Staatsräson gewährte Judenemanzipation“ keine Breitenwirkung erreichte, weil sie verordnet, nicht erkämpft wurde, wie die Demokratie als Ganzes. Walter Grab: Der deutsche Weg der Judenemanzipation 1789-1938, München 1991, S. 21.

223 Allerdings war die Wirksamkeit des Edikts nur auf das Preußen von 1812 beschränkt und wurde nicht auf die auf dem Wiener Kongress wieder dazu gewonnenen Länder ausgedehnt.

224 Der Hinweis auf die spätere Regelung der Frage der Zulassung zu den Staatsämtern (§15) sowie vergleichbar einer späteren Regelung der Art und Weise der Militäreinberufung wurde auf Wunsch des Königs Friedrich Wilhelm II. eingefügt. Vgl. Stern 1885, S. 260 f. 225 Vgl. dazu Erb / Bergmann 1989. 
Bewegung“, deren schweres Erbe weniger im materiellen Schaden bestand als darin, dass „über der Frage der Judenemanzipation [...] von nun an, von manchen nicht ohne Absicht beschworen, das Damoklesschwert des ,Volkszorns،“ schwebte. ${ }^{226}$ Sie erlebten nicht mehr die Forderungen in der Revolutionszeit, die das Thema völliger rechtlicher Gleichstellung wieder aufs Tapet brachte. Nach einer zweiten Phase intensiver politischer Auseinandersetzung von 1848 bis 1869/71 erlangten die Juden in der Verfassung des Norddeutschen Bundes und dann des Deutschen Kaiserreiches nach knapp einhundertjähriger Debatte schließlich das volle Bürgerrecht.227 Die Tatsache, dass die „Judenemanzipation“ so lange in der Öffentlichkeit verhandelt wurde, hat nach Auffassung einiger Historiker wesentlich dazu beigetragen, die „Judenfrage“ als zeitloses Problem zu betrachten und damit dem Antisemitismus Vorschub geleistet. ${ }^{228}$

\subsection{Die Haskala}

Ein wesentlicher Kritikpunkt an den Darstellungen der Emanzipationsdebatte ist, dass die zahlreichen Berührungspunkte mit den großen innerjüdischen Aufklärungs- und Reformbestrebungen nicht immer ausreichend wahrgenommen wurden. 229 Wenn es um den jüdischen Salon im Schnittpunkt der Emanzi-

226 Rürup 1987, S. 27.

227 Der Norddeutsche Bund erließ das Gesetz, betreffend die Gleichberechtigung der Konfessionen in bürgerlicher und Staatsbürgerlicher Beziehung, das 1871 als Reichsgesetz übernommen wurde. Von zwei „Hauptphasen der Judenemanzipation in Mitteleuropa“, deren erste von 1780-1815 und deren zweite von 1840-1870 dauerte, spricht vor allem Rürup 1987, S. 14 .

228 Eine ausführliche Untersuchung der gesellschaftlichen „Abwehrreaktion“ auf den Prozess der Judenemanzipation bieten Erb / Bergmann 1989. Als ein wesentlicher Grund für das Scheitern der Judenemanzipation wird die unterschiedliche Rechtslage der Juden in den Einzelstaaten betrachtet. Als weitere wesentliche Ursachen gelten das Konzept einer stufenweisen Emanzipation sowie der Versuch, eine Teilgruppe in einer noch nicht (wirklich) emanzipierten Gesellschaft zu emanzipieren. Weiter wurde darauf hingewiesen, dass die Opposition gegen die Judenemanzipation unter Veränderungswilligen sich auch aus der Vorstellung speise, dass andere Emanzipationen wichtiger seien. Aufschlussreich ist der Katalog von ausstehenden Emanzipationen eines Freiherrn von Closen, der von der Emanzipation der Kinder von Unwissenheit und Aberglauben durch bessere Bestellung der Volksschulen bis zur Emanzipation des Geistes von der Zensur reichte, die wichtiger waren als die der Juden. Die Emanzipation der Frau war in seinem Katalog nicht vorgesehen. Vgl. Rürup 1987, S. 44.

229 Noch bis 1999 galt die Haskalaforschung als „Stiefkind“ der Aufklärungsforschung. Christoph Schulte: Einleitung (mit einem Anhang ausgewählter Forschungsliteratur), in: 
pationsdiskurse geht, muss tatsächlich ein dritter großer zeitgenössischer Diskurs hinzu gedacht werden, der zentrale Fragen jüdischen Lebens sowie des Zusammenlebens von Juden und Nichtjuden berührte, die Haskala.230 Die jüdische Aufklärungsbewegung, deren „Vorboten“ bis zum Beginn des 18. Jahrhunderts zurückreichen, ${ }^{231}$ entfaltete ihre größte Wirkungsmacht in den 1780erund 1790er-Jahren, eines ihrer Zentren war Berlin. Nicht wenige Vertreter der Emanzipationsdebatte engagierten sich zugleich für innerjüdische Reformen, wie zum Beispiel Moses Mendelssohn und David Friedländer, um nur zwei der prominentesten jüdischen Aufklärer oder Maskilim zu nennen. Das Verhältnis der Haskala zur gesamteuropäischen Aufklärung ist in der Forschung nach wie vor umstritten, die jüngsten Monografien zum Thema attestieren ihr allerdings die Wirkungsmacht einer kulturellen Revolution, die einen wesentlichen Beitrag zur jüdischen Modernisierung bzw. zur Entstehung einer jüdischen Öffentlichkeit geleistet habe. ${ }^{232}$

Erste Großprojekte der Haskala waren die Gründung der jüdischen Freischule in Berlin 1778, der ersten jüdischen Lehranstalt, die Naturwissenschaften und Unterricht in Deutsch und Französisch in den Lehrplan mit einbezog, ${ }^{233}$ sowie die von Moses Mendelssohn betriebene Übersetzung der fünf Bücher Mose, die Juden das Erlernen der deutschen Sprache am heiligen Text ermöglichen sollte. Das Jahr 1782 markierte einen ersten Höhepunkt der Haskala mit der Gründung der „Gesellschaft der hebräischen Literaturfreunde“ in Königsberg, dem ersten Zusammenschluss jüdischer Gelehrter im nichtreligiö-

ders. / Carsten Zelle: Haskala. Die jüdische Aufklärung in Deutschland 1769-1812, in: Das achtzehnte Jahrhundert. Zeitschrift der Deutschen Gesellschaft für die Erforschung des 18. Jahrhunderts, 23, Heft 2 (1999), S. 143-151, hier S. 148. Grundlegend zum Verhältnis der Emanzipationsdebatte und der Haskala s. den Beitrag von Gerda Heinrich: Haskala und Emanzipation. Paradigmen der Debatte zwischen 1781 und 1812, in: ebd., S. 152-175. 230 Der hebräische Begriff Haskala steht für Bildung und Aufklärung und bezeichnet sowohl die jüdische Aufklärungsbewegung als auch das damit verbundene Zeitalter. Obwohl der Begriff Haskala spätestens seit dem Mittelalter im Sinne von „Vernünftigkeit“ gebraucht wurde, haben die jüdischen Aufklärer um 1800 inn nicht für sich in Anspruch genommen, allerdings ist der verwandte Begriff „Maskilim“ als programmatische Selbstbezeichnung der jüdischen Aufklärer seit 1783 nachweisbar. Schulte 2002, S. 17.

231 Die Datierung der Haskala ist eine noch immer diskutierte Forschungsfrage. Schulte sieht Vorläufer in der mittelalterlichen jüdischen Aufklärungsphilosophie. Schulte 1999.

Feiner sieht „Vorboten“ oder „frühe Maskilim“ schon zu Beginn des 18. Jahrhunderts wirken. Ab den 1770er / 80er-Jahren wird übereinstimmend von einer „Haskalabewegung“ gesprochen.

232 Eine aktuelle Forschungsdiskussion bei Feiner 2007, bes. S. 13-32.

233 Als ausführliche Dokumentation s. Ingrid Lohmann (Hrsg.): Chevrat Chinuch Nearim. Die Jüdische Freischule in Berlin (1778-1825) im Umfeld preußischer Bildungsreform und jüdischer Kultusreform. Eine Quellensammlung, 2 Bde., Münster 2001. 
sen Kontext. Es brachte aber auch einen Kulminationspunkt der Opposition, die die Haskala in der Orthodoxie entfacht hatte. Die Schrift Worte des Friedens und der Wahrheit des Maskil Naphtali Hartwig Wessely, in der er für eine auch weltliche Erziehung plädierte, wurde von einigen Rabbinern verbrannt. ${ }^{234}$ Ebenfalls 1782 wurde von Isaak Euchel ein anderes Großprojekt in die Welt gesetzt, die Zeitschrift Hameassef, [dt. der Sammler], die erste hebräischsprachige Zeitschrift überhaupt und ein wichtiges Forum der innerjüdischen Öffentlichkeit. ${ }^{235}$ Das oben erwähnte Werk Mendelssohns aus dem Jahr 1783, Jerusalem, war gleichermaßen „eine Kampfschrift für Judenemanzipation“ wie „ein philosophisches Werk über das Judentum und dessen Modernisierung“ und muss ebenso in diesem Kontext betrachtet werden wie in dem der Emanzipationsdebatte. ${ }^{236}$ Mendelssohn lehnte nicht nur staatliche, sondern auch rabbinische Oberhoheit in Glaubensfragen ab.

Die Jahre bis 1797, der Einstellung des Hameassef, gelten als Höhepunkt der Haskalabewegung, mit etwa 200 Mitstreitern - Ärzten ebenso wie Lehrern und freischaffende Publizisten -, und einem Zusammentreffen von literarischen, politischen und gesellschaftsreformerischen Interessen.237 Als eine der außergewöhnlichsten und langlebigsten Gründungen im Rahmen der Haskala sollte sich die Berliner „Gesellschaft der Freunde“ erweisen, 1792 als Interessensvertretung junger jüdischer Aufklärer gegründet.238 Ein weiteres außergewöhnliches Ereignis 1792 war die Veröffentlichung von Salomon Maimon's

234 Zwischen 1782 und 1785 publizierte Wessely vier Sendschreiben, die sich mit moderner jüdischer Erziehung befassten, auf Hebräisch. David Friedländer übersetzte das erste Sendschreiben 1782, allerdings nicht wortgetreu, das u. a. Sätze enthielt wie: „die Ausübung jeder Seelenkraft ist Euch vergönnt; das ganze Feld der Künste und Wissenschaften ist euch eröffnet. Macht Euch dieser Rechte würdig.“ Zit. nach: Bruer 1991, S. 120. Shmuel Feiner sieht diesen Vorgang als zentralen Punkt in dem von ihm so benannten „innerjüdischen Kulturkampf“. Feiner 2007, passim.

235 Im Profil wird der Hameassef der Berlinischen Monatsschrift verglichen. Vgl. Andreas Kennecke: „Hame’assef - Die erste jüdische Zeitschrift“, in: Schoeps 2001, S.171-188, bes. S. 178-180. Wie Christoph Schulte betont, galt eine solche hebräische Aufklärungszeitschrift als „geeignetes Propagandainstrument für die Verbreitung der Ideen der Haskala unter den Juden Mittel- und Osteuropas“. Schulte 1999, S. 146.

236 Heinrich 1999, S. 152-175, hier S. 158.

237 Zu dieser Schätzung kommt Feiner 2007, S. 270. Der Beginn der „Bewegung“ wird leicht abweichend datiert: Feiner nimmt das Jahr 1782 als Ausgangspunkt, Schulte sieht die Lavaterdebatte von 1769 als Auslöser.

238 Die Gesellschaft der Freunde bot jungen Maskilim, die als unverheiratete Männer und als Aufklärer einen doppelt schweren Stand in der traditionellen jüdischen Gesellschaft gehabt hatten, ein Forum, alte jüdische Traditionen unter aufklärerischen Vorzeichen zu verfolgen. Die Vereinigung bestand bis 1935. Zu dieser Gründung und Geschichte der Vereinigung s. die herausragende Dissertation Panwitz 2005. 
Lebensgeschichte, der ersten Autobiografie eines jüdischen Philosophen, die den Weg aus dem osteuropäischen Schtetl in die Berliner Aufklärung, aber auch die sozialen Schwierigkeiten eines unangepassten jüdischen Philosophen in der Berliner Gesellschaft schilderte, veröffentlicht für ein mehrheitlich nichtjüdisches Lesepublikum. ${ }^{239}$

Die jüdische Aufklärung war eindeutig ein mehrsprachiges Projekt, zu dem die aktuelle Forschung zwei Interpretationsmodelle anbietet: Christoph Schulte sieht die Haskala als „Aufklärung mit doppeltem Publikum aus Juden und Christen, mit einem jüdischen Binnendiskurs und einem nichtjüdischen Außendiskurs“, womit jüdische Aufklärer eine doppelte Vermittlungsfunktion bekamen. ${ }^{240}$ Shmuel Feiner argumentiert abweichend, dass die Maskilim der ersten Stunde verschiedene Wege gingen, um das Spannungsverhältnis zwischen jüdischer Reform und Anpassung an die christliche Umwelt aufzulösen: Einige Maskilim integrierten sich zunehmend in die nichtjüdische Kultur, ein Teil wandte sich in einer Gegenreaktion der Orthodoxie zu und nur wenige wurden „zur Führung der reifen Haskalabewebung“.241

239 Salomon Maimon's Lebensgeschichte. Von ihm selbst geschrieben und herausgegeben von K[arl]. P[hilipp]. Moritz. In zwei Theilen, Berlin 1792 und 1793. In der Biografie vermischen sich Anekdoten, Lebenserzählung und Philosophie, sie wurde auch als Bildungsroman gedeutet. Vgl. Abraham P. Socher: The Radical Enlightenment of Solomon Maimon. Judaism, Heresy, and Philosophy (Stanford Studies in Jewish History and Culture) Palo Alto 2006.

240 Schulte 2002, S. $30 \mathrm{f}$.

241 Je nachdem, ob Engagement innerhalb der allgemeinen Aufklärung zum Tätigkeitsbereich eines Maskil gerechnet wird, ergeben sich unterschiedliche Wertungen einzelner Personen: so wird etwa Salomon Maimon als bedeutender Außenseiter (Schulte 2002, S. 99-105) oder als „größter Verlust“ der Haskalabewegung“ gedeutet, da er in seinem umfänglichen Werkkatalog, abgesehen von seiner Autobiografie, keine jüdischen Themen aufgegriffen habe (Feiner 2007, S. 110 ff.). Eine der jüngsten Philosophiegeschichten nimmt an, dass Maimon zu gut vertraut war mit allen Aspekten des Judentums, als dass er sich an einem Projekt der Annäherung an den Protestantismus hätte beteiligen können. „Maimon never took part in the attempt to define the ,essence' of Judaism and by this to provide a theology that would imitate and be able to compete with modern Protestant theology. Being thoroughly knowledgeable about the variety of aspects and streams of Judaism, Maimon simply could not participate in this reductive project which unfortunately was quite central to modern Jewish philosophy. “ Peter Thielke / Yithak Melamed: Salomon Maimon, in: Stanford Encyclopedia of Philosophy (2007) unter: http://plato.stanford.edu/ entries/maimon/\#8 (22. 10. 2009). Hervorhebung im Original. Markus Herz gilt als radikaler Maskil oder Wanderer zwischen den Welten der Haskala und der sich assimilierenden jüdischen Intelligenz. Zu Herz in diesem Zusammenhang s. Schulte 2002, S. $163 \mathrm{ff}$. und Feiner 2007, S. 110 ff. sowie Leder 2007, S. 230-264. 
$\mathrm{Zu}$ diesen unterschiedlichen Modellen gehören auch unterschiedliche Datierungen und Wertungen des Endes der Bewegung:242 Wissenschaftler, die die Akkulturation als Parallelerscheinung zur Haskala sehen, datieren das Ende der jüdischen Aufklärung auf 1812, als ihre staatsbürgerlichen Forderungen erfüllt waren. ${ }^{243}$ Forscher, die gesellschaftliche Säkularisierung primär als Gefahr für die innerjüdische Reform betrachten, datieren das eigentliche Ende früher, auf die Jahrhundertwende, und begründen es mit der Konkurrenz der Lebenskonzepte: „Die Krise ist vor allem eine Krise der ,Berliner Haskala‘: [...] Die maskilischen Gesellschaften werden von den Salons überstrahlt, der hame'assef von deutschsprachigen Zeitschriften, die hebräische Kultur von der deutschen und die Maskilim aus den mittleren und niederen Schichten [...] werden von der gehobenen Intelligenz [...] in den Schatten gestellt““.244

\subsection{Zusammenfassung - Parallelen und Überschneidungen der Debatten}

Interessant ist festzuhalten, wo und wie, zum Beispiel über einzelne Personen, die sich für beide Themenkreise engagierten, die zeitgenössischen Diskurse über die Emanzipation der Juden und der Frauen verbunden waren. Auf eine bewusste Verknüpfung der beiden Emanzipationsdebatten durch den Politiker und Autor Theodor Gottlieb von Hippel wurde bereits hingewiesen. Neben der Titelübernahme von Dohm nahm er mit seinem Plädoyer für Bürgerrechte für Frauen auch explizit auf den Emanzipations-Diskurs die Juden betreffend Bezug: „Man hat uns in letzter Zeit so sehr die bürgerliche Verbesserung der Juden empfohlen; sollte ein wirkliches Volk Gottes (das andere Geschlecht) weniger diese Sorgfalt verdienen, als das so genannte“ ?245 Auch in den Argumentationslinien der Texte Dohms und Hippels lassen sich Ähnlichkeiten entdecken, insofern das mindere gesellschaftliche und Bildungs-Niveau der

242 Abgesehen von einem Wiederaufflackern der Bewegung im Osteuropa des 19. Jahrhunderts gilt die jüdische Aufklärung spätestens 1812 mit dem Erreichen zumindest ihrer staatsbürgerlichen Ziele als beendet.

243 Schulte 1999, S. 147 und Schulte 2002, S. 43 f. Lauers Darstellung reicht sogar de facto nur bis zum Auftreten Moses Mendelssohns. Lauer 2008.

244 Feiner 2007, S. 378. Feiner bringt hier den streitbaren Begriff einer „jüdischen Schicksalsgemeinschaft“ ins Spiel. Ebd. Zurecht wurde angemerkt, dass, entgegen seiner sonstigen Darstellung, Feiner mit seiner Datierung zur „germanozentrischen Deutung“ der Haskala zurückkehrt. Moshe Rosman: Haskalah. A New Paradigm, in: Jewish Quarterly Review 97.1 (2007), S.129-136, hier S. 135. Schulte attestiert den Salons keine Mitschuld an diesem Geschehen, sieht sie eher als Beweis dafür, dass die bürgerliche Akkulturation schon vollzogen gewesen sei, während die Debatte darum noch stattfand. Schulte 2002, S. 183.

245 Hippel 1977, S. $20 \mathrm{f}$. 
Frauen bzw. Juden nicht als naturgegeben, sondern historisch gewachsen betrachtet wurde, als Folge der Korruption durch Ausgrenzung und schlechte Erziehung. Die Gewährung von Staatsbürgerrechten bzw. Zugang zu Bildung und öffentlichen Positionen sollte nach beider Autoren Vorstellung aber auch nicht im Handstreich geschehen, sondern im Zusammenhang mit notwendig verbesserter Erziehung und moralischer Besserung. Diese Ambivalenz ist kennzeichnend für den ganz überwiegenden Teil der progressiven Schriften in beiden Debatten, es ging um schrittweise „Besserung“, nicht sofortige Gleichstellung.

Selbstverständlich unterschieden sich die Diskurse zur Emanzipation der Frauen und der Juden wesentlich nach ihren Ergebnissen, der Größe der betroffenen Gruppen sowie dem zeitlichen und qualitativen Verhältnis der Debatte zur Umsetzung der Forderungen. Vergleichbar sind jedoch der publizistische Aufruhr, die Vermengung von Staatsbürgerrechten mit dem „Wesen“ der Betroffenen und die grundsätzliche Tendenz der langsamen Erstarrung, wobei eine Phase der „Verwissenschaftlichung“ der Argumente jeweils einen Prozess abschloss, dessen Anfänge durch eher progressive und ironische Diskussionen gekennzeichnet waren.

Es gibt neben den genannten noch ein kaum erwähntes doppeltes Engagement in der Person des Predigers August Wilhelm Hupel, dessen Werk die Vermutung unterstützt, dass in beiden Debatten in der Frühzeit der 1770erJahre abgewogenere und progressivere Schriften erscheinen konnten:246 Hupel, der 1771 für die Trennung unglücklicher Ehen plädierte und darin für die Selbstbestimmung bzw. für ein Trennungsrecht auch der Frauen argumentierte, veröffentlichte im selben Jahr eine Verteidigungsschrift gegen die Forderung, dass ,anständige‘ Juden sich taufen lassen müssten. Sein Dienstfreundliches Promemoria an die, welche den Herrn Moses Mendelssohn durchaus zum Christen machen wollen, oder sich doch wenigstens herzlich wundern, daß er es noch nicht geworden ist ${ }^{247}$ enthielt, mit Bezug auf die Mendelssohn-Lavater-Debatte,

246 Hupels aufklärerisch ethnologische Arbeits- und Betrachtungsweise selbst blieb nicht auf die 1770er-Jahre beschränkt, sondern führte noch zu anderen geschlechtspolitisch interessanten Werken. 1791 veröffentlichte er in den „Nordischen Miscellaneen“ die Aufsätze „Über den Werth der Jungfrauenschaft unter Ehsten und Letten“ und „Über das Hauben esthnischer Dirnen“, in denen er Befragungen estnischer und lettischer Bauern zusammenfasste, die u.a. keinen Begriff von Jungfrauenschaft hätten, außereheliche Beziehungen nicht für amoralisch hielten und bei denen alleinstehende Mütter nicht abgewertet würden. Zugleich kritisiert er die Übernahme deutscher Moralnormen durch die estnische Oberschicht. Indrek Jürjö: Aufklärung im Baltikum. Leben und Werk des livländischen Gelehrten August Wilhelm Hupel (1737-1819), Köln 2006, S. 231-234. 247 Vgl. den denkwürdigen Sammelband: Lettres Juives du celebre Mendels-sohn [sic] Philosophe de Berlin. Avec les Remarques et Reponses de Monsieur Le Docteur Kölble et Autres Savants Hommes. Recueil Memorable concernant Le Judaïsme. Frankfurt 1771. 
deutlichen Spott wider den Zeitgeist. Zugleich aber argumentierte der Autor ernst, dass man es einem Gelehrten wie Mendelssohn schon zutrauen könne, sich selbst mit der Frage auseinanderzusetzen. Zudem zweifelte er hellsichtig daran, dass Mendelssohns Übertritt die Frage befrieden werde. Die Reaktion vieler Salongäste auf die getauften Jüdinnen, die „keine echten mehr“ seien, vorwegnehmend, schrieb Hupel: „Alle Achtung, die ein gelehrter Jude bey seinem Volk genießt, so lange er den väterlichen Satzungen treu bleibt, verwandelt sich in unauslöschlichen wohl gar wüthenden Haß, wenn er seine Religion verlässt"..248

Eine personifizierte Überschneidung beider Emanzipationsdiskurse und der Berliner Salons, die so noch kaum Beachtung fand, war wiederum die Schriftstellerin Esther Gad, alias Lucie Domeier. ${ }^{249}$ Bereits einige Jahre vor ihrer Intervention gegen Herrn Campes Behauptungen in der Geschlechterdebatte hatte sie sich öffentlich zur Lage der Juden geäußert. ${ }^{250}$ Dass ihr Engagement und ihre Auffassungen in Berliner Salons bekannt waren, lässt sich zwar nicht durch eine präzise Quelle belegen, ist aber wegen der engen Freundschaft zu Rahel Levin Varnhagen in der Zeit anzunehmen. Dass Esther Gad sich nicht scheute, in geselligen Kreisen über Geschlechterbilder zu streiten und ihre Veröffentlichungen ankündigte, zeigt ihre diesbezügliche Auseinandersetzung mit Jean Paul. ${ }^{251}$

Abschließend sei nochmals betont, dass der grundlegende Abwehrmechanismus gegen die bürgerliche Verbesserung der Frauen wie der Juden derselbe war, sofern die Ursache im „Wesen“ der Emanzipationsobjekte lokalisiert, also als „naturgegeben“ behauptet wurde. Einige wenige Texte machten die Paral-

248 Hupel 1771, S. 11-12. Inwieweit Hupels Texte in den Berliner Salons gelesen wurden, konnte leider noch nicht ermittelt werden.

249 Mit Rücksicht auf die verschiedenen Genres wird sie auch als Reiseschriftstellerin oder Übersetzerin kategorisiert. Vgl. den Eintrag „Domeier, Esther [E. Lucy n. d. Taufe] [geb. Gad; gesch. Bern[h]ard] Übersetzerin“, in: Lexikon deutsch-jüdischer Autoren (Archiv Bibliographia Judaica). Red. Leitung: Renate Heuer, München 1992 ff., Bd. 5, München 1997, S. 487-489. 250 Ein Chronist berichtete „als im Oktober 1786 Friedrich Wilhelm II. sich in Schlesien huldigen ließ, hielt E'G' für die Breslauer Juden eine kurze Ansprache“ und sie überreichte eine Adresse. Aron Heppner: Jüdische Persönlichkeiten in und aus Breslau, Breslau 1931, S. $14 \mathrm{f}$.

251 Unter anderem bemühte sie sich mehrfach darum, dass Jean Paul sie als Schriftstellerin anerkenne. Vgl. Hahn 1990(b), S. 35-46. Eine neuere Deutung zeigt, wie Esther Gad u. a. in ihrer Widerlegung Campes versuchte, „eine literarisch vermittelte Kommunikation mit Jean Paul einzufädeln“ über Geschlechterrollen, und dass Jean Paul seinerseits literarisch antwortete. Andrea Albrecht: Bildung und Ehe „genialer Weiber“. Jean Pauls „Diesjährige Nachlesung an die Dichtinnen“ als Erwiderung auf Esther Gad und Rahel Levin Varnhagen, in: Deutsche Vierteljahresschrift für Literaturwissenschaft und Geistesgeschichte 3/2006, S. 378-407, hier S. 392. 
lele in der Ausgrenzung sogar explizit. ${ }^{252}$ Den niedriger eingestuften Gruppen sei wegen naturgegebener Ungleichheit die Emanzipation zu verweigern: „So wenig jemals Unterthanen mit ihren Regenten, Kinder mit Erwachsenen, Weiber mit Männern [...] gleiche Rechte und Freyheiten erhalten, so wenig können Juden und Neger, so lange sie Juden und Neger sind, mit den Christen und Weissen, unter welchen sie wohnen, oder denen sie gehorchen, dieselbigen Freyheiten und Vorrechte verlangen“.253

Aber auch einer der progressiven Denker, Wilhelm von Humboldt, sprach von Nationalcharakter und Geschlechtscharakter als wesentlichen Kriterien jeder „Anthropologie“. Es ist daher zu fragen, inwieweit die Grundannahme unveränderlicher, durch die Geburt vorgegebener Konstanten im Menschsein die Debatten um 1800 nicht ebenso geprägt haben kann wie Antifeminismus und Antisemitismus.

Gemeinsam war beiden Debatten schließlich auch, dass Streiter für die Emanzipation auf die Dialektik des Ausschlusses deutlich hinwiesen: Moses Mendelssohn beklagte beispielsweise den fortgesetzten Ausschluss der Juden aus Wissenschaft, Künsten und nützlichen Gewerben und beklagte die Ironie: Man „versperret uns alle Wege zur nützlichen Verbesserung, und macht den Mangel an Cultur zum Grunde unserer ferneren Unterdrückung“.254 Ähnlich wies unter anderem Hippel darauf hin, dass man den Frauen das Talent für Kanzeln und Richterstühle nicht absprechen könne, wenn man ihnen das Recht, sich auf diesen auszuprobieren, noch nie gewährt habe. Viele Schriften wiesen darauf hin, dass die bisherige Erziehung und Behandlung die wesentliche Ursache der scheinbar mangelnden Fähigkeiten der Frau oder der Juden sei und forderten eine Übergangsphase des Probierens.

252 So der Göttinger Philosoph Meiners, der nicht nur Männer und Frauen hierarchisch betrachtete, sondern auch eine Dichotomie von „Hauptstämmen“ der Menschheit entwickelte, die sich nach Physis und Moral unterschieden. Dabei sei der „Kaukasische“ Stamm viel stärker und moralischer als der „Mongolische“. Christoph Meiners: Grundriß der Geschichte der Menschheit, Frankfurt [u. a.] 1786, S.3a-4a. Naoke Yuge hat am Beispiel Meiners' und Pockels' gezeigt, dass die Muster, nach denen „Wilde“ definiert bzw. kreiert wurden, denen des Geschlechterdiskurses vergleichbar sind. Naoko Yuge: Das „wilde“ und das „zivilisierte“ Geschlechterverhältnis? Die neue Blickrichtung in der anthropologischen Diskussion um 1800, in: L'Homme. Europäische Zeitschrift für Feministische Geschichtswissenschaft, 13,2 (2002), S. 205-223.

253 Christoph Meiners: Über die Natur der afrikanischen Neger und davon anhangenden Befreyung, oder Einschränkung der Schwarzen. 1790. Mit einem Nachwort hrsg. von Frank Schäfer, Hannover 1998, S. 6.

254 Mendelssohn 1983(a), S. 6. 


\section{Der Berliner Salon im Schnittpunkt der Diskurse. Konsequenzen für die Untersuchung}

Der Berliner jüdische Salon wurde in diesem Kapitel in zeitlichen Zusammenhang mit drei Emanzipationsdebatten gestellt. Festhalten lässt sich zunächst jenseits der Diskursivität: Mit dem örtlichen Nebeneinander in Berlin und der zeitlichen Überschneidung der so genannten „Blütezeit“ der Salons, mit Höhepunkten aller drei Diskurse in den 1790er-Jahren, war der Salon allerdings „Zeitgenosse“ dieser Debatten, er war zudem Treffpunkt vieler Debatteure. So verkehrten zahlreiche Autoren der Werke, die heute als grundlegend für die Debatten gelten, zu der Zeit der Entstehung ihrer Texte in den Häusern jüdischer Frauen: Wilhelm von Humboldt, Friedrich Schlegel und Friedrich Schleiermacher verfassten ihre grundlegenden Arbeiten zur Geschlechtscharakterdebatte zum Zeitpunkt intensiver Bekanntschaften mit Salonièren; Christian Conrad Wilhelm von Dohm und wiederum Wilhelm von Humboldt, zentrale Protagonisten in der Geschichte der preußischen Judenemanzipation, waren unter anderem Stammgäste des Hauses Herz. Mit Markus Herz und Moses Mendelssohn wurden zwei wesentliche ,Verwandtschaftsbeziehungen' des Salons zur Haskala genannt.

Die personelle Überschneidung der Salons und der zeitgenössischen Emanzipationsdiskurse wirft die Frage auf, welche Wechselwirkungen zwischen der spezifischen Form der Salongeselligkeit und den Debatteuren bestanden haben können. $\mathrm{Zu}$ prüfen ist auch, welchen Einfluss das Salongeschehen auf die beteiligten Männer hatte - emanzipierten sich deren Gedanken und Rollenvorstellungen durch eine von jüdischen Frauen geprägte Geselligkeit? Im Gegenzug muss gefragt werden, welche Geschlechter- und Emanzipationsmodelle in den Salons diskutiert, entworfen, möglicherweise rezipiert oder persifliert wurden. Wurde den theoretischen Entwürfen der Diskurse Beifall gezollt oder widersprochen? Welchen Stellenwert maßen die Frauen der Salons Texten bei, die heute zum Teil als grundlegend gelten?

\section{Neue Fragen zum Verhältnis Salon und Judenemanzipation}

Bei der Untersuchung der Verbindung zwischen Salons und jüdischen Emanzipationsdebatten kann es weder darum gehen, den Salons pauschal den Status einer Institution größerer öffentlicher Wirkung zuzuschreiben, noch eine Verbindung gänzlich zu leugnen. Die Salonfrauen waren nicht nur Zeitgenossen des widersprüchlichen Emanzipationsprozesses der Juden in Deutschland, sie waren unmittelbar betroffen, hatten Grund, für sich und andere auf rechtliche Verbesserung zu hoffen. Darüber hinaus waren die Salonfrauen mit einigen Agenten des Prozesses verwandt oder befreundet. Es besteht durchaus Grund 
für die bisher nicht summarisch gestellte Frage, ob und wie sich Salonfrauen mit den Forderungen nach Emanzipation identifiziert haben. ${ }^{255}$ Kapitel III fragt daher exemplarisch am Beispieljahr 1794/95, welche Texte oder Entwürfe sie diskutiert und wie sie sich in dem Prozess positioniert haben.

Der Gegenfrage, ob und inwieweit der Salonbesuch Einfluss auf die spätere Haltung und Handlungen der Salonbesucher hatte, wird in Kapitel IV und V nachgegangen. Zwar scheint die oberflächliche Reihung „Wilhelm von Humboldt: vom Herzschen Salon zum Wiener Kongress“ in biografischer Hinsicht wie als Klammer für eine geistesgeschichtliche Epoche reizvoll und wird nicht selten aufgemacht. ${ }^{256}$ Dennoch war das Verhältnis der genannten Debatteure zu den Salonièren, ihren jüdischen Bekannten beziehungsweise ihrer Haltung zur Situation des Judentums bisher kaum Gegenstand längerer Untersuchungen. Die Arbeiten, die dieses Thema streifen, kommen überdies zum Teil zu sehr unterschiedlichen Auffassungen, wie sich am Beispiel eben dieses heute prominentesten Debatteurs zeigt:257 In den Biografien zu Humboldt wird auf sein Verhältnis zu den Berliner Salonièren kaum näher eingegangen, wenngleich die Biografen seine Beziehung zu Henriette Herz ebenso deutlich $\mathrm{zu}$ kennen glauben wie sie sie unterschiedlich werten, als Liebhaberin, mütterliche Freundin oder Muse. ${ }^{258}$ Humboldts Besuchen bei ihr und anderen jüdischen Salonièren wird, je nach Perspektive und oft pauschal, kein oder großer Einfluss auf sein politisches Denken attestiert. Ähnlich randständig und widersprüchlich sind Äußerungen zu dem möglichen Zusammenhang der Ausbildung Humboldts in einem christlich-jüdischen Umfeld und seinem späteren

255 Wie in II erwähnt, gehen einzelne Biografen selbstverständlich, in oft unterschiedlicher Deutung, auf das Thema Emanzipation ein, vgl. besonders Spiel 1962.

256 Beispielsweise diskutiert Albert Bruer in seiner Geschichte der Juden in Preußen die Vergangenheit Humboldts „als Salon-Mann und Liebhaber der Henriette Herz“ als mögliches Motiv für sein Engagement, findet es aber nicht ausreichend. Bruer 1991, S. 287-289.

257 Vgl. dazu auch V.

258 Bruer bezeichnet Humboldt als Liebhaber der Herz, Steinberg ist hingegen überzeugt, dass sie ihn körperlich auf Abstand gehalten und ihren Mann dies Verhältnis nur amüsiert habe. Bruer 1991, S. 287 f. Heinz Steinberg: Wilhelm von Humboldt (Preußische Köpfe, 32), Berlin 2001, S. 12 f. Eine mehr als platonische Liebe ist insofern abwegig, als Humboldt noch 1817 seiner Frau schreibt, er habe die Herz jetzt zum ersten Mal in kurzen Ärmeln gesehen. Eduard Spranger deutet ihr Interesse als ein mütterliches (was bei einem Altersunterschied von drei Jahren unwahrscheinlich ist) und Kähler sieht Humboldt als ihren Schüler und ihre Beziehung als ein „moralisches Experiment im schlechten Stile der Zeit“. Beides nach Siegfried A. Kähler: Wilhelm von Humboldt und der Staat. Ein Beitrag zur Geschichte deutscher Lebensentwürfe um 1800, Göttingen 1963, S. 70 bzw. 457. 
Engagement für die Gleichstellung. ${ }^{259}$ Ein lohnendes, noch relativ unbearbeitetes Forschungsfeld ist die intellektuelle Auseinandersetzung Humboldts mit Vertretern der Haskala. ${ }^{260}$

Die vorliegende Arbeit analysiert Wilhelm von Humboldts Verhältnis zu den Salonièren und zur jüdischen Bevölkerung aus der neuen Perspektive des Vergleichs mit seinen langjährigen Freunden und Salonbesuchern Friedrich von Gentz und Gustav von Brinckmann, zu deren Umgang in den Salons es bisher wenig Literatur gibt [vgl. IV]. Friedrich von Gentz' Briefwechsel mit Rahel Levin Varnhagen, als einer der wenigen gedruckt, wurde sehr unterschiedlich gewertet, ${ }^{261}$ meist im Zusammenhang mit den hier diskutierten Geschlechterrollen, nicht seinem Verhältnis zu jüdischen Freunden.

259 Auch hier stehen sich ebenso kurze wie gegensätzliche Deutungen gegenüber. Von den bekannteren Biografien zu Humboldt deutet Scurla die zunehmende Distanz und „die Verhöhnung der Gesprächspartner in den Berliner Salons“ als Ausdruck einer allgemeinen „Unzufriedenheit mit sich selbst“ und mit seinem Berliner Umfeld. Herbert Scurla: Wilhelm von Humboldt. Werden und Wirken, Düsseldorf 1976, S.78. Berglar vermutet, dass Humboldt sich aus dem Umgang in den Salons ein gewisses „Kunst- und Künstlerverständnis“ bewahrt habe und sieht keinerlei Zusammenhang mit dessen späterer Haltung zur Judenemanzipation. Peter Berglar: Wilhelm von Humboldt. Mit Selbstzeugnissen und Bilddokumenten, Reinbek 1991, S. 26. Spiel geht hingegen davon aus, dass Humboldt sich als Schüler von Markus Herz und Freund von dessen Gattin Henriette in Preußen und auf dem Wiener Kongress konsequent für die Gleichstellung der Juden eingesetzt habe. Spiel 1962, S. 358 ff. und 438 ff. Siegfried Kähler erwähnt Humboldts Beziehungen zu Rahel Levin Varnhagen, Dorothea Schlegel und Henriette Herz allerdings überhaupt nicht unter dem Aspekt ihrer jüdischen Herkunft. Auch die Einzelheiten der politischen Laufbahn Humboldts sind in dieser intellektuellen Biografie untergeordnet. Einerseits ist Kählers Wahrnehmung dieser Frauen unabhängig von der Herkunft emanzipierter als diejenige seiner meisten Biografen-Kollegen, andererseits übersieht er dabei, dass Humboldt selbst innen eine spezielle „pikante“ Note attestierte, die nur jüdische Frauen besäßen.

260 Wilhelm von Humboldts Bekanntschaft mit dem Aufklärer Dohm, der ihn und seinen Bruder zeitweilig unterrichtete, seine Freundschaft zu den jüdischen Gelehrten David Friedländer und Israel Stieglitz werden in einigen Biografien erwähnt, jedoch kaum in ihrer Entwicklung dargestellt. Eine Dissertation über Humboldts Verhältnis zur Aufklärung liegt schon vor, leider ohne besondere Berücksichtigung etwa David Friedländers oder Markus Herz', die in den 1780er-Jahren wesentliche Gesprächspartner Humboldts waren. Christina M. Sauter: Wilhelm von Humboldt und die deutsche Aufklärung (Historische Forschungen Bd. 39), Berlin 1989. Wegweisend zuletzt: Julius H. Schoeps: Im Kreise der Aufgeklärten. Der Einfluss Moses Mendelssohns und David Friedländers auf die Reformkonzepte Wilhelm von Humboldts, in: Zeitschrift für Religions- und Geistesgeschichte 3/2010, S. 209-226.

261 Während Gentz' Herausgeber diese Briefe als „romantisierende Schamlosigkeit“ bezeichnen, finden moderne Interpretationen hier vor allem Hinweise auf ein modernes Rollenverständnis der Briefpartner. Wittichen 1910, S.13 f. Vgl. vor allem Juliane Vogel: 
Der Zusammenhang zwischen jüdischen Salons und innerjüdischen Reformdebatten ist, wie angedeutet, erst in Monografien der jüngeren Zeit thematisiert worden. ${ }^{262}$ Abgesehen von der interessanten Deutung, dass das Frauenbild der Maskilim weibliche Diskursfähigkeit nicht einschloss ${ }^{263}$ - was sie tatsächlich als ,typische“ Aufklärer kennzeichnete -, gab es doch zahlreiche familiäre und freundschaftliche Beziehungen, die sich näher auf die Frage hin untersuchen lassen müssten: Waren Salons auch Foren der entstehenden jüdischen (Teil)-Öffentlichkeit bzw. gab es Schnittmengen der Debatte, oder waren sie ein Parallelphänomen, wie es Shmuel Feiner formuliert, Teil einer individualistisch orientierten Kultur- und Finanzelite, die sich für innerjüdische Belange nicht interessierte?264

Mit Moses Mendelssohn und Markus Herz waren zwei der einflussreichsten Maskilim der älteren Generation der Vater, Mentor bzw. der (wesentlich ältere) Gatte mehrerer bekannter Salonfrauen. Ob und wie deren Arbeit, sowohl für innerjüdische Reform wie für bürgerliche Verbesserung im engeren Familienzusammenhang rezipiert wurde, ist leider mangels entsprechender Familienbriefe kaum zu rekonstruieren. Zusammengetragen werden in dieser Arbeit stattdessen Bezugnahmen auf Moses Mendelssohn in den Briefwechseln der Salongesellschaft, die es, anders als oft behauptet, durchaus gegeben hat. Vor dem Hintergrund des unter I. beschriebenen Umstandes, dass jüdische Gäste

Briefwechsel und Geschlechtertausch: Rahel Varnhagen und Friedrich Gentz, in: Christa Hämmerle / Edith Saurer (Hrsg.): Briefkulturen und ihr Geschlecht. Zur Geschichte der privaten Korrespondenz vom 16. Jahrhundert bis heute, Weimar [u. a.] 2003, S. 55-70. Eine detaillierte Analyse dieser Korrespondenz hat Barbara Hahn vorgelegt, die sie als ein briefliches „sich Verfehlen“ charakterisiert. Hahn 1990(a), besonders S.77-100, hier S.77. 262 Das Verhältnis der jüdischen Salons zur Haskala ist, sofern es überhaupt thematisiert wird, umstritten. Die Sonderstellung Berlins machte es möglich, dass Salons entstanden, die Rürup als Ausdruck eines „Emanzipationsanspruchs“ sieht, der nicht länger auf die Regierung warten wolle. Rürup 1987, S.22. Vergleichbar der Emanzipationsdebatte sehen Forscher, die dem Salon gesellschaftliche Prominenz attestieren, eine Gefahr des zu starken Werbeeffekts für Akkulturation.

263 Feiner 2007, S. 249. Wichtiger ist der Hinweis, dass die Veröffentlichung auf Hebräisch tatsächliche viele jüdische Frauen (und weniger gebildete Männer) als Publikum ausschloss. 264 Shmuel Feiner entwickelt in seiner Historiografie der Haskala zur Erklärung ihres Niedergangs u. a. das Modell konkurrierender Eliten in Berlin. Neben den Maskilim und den Orthodoxen habe es eine gewisse individualistisch orientierte Kulturelite gegeben, die sich für innerjüdische Belange nicht interessiert habe. Zu dieser sich vorschnell akkulturierenden Gruppe zählt Feiner, wenn auch nicht ausführlich belegt, einige Salonièren, denen er in angenommener Prominenz damit negative Auswirkung attestiert. Feiner 2007, S. 329-332. Feiners Aussage, der jüdische Salon entbehre jeglichen jüdischen Diskurses steht in klarem Gegensatz zu neueren Ergebnissen der Salonforschungen, u. a. zu jüdischen Themen in Briefwechseln der Familie Levin. 
des Salons bisher von der Salonforschung weitgehend ignoriert wurden, wird in dieser Arbeit exemplarisch am Beispiel der ausgewählten Protagonistinnen nach Hinweisen darauf gesucht, ob und welcher Kontakt zwischen den Salonfrauen und denen als jüngere Maskilim bekannt gewordenen jüdischen Männern ihrer Generation bestand, welche Texte und Themen diskutiert wurden.

\title{
Forschungsfragen zum Verhältnis Salon und Geschlechterdebatte
}

\author{
Allein hundertmal lieber würde ich ein Mädchen von einfacher und gewöhnlicher Erzie- \\ hung nehmen, als eine Gelehrte und einen Schöngeist, \\ die in meinem Hause einen literarischen Gerichtshof errichten \\ und sich zur Präsidentin desselben aufwerfen würde. \\ Jean Jacques Rousseau, Philosoph und Salonbesucher ${ }^{265}$
}

Die Rekonstruktion eines Debattenstranges wie jenes zur Geselligkeit legt den Schluss nahe, dass zeitliche und personelle Überschneidungen nicht notwendigerweise bedeuteten, dass männliche Salongäste progressive Geschlechterbilder an die Öffentlichkeit brachten - ein Befund, mit dem sich der deutsche Salon nahtlos in die internationale Salongeschichte einreiht. Der Widerspruch zwischen dem privaten Umgang mit klugen Frauen im Salon und der öffentlichen Verdammung oder Verbrämung weiblicher Gelehrsamkeit ${ }^{266}$ wurde geradezu als Merkmal europäischer Salongeschichte bezeichnet. ${ }^{267}$

265 Jean Jacques Rousseau: Emil oder Ueber die Erziehung. Frei aus dem Französischen übersetzt von H. Denhardt, 2 Bde., Leipzig 1910, Bd. 2, S.400. Nach Rousseau „erscheinen ihr die Pflichten, die sie als Weib zu verrichten hat, lästig, und sie lässt es deshalb ihr Erstes sein, nach Art des Fräulein von Lenclos den Mann zu spielen.“ Ebd. In späteren Übersetzungen wurde das Wort Gelehrte auch durch Blaustrumpf ersetzt, damit (unbeabsichtigt?) auf den englischen Salon anspielend. Vgl. Jean Jacques Rousseau: Emile oder Über die Erziehung, Stuttgart 1970, S. 818. Daß eine Frau wie Ninon de l'Enclos als zu männlich kritisiert wird, erschließt sich nur, wenn man annimmt, dass den Autoren Gelehrsamkeit bzw. Äußerungen derselben in der Öffentlichkeit als männliches Privileg galten.

266 Der Widerspruch ist keineswegs auf Salongäste beschränkt, sondern findet sich um 1800 bei vielen Männern, die beruflich mit weiblichen Intellektuellen zu tun hatten, so wie Schiller die „Horen“, die Zeitung, die sein eigenes Frauenideal der zurückhaltenden Sanftmut popularisierte, mit Beiträgen weiblicher Autorinnen am Leben halten musste. Janet Besserer Holmgren: The Women Writers in Schiller's Horen: Patrons, Petticoats and the Promotion of Weimar Classicism, Newark 2007.

267 Vgl. das Überblickkapitel „Women in the Salons“ in: Bonnie S. Andersson / Judith P. Zinsser: A History of Their Own. Women in Europe from Prehistory to the Present, 2 Bde., London 1990, Bd.2, S. 103-128. „The men who socialized with the least domestic women of their era idealized a domestic role for all women.“ Ebd., S. 116. 
Die zeitliche und personelle Überschneidung zwischen der Geschlechtscharakterdebatte und den Berliner Salons ist als solche bisher noch nicht Gegenstand einer wissenschaftlichen Untersuchung geworden.268 Einzelne Arbeiten thematisierten ausgewählte Zweierbeziehungen zwischen einzelnen Debatteuren und Salonfrauen, so wurde Henriette Herz ,aus der allgemeinen Situation heraus' als Mitautorin von Schleiermachers Katechismus vermutet, ${ }^{269}$ und Texte Jean Pauls wurden als Fortsetzungen des Salongesprächs analysiert. ${ }^{270}$ Häufiger sind Pauschalisierungen vom großen Einfluss der Frauen auf die Denker oder - im Gegensatz dazu - Bemerkungen über die eher patriarchalen Maximen mancher Salonbesucher. ${ }^{271}$ Eine umfassende Analyse der Wechselwirkungen ist wahrscheinlich kaum möglich, da auch hier die sehr heterogene Überlieferung keine endgültigen Aussagen zur Rezeption der Debatte zulässt und eine Gewichtung verschiedener Aussagen zu nur einem Werk kaum

268 Wenn in der Forschung auf die Zeitgenossenschaft der Salons und der Geschlechterdebatte eingegangen wurde, wurde den Salons meist pauschal ein nicht spezifizierter Einfluss attestiert. Eine erste spezifische Untersuchung zum Spiel mit den Geschlechterrollen findet sich bei Vogel 2003. Zu recht formulierte Ulrike Weckel im jüngsten Forschungsbericht zum Thema als ein zentrales Anliegen: „To what extend hostesses and guests played with gender-specific expectations [...] and perhaps [...] parodied, exaggerated and undermined them, remains to be investigated.“ Weckel 2000(a), S. 336.

269 Schleiermachers „Katechismus“ hat im Zusammenhang mit seiner bekannten Freundschaft zu Henriette Herz einige Aufmerksamkeit erfahren. Unbewiesen bis heute, wurde eine potentielle Autorschaft Herz' am Katechismus zum ersten Mal von denjenigen Schleiermacherinterpreten ins Spiel gebracht, die den Katechismus so aus seiner Philosophie herausragen sahen, dass sie seine Autorschaft für unmöglich hielten, und sie wegen des enthaltenen „Frauenegoismus und Frauenklugheit“ der Salonière zuschrieben. Hermann Walsemann: Schleiermacher und die Frauen, in: Preußische Jahrbücher, Bd. 194 (1913), S. 451-482, hier S. 463 und 460. Siehe dazu auch Anne Conrad: Jenseits der Schranken des Geschlechts. Friedrich Schleiermachers Entwurf einer Religion für eine „religionslose Zeit“, in: Peter Burschel / Anne Conrad (Hrsg.): Vorbild-Inbild-Abbild. Religiöse Lebensmodelle in geschlechtergeschichtlicher Perspektive, Freiburg 2003, S.151-169. In jüngster Zeit haben Schleiermacherbiografien sowie Arbeiten aus dem Bereich der feministischen Theologie einen Zusammenhang mit den Salons vermutet, aber nicht zu rekonstruieren gesucht. Patricia E. Guenther-Gleason: On Schleiermacher and gender politics (Harvard theological studies, 43), Harrisburg PA. 1997, S. 2, Fn. 3.

270 Albrecht 2006 rekonstruiert, wie der Dichter einen persönlichen Disput mit den beiden Salonfrauen „in literarisch virtualisierter Form fortsetzt“. Zugleich zeigt sie Jean Paul als relevanten Beiträger zur Geschlechterdebatte. Ebd., S. 378.

271 So beispielhaft Gerhard Söhn über Schleiermacher, in: ders.: Die stille Revolution der Weiber. Frauen der Aufklärung und Romantik. 30 Porträts, Leipzig 2003, S. 14. Söhn summiert prägnant, wenn auch eher populärwissenschaftlich: „Trotz Aufklärung und zunehmender Präsenz geistvoller Frauen war man um die Jahrhundertwende von jeglicher weibliche Emanzipation noch meilenweit entfernt." Ebd. 
zu leisten ist. Es ist aber anzunehmen, dass pauschale Zuschreibungen eines nachhaltigen Einflusses der Salonièren auf die Debatteure ebenso abzulehnen sind wie das wiederholte Verdikt, dass eine Rezeption progressiver Schriften, wie etwa die Hippels oder Wollstonecrafts, im Salon gar nicht stattgefunden habe. ${ }^{272}$ Letzteres lässt sich in Detailarbeit wiederlegen, beispielsweise durch den Hinweis, dass mehrere Schriften Hippels in Friedrich Schleiermachers Bibliothek standen, unter anderem Über die bürgerliche Verbesserung der Weiber, und dass, wie auch Kapitel III zeigt, Wollstonecrafts Buch von einer Salonfrau empfohlen wurde. ${ }^{273}$

Diese Arbeit behandelt ausgewählte Wirkungs- und Rezeptionszusammenhänge zwischen den Berliner Salons und der Geschlechtscharakterdebatte am Beispiel zwei der prominentesten Texte: Wilhelm von Humboldts Horen-Aufsätzen [III] und Friedrich Schlegels Lucinde [V]. Dabei ergibt sich aus der Zusammenschau der Forschung zu internationalen Salons eine interessante Herausforderung für den Berliner Fall: Während für Frankreich die Genese einer weiblichen Sonderanthropologie - die wissenschaftliche Begründung eines weiblichen Geschlechtscharakters - im direkten Umfeld der Salons nachgezeichnet wurde, ${ }^{274}$ habe in England aber die Existenz des Salons, des Bluestocking Circle, die Prominenz gelehrter Frauen und ihre Betätigung in ,männlichen' Genres, die Entfaltung einer solchen Sonderanthropologie gerade erschwert. 275 Welche Konsequenz hatte dann, wenn überhaupt, die Existenz der Berliner Salons auf die deutsche Geschlechterdebatte? Dabei ist zu beach-

272 So ist Barbara Becker-Cantarinos Aussage, „es gibt kein Anzeichen dafür“, dass Hippel in den Salons „in irgendeiner Weise rezipiert“ wurde, zu absolut. Becker-Cantarino 2000, S. 197.

273 Der Auktionskatalog des Schleiermacher-Nachlasses verzeichnet vier Werke Hippels. Günter Meckenstock (Hrsg.): Schleiermachers Bibliothek. Bearbeitung des faksimilierten Rauchschen Auktionskataloges und der Hauptbücher des Verlags G. Reimer. Im Anhang eine Liste der nichtliterarischen Rechnungsnotizen der Hauptbücher Reimer (SchleiermacherArchiv 10), Berlin [u.a.] 1993, S. 202. Schleiermachers Einbindung in die Geschlechterdebatte ist natürlich darüber hinaus durch seinen Katechismus und seinen engen Umgang mit Friedrich Schlegel während der Entstehungsphase der Lucinde gegeben [s. VI]. Auf Mary Wollstonecraft bezog sich explizit auch Esther Gad in ihren Bemerkungen über Kampe. Gad 1798, S. 577 Fn. Allerdings behauptet sie, das berühmte Buch nicht gelesen zu haben.

274 Honegger 1991. In ihrem Kapitel zur Genese einer weiblichen Sonderanthropologie in Frankreich verweist Honegger mehrfach darauf, dass die Theoretiker in den Salons verkehrten, etwa bei Madame Geoffrin und Madame Helvetius. Honegger 1991, S. 126-167. 275 Ina Schabert hat darauf hingewiesen, dass obzwar die Polarisierung der Geschlechter ein gesamteuropäisches Phänomen des 18. Jahrhunderts war, sich nationale Unterschiede ausmachen lassen. In Frankreich stehe ein materialistisch-anatomisches Erklärungsmodell im Vordergrund, während in Deutschland tendenziell eine philosophische Überhöhung der anatomischen „Ergebnisse“ stattfinde. Schabert 1997, S.43-44. In England sei zwar der kontinentale Diskurs wahrgenommen worden, unter anderem wurde Meiners' Plädoyer für 
ten, dass die Forschung zu London und Paris den gesellschaftlichen Status der Salonièren betont bzw. die Tatsache, dass die zeitgenössische Rezeption der Salons eine wesentliche Rolle gespielt habe. $\mathrm{Zu}$ fragen ist also, ob die Salons und Salonièren in Deutschland einen vergleichbar beachteten Status überhaupt hatten, sodass sie die Rezeption der Debatte hätten beeinflussen können. Umgekehrt ist zu fragen, wie ernst die Frauen die Geschlechterdebatte nahmen, inwieweit sie sich von den Rollenbildern beeindrucken ließen und zu den „Schmetterlingen“ wurden, die manche Männer sich erträumten.

Aus der Positionierung des Salons im Schnittpunkt der Forschungsdiskurse ergeben sich abschließend folgende Feststellungen: Zwei Faktoren führten zur Glorifizierung des Salons in der Frauengeschichte:

1. die Annahme, dass der Umgang mit berühmten und einflussreichen Männern bzw. solchen, die dies werden sollten, die Salonièren selbst an Ruhm oder Einfluss gewinnen ließ.

2. die Vorstellung von weitgehend getrennten Lebenswelten der Geschlechter, die vor allem für bürgerliche Frauen um 1800 keine Möglichkeiten vorsahen, an der männlich dominierten Öffentlichkeit zu partizipieren und die Vorstellung des Salons als eine der wenigen Ausnahme-Orte. Vergleichbar wurde der Salon in der Historiografie der Juden in Deutschland als Ort des Dialogs betrachtet, an dem ein Prinz „ordentliche Dachstubenwahrheiten“ von einer Jüdin gesagt bekommen konnte. Die Rückbindung dessen, was als Berliner jüdischer Salon um 1800 bekannt wurde, in die Geschlechterund Gesellschaftsgeschichte der Zeit und der Region sollte daher Antwort auf zwei Fragen bringen:

1. Hatten die „berühmten Salons“ innerhalb der Berliner Gesellschaft wirklich eine Ausnahmestellung, welche Funktionen und welcher Wert wurde ihnen von Teilnehmenden und Umlebenden um 1800 attestiert? Hatten die „Wahrheiten“, die hier möglicherweise gesagt wurden, irgendeine Tragweite außerhalb dieses Ortes?

2. Welche Möglichkeiten gewannen die beteiligten Frauen, besonders die jüdischen Frauen, durch die Partizipation an einem Salon, die ihnen ihr Leben sonst nicht geboten hätte? Am Beispiel der ausgewählten jüdischen Häuser und vor allem ihrer weiblichen Bewohner ist zu fragen: Ist das Bild der öffentlichen und privaten Sphäre haltbar für die Berliner Gesellschaft um 1800 und welche Rolle spielte der Salon im Vergleich zu anderen Geselligkeitsformen?

eine Männerkultur übersetzt, konnte sich aber, unter anderem wegen der Existenz und Ausstrahlung des englischen Salons, nicht wirklich durchsetzen. Ebd. 


\section{4 „Mündlich mehr.“ - Briefe und Billets als Quelle für Salonforschung und Salonkommunikation}

Das erste, was uns bey einem Briefe einfällt, ist dieses, daß er die Stelle eines Gesprächs vertritt.

Christian Fürchtegott Gellert, 1751

So setzte gegen Ende des 18. Jahrhunderts eine Wende ein, die ich [...] vollständiger beschrieben und für wichtiger halten würde, als die der Kreuzzüge oder Rosenkriege.

Die mittelständische Frau begann zu schreiben.

Virginia Woolf 276

Betrachtet man den Berliner Salon als kommunikatives Netz, sind die Verbindungen zwischen den Personen darin, die verbindenden ,Fäden', gleichermaßen im Schriftlichen und Mündlichen zu suchen. Damit ist keineswegs eine Ineinssetzung von Brief und Gespräch gemeint, im Gegenteil: Wie in der Kommunikationswissenschaft allgemein wird auch in der speziellen Forschung zu Salons die These diskutiert, inwieweit die hinterlassenen Briefe der (Salon-)Gesellschaft Fortsetzung oder Abbildung der (Salon-)Gespräche sind.277

Das 18. Jahrhundert gilt als das „Jahrhundert des Briefes“, die Epistolomanie unter Männern und Frauen besonders in der zweiten Hälfte des Jahrhunderts wurde schon unter Zeitgenossen sprichwörtlich und ist durch die For-

276 Christian Fürchtegott Gellert: Briefe, nebst einer praktischen Abhandlung von dem guten Geschmacke in Briefen, Leipzig 1751, S. 2-3; Woolf 1992, S. 64 f. Das Zitat in der Überschrift nach einem Billet von Jeannette Ephraim Stieglitz an Gustav von Brinckmann, undatiert, ungedruckt, BA E.

277 Von den Kommentaren zu dieser Beziehung sind drei für diese Arbeit besonders interessant, die auf die Disparität zwischen Brief und Salongespräch hinweisen. Gert Mattenklott vertritt und belegt die These, dass der Brief einen freien Umgangston, besonders zwischen den Geschlechtern vor-entworfen habe, bevor er in der Realität anzutreffen gewesen sei. Gert Mattenklott / Hannelore Schlaffer / Heinz Schlaffer: Einleitung der Herausgeber, in: dies.: Deutsche Briefe 1750-1950, Frankfurt/M. 1988, S.7-18, hier bes. S. 13. Claudia Schmölders hingegen entwirft das gegenteilige Modell, demnach im Brief um 1800 erlaubt wurde, was im Gespräch nicht mehr erlaubt war, dass der Brief ein Erbe der Kommunikationsepoche war. Claudia Schmölders (Hrsg.): Die Kunst des Gesprächs. Texte zur europäischen Konversationstheorie, München 1986. Hier ist allerdings der Unterschied zwischen Deutschland und Frankreich und den jeweiligen Salons zu bedenken: Um 1800 war die klassische, freieste Phase der Pariser Salons bereits vorbei. Ursula Isselstein stellt die These auf, dass Rahel Levin Varnhagen u. a. deswegen so viel geschrieben habe, weil sie sich von ihren Salongästen und Freunden so oft missverstanden gefühlt habe und dem briefliche Selbstentwürfe entgegensetzen wollte. Ursula Isselstein: „Dies ist die Beute“. Zu Rahel Levins Tagebüchern, in: Barbara Hahn / Ursula Isselstein 1987, S. 86-103, hier S. 95 f. 
schung seitdem in nahezu vergleichbarer Schreiblust untersucht worden. ${ }^{278}$ Dabei ist neben der Begeisterung der Schreibenden die Reflexion über die Möglichkeiten und Grenzen des Mediums Brief von Anfang an ein Merkmal des Redens über Briefe. ${ }^{279}$ Im Zusammenhang mit dem Salon ist darauf hinzuweisen, dass der Brief nicht nur als Ausdruck und Medium eines umfassenden medialen Wandels im 18. Jahrhunderts gilt, ${ }^{280}$ sondern dass dem Briefschreiben ein besonderer Stellenwert für das literarische Mündigwerden der Frauen um 1800 zugesprochen wird. Seit etwa 30 Jahren sind die „Frauenbriefe der Romantik“, lange als illustratives Element der Epoche betrachtet, ${ }^{281}$ ein eigener

278 Besonders präzise Zusammenfassungen der aktuellen Fragestellungen bei Johannes Anderegg: Schreibe mir oft! Zum Medium Brief zwischen 1750 und 1830. Mit einem Beitrag von Edith Anna Kunz, Göttingen 2001 und Tanja Reinlein: Der Brief als Medium der Empfindsamkeit. Erschriebene Identitäten und Inszenierungspotentiale (Epistemata 455), Würzburg 2003. Als jüngste Annäherung mit objektgeschichtlichem Ansatz s. Anke Bohnenkamp / Waltraud Wiethölter: Der Brief - Ereignis und Objekt. Katalog zur Ausstellung, Frankfurt/M. 2009. Die jetzige Literaturflut darf nicht darüber hinwegtäuschen, dass es der Brief lange schwer hatte, als literarische Gattung ernst genommen zu werden. Zu kulturgeschichtlichen und literatursoziologischen Untersuchungen des Mediums Brief als Gebrauchsform traten seit etwa 1970 auch geschlechterspezifische Analysen. Exemplarisch: Reinhard M. G. Nickisch: Die Frau als Briefschreiberin im Zeitalter der Aufklärung, in: Wolfenbütteler Studien zur Aufklärung, Bd. 3, 1976, S. 29-65; Barbara Becker-Cantarino: Leben als Text. Briefe als Ausdrucks- und Verständigungsmittel in der Briefkultur und Literatur des 18. Jahrhunderts, in: Hiltrud Gnüg / Renate Möhrmann (Hrsg.): Frauen Literatur - Geschichte. Schreibende Frauen vom Mittelalter bis zur Gegenwart (Stuttgart 1985), S. 83-103. Inwieweit der „jüdische Brief“ eine eigene Gattung sein könne, fragte Gert Mattenklott: Jüdische Frauen im Briefwechsel um 1800. Gedanken zu ,Geschichtlichkeit und Erbe der Romantik‘, in: Zeitschrift für Germanistik 8 (1987), S. 39-49.

279 Zu den diskutierten Mängeln des Mediums gehören praktische Risiken wie verlorene Post oder die Zensur, ebenso wie die immer wieder aufgeworfene Frage, ob das verstanden wird, was verstanden werden soll.

280 Das exponentielle Anwachsen des Briefverkehrs im 18. Jahrhundert ist Teil eines umfassenden Wandels der Kommunikationsformen, der auch als Medienrevolution bezeichnet wurde. Robert Vellusig sieht drei große „Wuth- und Suchtkrankheiten“ des Jahrhunderts. Vor der Briefwut hatte es bereits die „Zeitungswuth“ und die „Lesesucht“ überstanden, alle drei Phänomene wurden von Zeitgenossen ausführlich kommentiert. Vellusig nennt diese Klagen „Dokumente des Umbruchs in den Leitformen sozialer Kommunikation“. Robert Vellusig: Schriftliche Gespräche. Briefkultur im 18. Jahrhundert, Wien [u.a.] 2000, S. 9.

281 Es gibt mehrere Sammlungen unter diesem Titel, zuletzt: Katja Behrens (Hrsg.): Frauenbriefe der Romantik. Frankfurt/M. 1981. An den unterschiedlichen Wertungen der Briefe etwa Levin Varnhagens oder Bettina von Arnims lässt sich der Paradigmenwechsel in der Briefforschung ablesen: Galten sie den ersten Herausgebern als Abbild einer „schönen Seele“ oder „Denkmale“ der Zeit, werden sie heute als genuine Beiträge zur Ästhetisierung und Literarisierung des Mediums Brief gewertet. Becker-Cantarino 2000, S. 183. 
Forschungsgegenstand. ${ }^{282}$ Im Zusammenhang mit den Grundfrage der Arbeit ist hier vor allem nach den in der Forschung diskutierten emanzipatorischen Funktionen des Mediums Brief und seiner Handhabung um $1800 \mathrm{zu}$ fragen ${ }^{283}$ sowie nach den Wechselbeziehungen zwischen dem viel propagierten „Frauenzimmerbrief“ und dem Salon, die ebenfalls oft beschrieben und nichtsdestoweniger streitbar sind [II.4.1].

Das „Billet“ hingegen, obzwar ein wesentliches Ausdrucksmittel des 18. Jahrhunderts, ist kaum definitorisch oder funktional untersucht. Da es in der Salonkommunikation eine entscheidende Rolle spielt und eine besondere Stellung zwischen Mündlichkeit und Schriftlichkeit einnimmt, wird in II.4.2 eine gattungstheoretische Annäherung unternommen.

\subsection{Zwischen „Öffentlich“ und „Privat“ - Salon, Brief und „Frauenzimmerbrief“"}

Dem Brief als Quelle kommt in der Geschlechtergeschichte eine besondere Stellung zu, da er erstens für Frauen um 1800 als Ausdrucksmedium par exellence galt und zweitens auch in der Forschung lange als solches diskutiert wurde. ${ }^{284}$ Forschungsgeschichtlich ist der Brief dem Salon darin vergleichbar, dass beide als erweiterter Schreibort für Frauen um 1800 diskutiert wurden. Im Modell der getrennten Sphären gedacht, boten beide Medien Frauen die Möglichkeit, Kontakte anzuknüpfen und zu pflegen, ohne dafür den ihnen gesellschaftlich zugedachten Raum verlassen zu müssen. Ein Salon fand im eigenen oder elter-

282 Beim so genannten Frauenbrief wie beim Brief allgemein hat die von der Brieftheorie des 18. Jahrhunderts angenommene Nähe zum „Privaten“ und „Natürlichen“ lange dazu geführt, ihm die Literaturfähigkeit abzusprechen. So heißt es noch in der grundlegenden Briefgeschichte von Nickisch, dass ,unter den führenden Romantikerinnen [...] der Frauenbrief in Deutschland eine neue Blüte erreichte“, dass aber die Texte beispielsweise Rahel Levin Varnhagens „nicht eben besonders gut lesbar“ gewesen seien. Reinhard M. G. Nickisch: Brief, Stuttgart 1991, S.55. In dieser Wertigkeit wurden zahlreiche Quellen, auch von Schreiberinnen selbst, vernichtet, von Nachlebenden nur partiell bewahrt oder publiziert.

283 Beispielsweise wurde diskutiert, dass der Erfolg der Frauen beim Briefschreiben „zu einer irreversiblen Steigerung ihres Selbstwertgefühls“ beitrug. Reinhard M. G. Nickisch: Briefkultur. Entwicklung und sozialgeschichtliche Bedeutung des Frauenbriefs im 18. Jahrhundert, in: Gisela Brinker-Gabler (Hrsg.): Deutsche Literatur von Frauen, 2 Bde., München 1988, Bd.1, S. 389-409, hier S. 409.

284 Vgl. Nickisch 1988, Becker-Cantarino 2000. Ende der 1980er-Jahre wurden Briefe von Frauen als Ausdrucksform der bürgerlichen Öffentlichkeit ,wiederentdeckt‘. Karin Sträter: Frauenbriefe als Medium bürgerlicher Öffentlichkeit. Untersuchungen anhand von Quellen aus dem Hamburger Raum in der 2. Hälfte des 18. Jahrhunderts, Frankfurt/M. 1991. 
lichen Haus statt, ein Brief konnte, analog, am eigenen Tee- oder Küchentisch verfasst werden, mit der Hand- oder Küchenarbeit in Sichtweite. ${ }^{285}$

Aus dem Umfeld der hier untersuchten Salonbeteiligten lässt sich bestätigen: Der Brief diente tatsächlich dazu, Kontakte zu knüpfen, besonders für Frauen und auch auf Initiative der Frauen. Einige bekannte Frauenfreundschaften, wie die zwischen den Autorinnen und Salonièren Sophie von La Roche und Julie Bondeli, beruhten nur auf Briefkontakt. Wie sich an einem noch ungedruckten Briefwechsel des Salongastes Brinckmann mit der Wienerin Henriette Arnstein Pereira detailliert zeigen ließe, war es durchaus statthaft für eine Frau, einen ihr noch unbekannten Mann brieflich als erste anzusprechen. In diesem Bereich war weibliche Initiative nicht nur gestattet, sondern gern gesehen.

Aus diesem Grunde kann man sich sagen, woher es kömmt, daß die Frauenzimmer oft natürlichere Briefe schreiben als die Mannspersonen. ${ }^{286}$

Dass etwa seit Mitte des 18. Jahrhunderts das Briefschreiben von Frauen seitens männlicher Aufklärer nicht nur geduldet, sondern propagiert wurde, lag an einer stilistischen Wende, die etwa seit 1740 stattfand. In der an Briefstellern, also Regelwerken für das Verfassen von Briefen, ohnehin reichen Späten Neuzeit markierten die Schriften von Johann Christoph Gottsched und vor allem Christian Fürchtegott Gellert den Durchbruch eines neuen Ideals, des „natürlichen Briefes“. Man propagierte und beschrieb die Abkehr vom Gelehrten- oder „Kanzleistyl“ einerseits und von übertrieben künstlicher, unter französischem Einfluss stehender Galanterie andererseits. ${ }^{287}$ Ihrer ,angeborenen' zarten Regungen wegen und da sie von Regelwerk unverdorben seien, konnten Frauen Vorbilder der neuen Schreibart werden: „Die Empfindungen der Frauen sind zarter und lebhafter [...] und weil sie nicht durch die Regeln der Kunst ihrem

285 Der Brief galt als das wesentliche Mittel, Kontakte zu halten, Entfernungen zu überbrücken, unter anderem mit dem Hinweis, dass bürgerliche Frauen nicht ohne Erlaubnis des Ehemanns reisen durften, schreiben aber schon. Mit Recht fordert Ann Charlott Trepp, „der gängigen These, daß das Briefeschreiben für Frauen vor allem ein Ersatz für nicht erfahrbare persönliche Beziehungen und für mangelnde Geselligkeit war“, mit Skepsis zu begegnen, da sie von einer nicht zutreffenden Gleichsetzung von geforderter Beschränkung der Frau auf das Häusliche und deren realer Lebenswelt ausgeht. Trepp 1996, S. 34.

286 Gellert 1751, S. 75.

287 Gellerts grundlegende Schriften, „Gedanken von einem guten deutschen Briefe, an den Herrn F. H. v. W.“ (1742) und „Briefe nebst einer praktischen Abhandlung von dem guten Geschmacke in Briefen“ (1751) erschienen in der Regierungszeit des frankophilen Friedrichs II. und hatten mit dem Monarchen einen prominenten, aber auf diesem Gebiet glücklicherweise nicht einflussreichen Gegner. 
Verstande eine ungewöhnliche Richtung gegeben haben: so wird ihr Brief desto freyer und weniger ängstlich“. ${ }^{288}$

Der Brief teilte mit dem Salon noch das zweite Paradox, dass die Frauen aus einer ihnen zugedachten Einschränkung eine „Paradegattung“ machten und ihre „Natur“ dies Engagement legitimierte. ${ }^{289} \mathrm{Zu}$ recht ist hier von einer „Dialektik des Ausschlusses“ gesprochen worden:290 Das Fernhalten von Frauen von beruflicher Einbindung oder einem ,Übermaß‘ an Bildung, die Nähe zum ,Allgemein-Menschlichen' und Alltag wurde hier positiv gewendet $\mathrm{zu}$ einer besonderen Eignung für die weniger spezialisierte - und weniger angesehene - Gattung des Briefs, später auch des Romans. Elemente des „Natürlichen“, des unkonventionell „Lebhaften“, die man sowohl im Idealbild des weiblichen Geschlechtscharakters als auch im Ideal des Briefschreibens zu finden glaubte, gaben den Zeitgenossen Anlass, an ein spezifisches Talent der Frauen zum Briefeschreiben zu glauben. ${ }^{291}$ Nicht unähnlich argumentierte Schleiermacher in seiner Theorie der Geselligkeit, dass wahre zweckfreie Geselligkeit am besten geschaffen werde von Personen, die mit berufstätigen Männern „keinen Stand gemein haben als den der gebildeten Menschen“, eben von Frauen. 292

Der Brief wurde zudem in die Richtung eines Dialogs unter Freunden gerückt, mit Gellerts berühmter Formulierung als „freye Nachahmung des guten Gesprächs“ verstanden. ${ }^{293}$ Nicht zufällig wurde Gellerts epochemachendes Buch in der Zeit veröffentlicht, die als Entwicklungsphase der bürgerlichen Öffentlichkeit gilt. Briefe wurden vorgelesen, weitergereicht, abgeschrieben und formierten so ein Publikum von mehr als einem Leser. Der Brief war um 1800 selbst ein „halböffentliches“, besser ein geselliges Medium, insofern das Verlesen im Familien- und Freundeskreis und auch das Weiterreichen an Bekannte zum normalen Procedere gehörten. Beinahe notwendig enthielten Briefe daher ein gewisses Inszenierungspotential, ${ }^{294}$ wie präsent der Gedanke

288 Gellert 1751, S. 75 f.

289 Die These, dass die Frauen aus einer innen zugestandenen Nische eine Paradegattung machten, wurde formuliert von Nickisch 1988, S. 391.

290 Bovenschen 1979, S. 209.

291 Zur spezifischen Definition Gellerts dieses Ideals s. Rafael Arto-Haumacher: Gellerts Briefpraxis und Brieflehre. Der Anfang einer neuen Briefkultur, Wiesbaden 1995.

292 Schleiermacher 1984, S. $56 \mathrm{f}$.

293 „Ein Brief ist kein ordentliches Gespräch; es wird also in einem Briefe nicht alles erlaubt sein, was im Umgang erlaubt ist. Aber er vertritt doch die Stelle einer mündlichen Rede, und deswegen muß er sich in der Art zu denken und zu reden, die in Gesprächen herrscht, mehr nähern als einer sorgfältigen und geputzten Schreibart. Er ist eine freye Nachahmung des guten Gesprächs." Gellert 1751, S. 3.

294 Dazu ausführlich Reinlein 2003. 
an Drittleser war, zeigt sich in Leseanweisungen wie der Bitte, einen Brief nicht als „Zirkulärschreiben“295 zu verwenden oder in Geheimzeichen wie den Nadelstichen, die Jeannette Wohl in ihren Briefen an Ludwig Börne für Küsse einsetzte. Die Forschung hat betont, dass die Herausbildung des natürlichen Briefstils mit der Formulierung neuer bürgerlicher Werte zusammenhing, entgegen dem höfischen werde hier ein bürgerliches Kommunikationsideal formuliert, mit der Titulatur und festen zeremoniellen Wendungen sollten die Standesgrenzen aus Briefen entfernt werden. ${ }^{296}$ In der zweiten Hälfte des 18. Jahrhunderts wurde der Brief zunehmend als Ausdruck der Persönlichkeit, der „Seele“ verstanden, Briefe wurden Medien der Empfindsamkeit. In der prägnanten Formulierung Bernd Wittes war ,seit den Leiden des jungen Werthers [...] nicht mehr Gebete sprechen, sondern Briefe schreiben die bürgerliche Form der Inszenierung von Innerlichkeit“.297

Trotz dieser Formen der Verbürgerlichung ist der emanzipatorische Effekt der „Briefwut“ in der neueren Forschung umstritten, nicht zuletzt weil Schreiben, auch und besonders das Schreiben von Briefen, auch bei verbesserter Infrastruktur, eine Tätigkeit der Oberschicht blieb. Neben der zwar sinkenden, aber immer noch großen Analphabetenrate unter Frauen und Personen niederen Standes schränkten die großen Kosten, die mit der Zustellung verbunden waren, die nach damaliger Regelung der Empfänger trug, das Briefschreiben weiter ein. Um die briefintensive Salonkommunikation sozialgeschichtlich einzuordnen, muss man sich vergegenwärtigen, dass ein Brief zwischen Berlin und Magdeburg Ende des 18. Jahrhunderts etwa zweieinhalb Groschen kostete, etwa soviel wie drei Kilogramm Brot.298

\section{Der „natürliche Frauenzimmerbrief“ und Geschlechterdiskurse in Briefen}

Für die Fragestellung dieser Arbeit ist von Bedeutung, inwieweit sich die zeitgenössischen Diskussionen um Geschlechterrollen im Brief niederschlugen und aus ihnen herauslesbar sind. Während der Brief bis in die 1970er-Jahre

295 Gustav von Brinckmann an Lea Mendelssohn Bartholdy, 9. 2. 1799, dies ungedruckt, BA M. Vgl. V.

296 Auch wenn die Schreibenden um 1800 sich weiterhin Gedanken um Ehrbezeigungen machten, hatte der Hof deutlich an Vorbildfunktion verloren. „Der Wandel des Briefstils spiegelt und fördert eine weitgehend irreversible gesellschaftspolitische Gewichtsverschiebung und lässt einen Emanzipationswillen erkennen, der bald weit über das Briefwesen hinausgehen wird.“ Anderegg 2001, S. 16.

297 Bernd Witte: Die Individualität des Autors. Gellerts Briefsteller als Roman eines Schreibenden, in: The German Quarterly, Winter 1989, S.5-14, hier S. 13.

298 Angaben nach Becker-Cantarino 2000, S. $162 \mathrm{f}$. 
überwiegend als unliterarische Gebrauchsform diskutiert wurde, „,bei dem die gesellschaftliche Herkunft immer durchscheint“, 299 ist heute die „Zwitterform“ des Briefes zwischen Echtheit und Literarizität ein unumstrittenes Faktum. Diskutiert werden die Spielarten des Literarischen im Brief, das Verhältnis von Authentizität und Fiktion sowie das Potential des Briefes für Selbstinszenierungen. ${ }^{300}$ Die vieldiskutierte Natürlichkeit, die lange noch zur Abwertung von Frauenbriefen führte, ${ }^{301}$ wird zunehmend als Topos und Strategie begriffen. Dabei war schon dem Erfinder des Ideals klar, dass der Eindruck des Natürlichen durch intensive Vorbereitung erzeugt werden müsse. Natürlichkeit als rhetorisches Mittel konnte auch subversiv eingesetzt werden, beispielsweise von Autorinnen, die in Briefen an ihre Verleger ihr „Naturtalent“ zur Pädagogik als Legitimation für gute Preise nutzten. ${ }^{302}$ Allgemein ist festzuhalten, dass die Orientierung an geschlechterideologischer Zuschreibung nicht nur das strategische Potential von Frauen verdeckt, sondern den Umstand, dass allen Schreibenden Ende des 18. Jahrhunderts ein ganzes Stilrepertoire offen stand, ${ }^{303}$ dass Stile wie „natürlich“ oder „empfindsam“ auch bewusst, für einen Selbstentwurf im Brief, eingesetzt werden konnten.

299 Helmut Hartwig: Zwischen Briefsteller und Bildpostkarte. Briefverkehr und Strukturwandel bürgerlicher Öffentlichkeit, in: Ludwig Fischer / Knutz Hickethier / Karl Riba: Gebrauchsliteratur. Methodische Überlegungen und Beispielanalysen, Stuttgart 1976, S. 114-126, hier S. 124, zit. nach: Sträter 1991, S. 9.

300 Annette C. Anton: Authentizität als Fiktion. Briefkultur im 18. und 19. Jahrhundert, Stuttgart [u. a.] 1995.

301 Dabei gilt für Frauenbriefe, was Susanne Kord für Frauenliteratur im Allgemeinen festhielt: Bis zum heutigen Tag wird Frauenliteratur entweder im Kontext der Männerliteratur gelesen, die als „die Literatur“ oder gar „Weltliteratur“ missverstanden wird, oder im Kontext der neueren feministischen Forschung, die die Ästhetik, die dieser Annahme zugrunde liegt ablehnt und daher vorwiegend Werke diskutiert und tradiert, die diese Ästhetik ebenfalls ablehnen [...]. Autorinnen, die weder den ästhetisch-ideologischen Kriterien der Männerliteratur noch den ideologischen der feministischen Literaturwissenschaft entsprechen, werden weder hier noch dort tradiert.“ Kord 1996, S. 170. 302 Helen Fronius belegt an Briefen von erfolgreichen Autorinnen an Verleger, dass Frauen sich, anders als in veröffentlichten Vorworten, für ihr Tun nicht entschuldigten, sondern als zähe Verhandlungspartnerinnen erwiesen. Nicht wenige spielten mit dem Natürlichkeitsideal, um finanzielle Verbesserung zu gewinnen. Helen Fronius: Der reiche Mann und die arme Frau: German Women Writers and the Eighteenth-Century Literary Market-Place, in: German Life and Letters (Vol. LVI, No. 1, Jan 2003, S. 1-19); dies.: „Nur eine Frau wie ich konnte so ein Werk schreiben“. Reassessing German Women Writers and the Literary Market 1770-1820, in: Müller-Adams / Bland 2007, S. 29-52.

303 „Mit der Abwendung ,vom normativen Stildenken“ (Rainer Brockmeyer) [...] hat das 18. Jahrhundert der Briefsprache alle Möglichkeiten erschlossen. [...] Eine uneingeschränkte Subjektivität war die Folge.“ Nickisch 1991, S. 49-50. 
Wie Silvia Bovenschen gezeigt hat, wurde gerade der Brief letztlich zum Entreebillet der Frauen in die Literatur. 304 Über das „trojanische Pferd“ Briefroman machte sich eine stattliche Zahl Frauen einen Namen als Autorin. ${ }^{305}$ Auch die seit der Antike bekannte Methode, die Form des Briefes als Anlass oder Gewand für philosophische Belehrungen oder Essays zu nutzen, die an ein allgemeines Publikum gerichtet sind, wurde um 1800 von Autoren beider Geschlechter angewandt. Zu den Autorinnen, die sich zunehmend der Gattung des fiktiven Briefs bedienten, um sich politisch oder gesellschaftskritisch zu äußern, gehörte auch Esther Gad, deren Reisebriefe viel gelesen wurden. ${ }^{306}$ Offiziell anonym, aber deutlich kritisch äußerte sich Helene Unger 1798 in Briefen Über Berlin auch über jüdische Geselligkeit - ihre Autorschaft war so bekannt, dass ihr persönlich geantwortet wurde. ${ }^{307}$

Feministische Forschungen haben darauf hingewiesen, dass der Brief um 1800 nicht nur ein Medium war, um Geschlechterrollen auszudrücken oder zu diskutieren, sondern dass er für das bürgerliche Geschlechterideal auch zum Bildungsmedium werden konnte. Nicht nur Briefe in Moralischen Wochenschriften moralisierten über die Geschlechterrollen, in Briefen zwischen Paaren, wie den berühmten Brautbriefen, die Flachsland mit Herder wechselte, wurde geschlechtertypisches Rollenverhalten ,eingeübt': $E r$ gibt ihr Lektüreempfehlungen, sie bittet ihn um Beratung und Anleitung. Briefe sollten daher nicht als nur Spiegel zeitgenössischer Debatten genutzt werden, sie waren so auch Teil des normativen Diskurses. ${ }^{308}$ Eine Frage, die sich an die Briefe der Salongesellschaft richtet, wäre, ob die ungewöhnlich prominente Rolle einer Frau sich in den Briefen niederschlug, ob die Geschlechterpolarität auch hier

304 Vgl. Bovenschen 1979, bes. S. 200-219.

305 Der erste echte deutsche Briefroman war bekanntlich nicht Goethes „Leiden des jungen Werther“, sondern Sophie La Roches „Fräulein von Sternheim“ 1771. Dieser Text, ihr laut der bekannten Vorrede des Herausgebers Christoph Martin Wieland wider Willen entrissen, wurde zur Grundlage einer lebenslangen Schriftstellerinnenkarriere und die kontinuierliche Behauptung, mit Veröffentlichungen in den „inferioren“ Gattungen Brief und Briefroman lediglich die weiblichen Aufgaben der Erziehung wahrnehmen zu wollen, ein taugliches Versicherungsmodell gegen Vorwürfe, Frau La Roche wolle eine öffentliche Person sein. Dieser „Bescheidenheitstopos“ lässt sich als rhetorisches Mittel von Schriftstellerinnen durch die Jahrhunderte verfolgen und wird durch ihre Erfolge konterkariert.

306 Esther Gad: Briefe während meines Aufenthalts in England und Portugal, 2 Bde., Hamburg 1802-1803.

307 Friederike Helene Unger: Über Berlin. Aus den Briefen einer reisenden Dame. Mit einem Nachwort von Diana Spokiene, Hannover-Laatzen 2006.

308 Beatrix Niemeyer: Der Brief als weibliches Bildungsmedium im 18. Jahrhundert, in: Kleinau / Opitz 1996, Bd.1, S. 440-452, hier S. 445. 


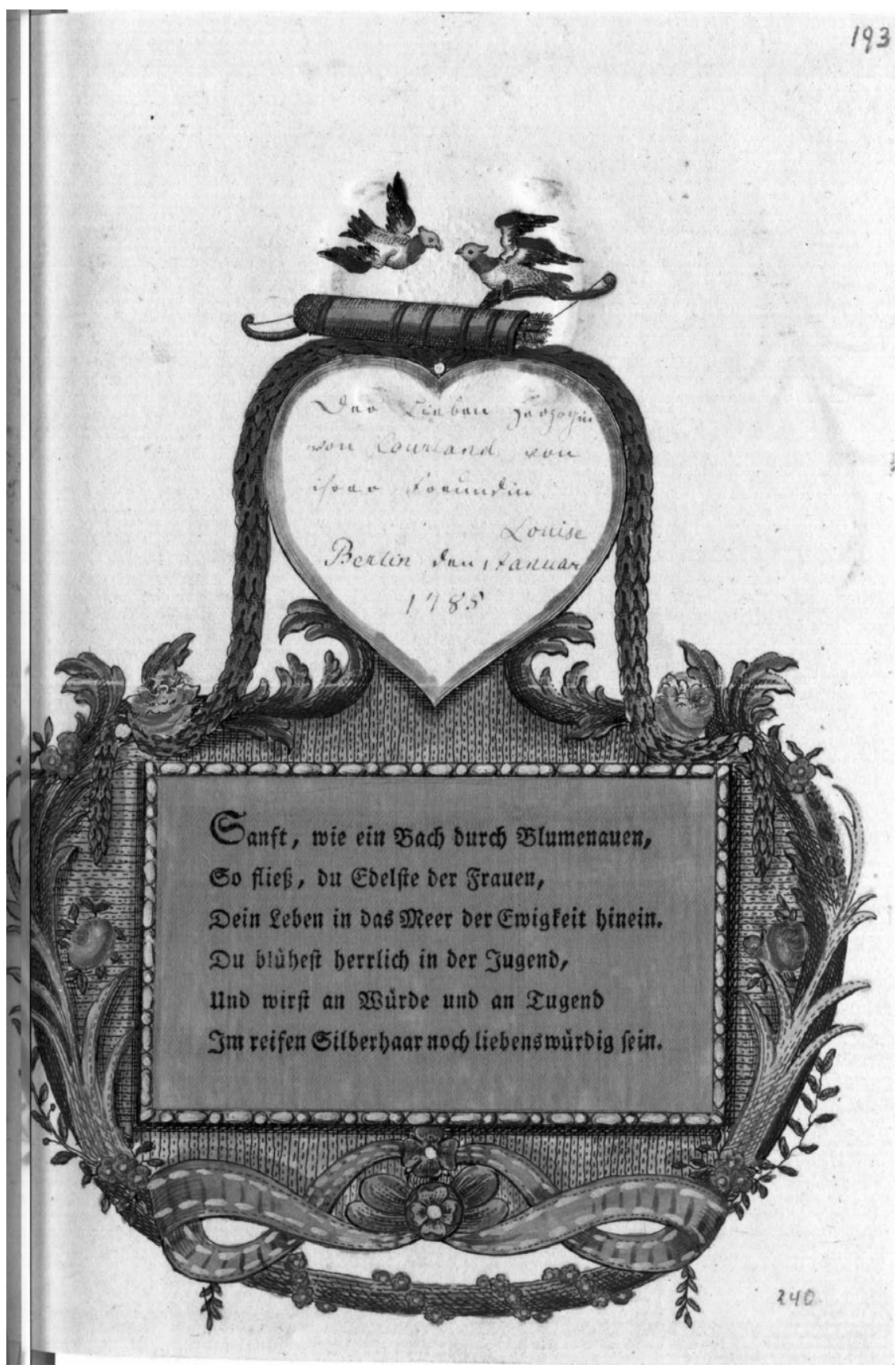

Abb. 7: Tugend als Frauenschmuck - Schmuckbillet an die Salonfrau Dorothea von Kurland. 


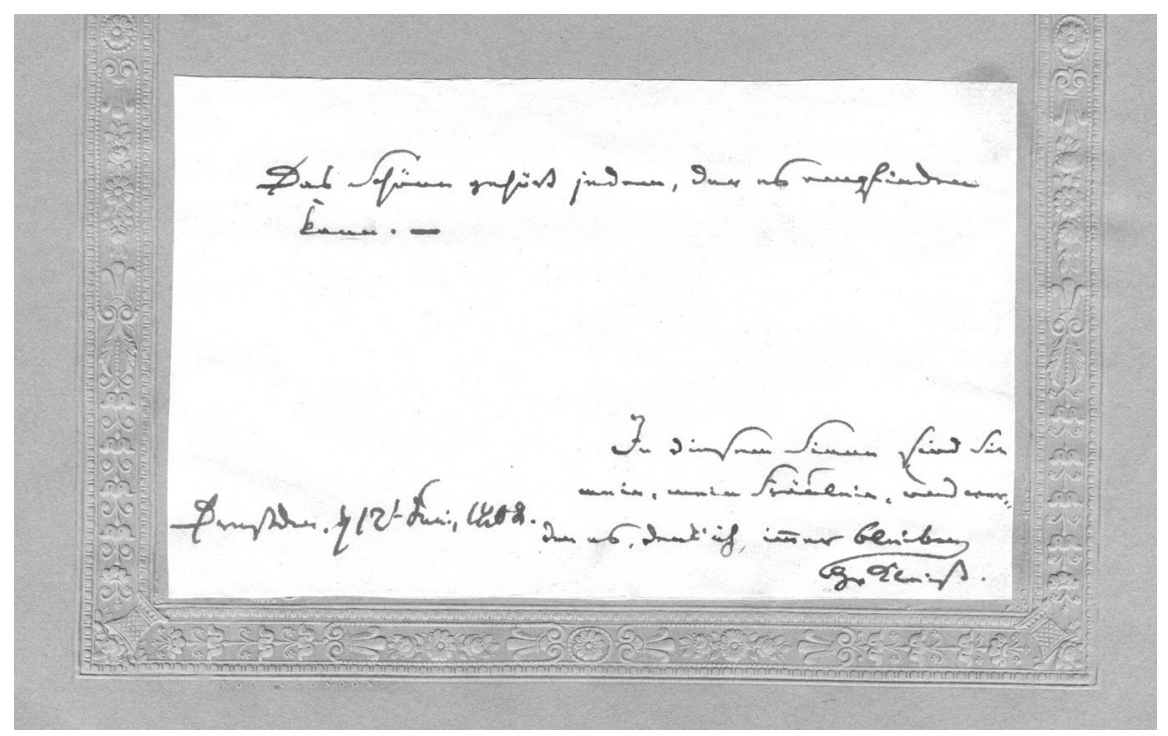

Abb. 8: Die Schönheit in Schönheit erziehen - Stammbucheintrag Heinrich von Kleists.

,eingeübt‘ oder umgangen wurde. ${ }^{309}$ Die Arbeit fragt an ausgesuchten Beispielen, welcher stilistischen Mittel sich Frauen und Männer der Salongesellschaft bedienten, in der Korrespondenz untereinander und ,nach außen', ob und wie sich der Stil nach Geschlecht, familiärer Herkunft und oder Rang des Schreibenden und der Adressatin unterschieden.

\subsection{Die kommunikationsgeschichtliche Bedeutung des Billets und die verschiedenen Ebenen der Salonkommunikation}

///haben sie den keine Zeit heute zu mir zu komen? wie wäre es wen Sie bey mir dinirten; wir könten den so gut die Briefe der Levin die heute Nachmittag kamen zusamen lesen; überhaupt möchte ich Sie gerne über die Geschichte vom Sonabend sprechen.

Wissen Sie den dass Jette Mendelsohn hier ist?

ich bin nur bis 5 zuhause und von 3 bis 4 habe ich eine stunde.

Friederike Liman.///

309 Bisher wurden Auszüge aus Rahel Levin Varnhagens Korrespondenz, vor allem der Briefwechsel mit Friedrich von Gentz, in der Genderforschung als Beleg dafür herangezogen, dass per Brief Geschlechtskonstruktionen sowohl errichtet als auch subversiv umgangen werden konnten. Vogel 2003. 
///Der Inhalt Ihres Billets ist von der Art dass ich glaube es sey besser für mich ihn mündlich zu beantworten, so bald ich die Ehre haben werde Sie zu sehen soll es geschehen.

MM.///

Im Bette noch erhielt ich einliegendes Billet von Sarchen. Halb im Schlaf, also aus Instinkt ließ ich das formidable Ja sagen. [...] Im Fall Sie mir etwa nicht schreiben wollten; so wissen Sie doch, ich bin heute nur bis 3 Uhr zu Hause, denn ich muß weg pour le cafè, le thè et le soupè.

Ihre ergebne R. L. Ich muß Ihnen doch auch einmal eine Mühe ersparen, und das Datum selber schreiben. Berlin, den 24. Decr. $1794^{310}$

Im Gegensatz zu der umfassenden Forschungsliteratur zum Brief im „tintenklecksende[n] Säkulum“, 311 liegen keine Untersuchungen zu dem um 1800 womöglich ebenso oft verfassten Billet vor. Es gibt weder eine zeitgenössische noch eine literaturwissenschaftliche eindeutige Abgrenzung der beiden Kommunikationstypen Brief und Billet. Da sie in dieser Arbeit als zwei verschiedene, wenn auch in einander übergehende Gattungen $\mathrm{zu}$ begreifen sind, werden auf der Grundlage des hier untersuchten Materials nachstehend Definitionsmerkmale zur Diskussion gestellt. „Billet“ ist ein zeitgenössischer Ausdruck für Kurznachrichten, Mitteilungen informelleren Charakters, die überwiegend innerhalb desselben Ortes ausgetauscht, bzw. von Boten überbracht werden. ${ }^{312}$ In Nähe und Abgrenzung zum Brief bezeichnet Billet ein

310 Friederike Liman an Gustav von Brinckmann, Sommer 1795, zit. nach: Bosold 1996, S. 123. Marianne Meyer Eybenberg an Gustav von Brinckmann, ohne Datum, ungedruckt, BA E. Komplett abgedruckte Billets werden in der Arbeit durch einen Dreistrich vor und nach dem Text gekennzeichnet, auszugsweise zitierte Schreiben ungerahmt; Rahel Levin Varnhagen an Gustav von Brinckmann, 24. 12. 1794, ungedruckt, BA V. „Sarchen“ ist Sara Meyer Grotthus. Hervorhebung im Original.

311 Das Zitat von Schillers Räuberhauptmann wurde bereits im ausgehenden 18. Jahrhundert, im positiven wie negativem Sinne zur Selbstbezeichnung verwandt. „Mir ekelt vor diesem Tintengleksenden Sekulum, wenn ich in meinem Plutarch lese von grossen Menschen.“ Friedrich von Schiller: Die Räuber (I, 2), in: ders.: Schillers Werke (Nationalausgabe), hrsg. von Julius Petersen und Hermann Schneider, Bd.3, Weimar 1953, S. 20.

312 Der Begriff „Billet“ stammt aus dem Französischen und wird vom lateinischen Bulla (Amulettkapsel) hergeleitet. Erhalten hat sich der Begriff vor allem im „Billet doux“, das sich als „zärtliches Geständnis auf einem Zettel“ umschreiben ließe. Vgl. Friedrich Ludwig Karl Weigand: Deutsches Wörterbuch. 5. Auflage, in der neusten für Deutschland, Österreich und die Schweiz gültigen amtlichen Rechtschreibung, hrsg. von Herman Hirt, 1. Bd., Gießen 1909, S. 239; Karl Sachs / Césaire Villatte: Enzyklopädisches französisch-deutsches und deutschfranzösisches Wörterbuch. 1. Teil Französisch-Deutsch (Sachs-Villatte), Vierte Bearbeitung, Berlin 1963, S. 95. Bereits im Alt-Niederländischen ist „Billiet“ auch als Familienname bekannt, der vermutlich Briefschreiber oder Stadtbote bedeutet; das Wappenschild einer Familie Billiet in Brügge zeigt eine Taube mit einem Briefchen im Schnabel. Vgl.: Frans 
kurzes privates Schreiben, das überwiegend der schnelleren Information dient und daher auf Form und Formalia weitgehend verzichtet, bzw. eines, das sich durch bewusste Formlosigkeit den Anstrich von Spontaneität, Tempo und authentischer Momentaufnahme gibt. ${ }^{313}$ Meist ist es auch in der Papiergröße vom Brief unterschieden, oft „eingelegt“ in Briefe, nie versiegelt. Die angestrebte Schnelligkeit der Kommunikation spiegelt sich sozusagen im Material: man schreibt sich auf halben oder abgerissenen Bogen, oft in fliegenden Linien (nicht auf vorgezeichneten Strichen), manchmal wird auf der Rückseite umgehend geantwortet. Die Inhalte der Billets sind kultur- und kommunikationsgeschichtlich deswegen besonders interessant, weil sie ausgeliehene Bücher begleiten und kommentieren, auf Theatereinladungen, neue Bekanntschaften ebenso verweisen wie auf Krankheiten und zeitgenössische Heilmittel. Sie sind der Mündlichkeit näher als die Briefe. Funktional wären Billets etwa heutigen Telefonanrufen, SMS oder E-Mails vergleichbar und könnten daher im weitesten Sinne als „Kurzmitteilung“ umschrieben werden. Dennoch hat diese Gattung einen stilistischen Anspruch: Die hier untersuchten Billets sind nicht selten mehrsprachig, fast immer doppeldeutig, oft gereimt und wirken manchmal durch Abkürzungen, Spitznamen und Geheimzeichen geradezu kryptisch. Trotz der Kürze und scheinbaren Formlosigkeit fordert das Billet bekennende Briefschreiber manchmal zu stilistischen Kunstwerken heraus.

Stil und Form der Billets können heutigen Lesern einen Eindruck vom Tempo und dem Umgangston der Salongesellschaft vermitteln, genauer von einer Sprachebene der Salongesellschaft. Dafür, dass die Billets mehr als Alltagsabfall und ein eigenständiges kommunikatives Band zwischen den Teilnehmern der Salongesellschaft waren, spricht unter anderem auch die Tatsache, dass die großen Autografensammler Brinckmann und Varnhagen in ihren

\footnotetext{
Debrabandere: Wordenboek van de Familiennamen in Belgie \& Nord-Frankrijk, uitgegeven door het Gemeentekrediet (Brussel 1993), zit. nach: Betekenis van de Familienaam Billiet, unter: http://www.angelfire.com/space/billiet/Stbo_Billiet/alg_betekenis_naam_Billiet.htm (10. 7. 2006). Das Grimmsche Wörterbuch führt den Begriff Billet nicht.

313 Tatsächlich ist der Begriff auch aus der militärischen und höfischen Kommunikation bekannt, bezeichnet hier aber ebenfalls ein kurzes privates oder privatdienstliches Schreiben. Das „Hand-Billet“ ist die österreichische Variante der Kabinettsordre, eine „notizartige formlose Niederschrift zur schnellen externen Befehlsübermittlung“. Auch das zwischen Militärs und Diplomaten verwandte Billet ,verzichtet (meist absichtlich) auf Berücksichtigung der Rangverhältnisse zwischen Absender und Empfänger“. Die hier zur Definition dienende Regel ,Je näher der Feind, desto knapper die Form“ wäre von der Salongesellschaft durchaus verstanden worden. Vgl. Jürgen Klosterhuis: Amtliche Aktenkunde der Neuzeit. Ein hilfswissenschaftliches Kompendium, in: Archiv für Diplomatik 45 (1999), S. 465-563, zit. nach: http://www.gsta.spk-berlin.de/downloads/Int27-1.pdf (1. 1. 2006).
} 
Briefbündeln zahlreiche Billets aufhoben, zum Teil mit den Briefen, zum Teil in eigenen Paketen. Die Übergänge zwischen Billet und Brief sind notwendigerweise fließend. Sie sind nach Form und Inhalt nicht immer voneinander zu trennen. Im Zusammenhang dieser Arbeit wird der Ausdruck Billet zur Bezeichnung der vielgenutzten schriftlichen Kurzform verwendet bzw. dann, wenn die Korrespondenten ihre Texte selbst als Billets bezeichnen. Abgesehen von der Kürze und Form gibt es gattungstheoretisch aber noch drei wesentliche Unterscheidungsmerkmale: Billets richten sich erstens, anders als die (nur) so genannten Privatbriefe des 18. Jahrhunderts, oft wirklich nur an eine Person und sie werden zweitens, im vorliegenden Untersuchungsfeld, nur an Personen gerichtet, mit denen der Schreiber bereits bekannt ist. Für den nicht seltenen Fall, dass mit einer unbekannten Person schriftlich Kontakt aufgenommen werden soll, wird immer die Form des Briefes genutzt, die mehr Möglichkeiten für Höflichkeitsformeln und Erklärungen bietet. ${ }^{314}$ Drittens ist festzuhalten, dass die Gattung Billet, wie der Brief, von Männern und Frauen genutzt wird. Eine dem „Frauenzimmerbrief“ entsprechende geschlechtsspezifische Billetart ist aber nicht definiert und auf der Grundlage der hier untersuchten Billets auch nicht nachweisbar.

Zum Verhältnis von Mündlichkeit und Schriftlichkeit deuten die oben zitierten Schriftstücke aus dem Jahre 1794/95 schon ein variables Nebeneinander an: Rahel Levin Varnhagen empfing im Bette ein Billet, das sie dem Boten mündlich beantwortete und zugleich in einem Brief kommentierend weiterleitete; Friederike Liman lud per Billet Brinckmann dazu ein, die Briefe „der Levin“ bei einem Nachmittagsbesuch gemeinsam zu lesen und Marianne Meyer Eybenberg beantwortete ein Billet mit einem ebensolchen, in dem sie sagte, dass sie lieber nicht schriftlich antworten wolle. Selbstverständlich gab es auch in der nicht klatschfreien Salongesellschaft Themen, die nur mündlich behandelt und keinem Papier anvertraut wurden - Billets dienten oft gerade dazu, eine Art Überschrift $\mathrm{zu}$ vermitteln oder durch Andeutungen zum Vorbei-

314 So etwa begann Henriette Arnstein Pereira einen Briefwechsel mit ihrem späteren Verehrer Brinckmann, indem sie eine Nachfrage ihrer Mutter in einen sehr charmanten Brief kleidete, der sie selbst vorstellt. Ihre Art, sich als weibliche schüchterne Schreiberin zu ,erdreisten“, wäre ganz im Sinne Gellerts gewesen. „Wenn ich meinen Brief mit dem aufrichtigen Geständniß anfange, dass ich in sehr großer Verlegenheit bin, so darf ich hoffen [...] da mir aber daran liegt, nicht noch dümmer zu scheinen als ich bin so denke ich dass es besser ist, Ihnen freymüthig zu gestehen, dass aus lauter Angst, recht schlechte Geschäfte zu machen (dieß Familiensprichwort ist Ihnen doch bekannt?) ich gewiß einen recht steifen und dummen Brief zur Welt bringen werde, ob ich sonst gar nicht steif zu seyn pflege [...].“ Henriette Arnstein Pereira an Gustav von Brinckmann, 23. 8. 1797, ungedruckt, BA P. 
schauen zu locken. Statt der Details folgt, zum großen Bedauern der Nachlebenden, die Versicherung, das Wesentliche später mündlich zu berichten. Andererseits gab es nachweislich auch den Fall, dass nach dem Nachttee Gedanken zu Themen schriftlich ausformuliert wurden, die im Salon am Teetisch angerissen worden waren, ,aber sich [dort] nicht bis auf die Lippen wagten“, dann allerdings meistens als Brief. ${ }^{315}$

Die Ergebnisse anschließender Kapitel hier einmal vorwegnehmend kann festgehalten werden, dass die Salonkommunikation bei aller Kunstfertigkeit, die in Billets investiert wurde, keineswegs innerhalb derselben Stadt und in Laufnähe auf die Briefform verzichtete. Wie an verschiedenen Längsschnitten durch die Salonkommunikation deutlich wird, werden gegenüber verschiedenen Personen und dem Bedürfnis der Situation nach unterschiedliche Kommunikationsformen bevorzugt. Gustav von Brinckmann beispielsweise wechselte innerhalb Berlins mit Wilhelm von Humboldt und Friedrich von Gentz überwiegend Billets, die nur Details der nächsten Verabredung und Praktisches enthielten. Darin integriert oder begleitend fanden sich nicht selten (Spott-)Verse auf gemeinsame Bekannte. Längere Briefe waren in dieser Dreiecksfreundschaft anscheinend nur zur Klärung persönlicher Missverständnisse oder zur Übermittlung von Text und Textkritik angezeigt. Mit der Hofdame Luise von Voss, obwohl er sie in denselben Jahren und fast täglich sah, wechselte Brinckmann hingegen nur formvollendete Briefe. Die Kommunikation mit Rahel Levin Varnhagen umfasste hingegen alle Formen, innerhalb Berlins informative und komplimentierende Billets, Briefe, verabredete und spontane Besuche ihres Teetisches sowie Treffen an dritten Orten. Während der Abwesenheit der Salonière enthielten Brinckmanns Briefe vor allem Nachrichten über Treffen, die sie ,verpasst" hatte, sowie von und aus dem Haus ihrer Familie. Brinckmann war der Berichterstatter aus dem Berliner Freundeskreis, so wie David Veit für seine Berliner Freundinnen zum Reporter der „großen Welt“ Weimar-Jenas wurde.

Die hier gewechselten Briefe waren nicht selten „uneigentliche Briefe“ im Sinne einer mit einberechneten erweiterten Öffentlichkeit. ${ }^{316}$ Sie erschienen

315 Gustav von Brinckmann an Rahel Levin Varnhagen, 20.5.1794, ungedruckt, BA, V. 316 Nickisch spricht von „uneigentlicher Verwendung“, wenn die Nachrichtenübermittlung zwischen Sender und Empfänger fingiert ist, dadurch dass Schreiber oder Adressat fiktiv ist, oder aber dadurch, dass eine breitere Öffentlichkeit schon bei der Niederschrift in Kauf genommen wird. Nickisch 1991, S. 19 ff. Allgemein ist der These zuzustimmen, dass die Briefe Rahel Levin Varnhagens vor allem „wirkliche Briefe“ sind, dem Gespräch und Salon verpflichtet, und ihre „Flüchtigkeit, Diskontinuität und paradoxale Widersprüchlichkeit nicht von einer absichtsvoll formulierenden Autorin, sondern aus der spezifischen Lebens- und Schreibsituation“ Levin Varnhagens bekommen. Marianne Schuller: „Unsere Sprache ist unser gelebtes Leben.“ Randbemerkungen zur Schreibweise Rahel Varnhagens, in: GW X, 
außerdem in Form anderer literarischer Gattungen, sie waren oder enthielten Rezensionen, philosophische Entwürfe, Gedichte oder eben Reportagen. Viele waren essayistisch oder im Plauderton gehalten, andere spielten mit der Dialogform, indem zum Beispiel Bindestriche oder verschiedene Schriftformen imaginierte Dialoge abbildeten. 317 Daneben gab es aber auch die zweckgebundenen Briefe, die primär nicht literarischen, sondern funktionalen Gesetzen folgten: Sie enthielten Berichte über Kuraufenthalte oder die familiäre Gesundheit (Brief als Information), vermittelten positive Informationen über den Überbringer (Empfehlung) oder wollten sich durch Nettigkeiten der Gunst des Andern versichern (Kompliment).

Die Grenzen zwischen den Gattungen verschwimmen. Wie am Beispiel des Briefwechsels Rahel Levin Varnhagens mit David Veit gezeigt werden wird, konnten Briefe nicht nur Gedichte und Reisebeschreibungen enthalten, sondern auch ganz dazu werden, ebenso wie zu Theaterkritiken oder literarischen Rezensionen. Dabei wäre im Einzelnen, wie im Beispiel von Rahel Levin Varnhagens Kritik eines Humboldtschen Aufsatzes, noch zu fragen, ob ihr Text ein rezensierender Brief war oder nicht eine wirkliche Rezension, die nur zufällig oder aus Schicklichkeit die Anrede „Lieber Veit“ im Titel trug. Autorschaft von Frauen, hieße das, ist auch mithilfe ungedruckten Materials zu belegen.

Bei allen zeitgenössisch wie heute geläufigen Gleichsetzungen von Brief und Gespräch bleiben im Falle der Salonkommunikation - vor allem mangels anderer Quellen - Briefe und Billets als wesentliche Zeugen, Reste, entfernte Verwandte der verlorenen Mündlichkeit. Es muss deutlich als Option formuliert werden: Briefe sind Medien, in denen persönliche Gespräche fortgesetzt werden können, in denen sich auch Diskurse niederschlagen können.

Die These dieser Arbeit dazu lautet, dass im Salon diese Kommunikationsformen nicht nur von Anfang nebeneinander bestanden, sondern dass auch bewusst auf verschiedenen Ebenen kommuniziert wurde: in Gesprächen, mit Briefen, mit Billets und über Dritte (Personen oder Medien).

\footnotetext{
S. 43-59, hier S. 59. Briefe und Billets der Salongesellschaft haben oft diesen flüchtigen, paradoxreichen Charakter und dabei ebenso oft gestalterischen Anspruch. Diese Arbeit vertritt die These, dass die Ursachen für diese spezifische Sprachform nicht nur in der Psychologie der Schreibenden, der ,Identitätslosigkeit‘ einer Jüdin etwa, sondern in der Absicht, einen gewissen Ton zu schaffen und zu halten, zu suchen sind.

317 Der derzeit in der Forschung viel verwendete Begriff „dialogisches Schreiben“ wird an einigen Briefen der Salongesellschaft nicht nur inhaltlich belegbar, sondern optisch sinnfällig, etwa wenn Rahel Levin Varnhagen Briefe David Veits beantwortete, indem sie ihre Fragen und Antworten zwischen seine Zeilen schrieb, oder wenn Alexander von Humboldt statt Brief seinen Gastgeberinnen einen imaginierten Dialog schickte, in dem er sie über sich reden ließ. [Vgl. III.6]
} 
Die hinterlassenen Briefe und Billets der Salongesellschaft sollten nicht als „freie Nachahmung des guten Gesprächs“ im Sinne einer Abbildung der Salonkommunikation gelesen werden, sondern von vornherein jeweils als ein den Gesprächen ebenbürtiger Teil der Salonkommunikation. 